\title{
EINZELAUSGABE
}

\section{EIN VERZEICHNIS \\ MUHAMMEDANISCHER DYNASTIEN}

VON

\section{EDUARI SACHAU}

AUS DEN ABHANDLUNGEN DER PREUSSISCHEN AKADEMIE DER WISSENSCHAF'TEN JAHRGANG 1923. PHIL.-HIST. KLASSE. NR. 1

\section{BERLIN 1923}

VERLAG IDER AKADEMIE DER WISSENSCHAFTEN

IN KOMMISSION BEI WALTER DE (IRTYTER R.CO. 




\section{EIUUARI) SACIAU}

(AUS DEN ABHANDLUNGEN DER PREUSSISCHEN AKADEMIE DER WISSENSCHAFTEN JAHRGAN(: I923. -PHIL.-HIST. KLASSE. Nr. 1

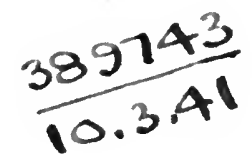

\section{BERLIN 1923}

VERLAG DER AKADEMHE DER WISSENSCHAFTEN

IN KOMMISSION BEI WALTER DE GRU YTER I. COO. 
rash

तi e

Vorgelegt von IIrn. Sachay in der Gesamtsitzung am 22. März 1923.

Zum Druck genehmigt am gleichen Tage, ausgegeben am 3. Mai 1923. 


\section{Vorwort.}

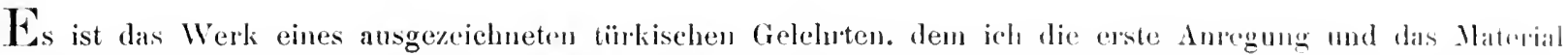
\%u dieser meiner Studie verdanke, das Werk des Ahmed Ibn Lutf-illah Alsclànikì. hekannt unter scinel Berufsbezeichnung als Muneğğim Baschy, d.i. Der Oberastronom. Als ich das Werk im Sommer des dahres 187.3 in Stambul, wo mich Beruni-Arbeiten beschäftigten, zuerst kennen lernte, gewanu iøh soliont den Eindruek. dah es hervorragend niitzlich sei, dab es gleich wie eine bändereiche Spezialbibliothok in gednängtep Fassung einen Uberblick ïber die gesamte Entwicklung der mulammedanischen W Velt bis \%u sciner Zeit gewähre. und daß es besonders fïr eine zusammenfassende Ahhandlung ïber die verschiedenen Dynastien. Welche das Gerippe der einheimischen Geschichtsdarstellung bilden, ein vortrefflich gecignetes Material in reirhater duswhl biete. Indessen durch anderweitige Pllichten verhindert, dieser Erwägung rine praktische Folge zu geben, habe ich zwar Ahmeds Werk niemals aus den Augen verloren, jedoch erst in den jïngsten lahren die nötige Muße gewonnen, mich darin zu vertiefen.

Zunächst ein Wort ïher unseren Oberastronomen. Er ist z.n Selanik (Saloniki) im lalure 1070/s6zo geboren, hat in Stambul studiert und ist frïhzeitig dem Mewlewi-Orden beigetreten. Er beschältigte sich singehend mit Astronomie und Astrologie und diente als Hofastronom unter Sultan Muhammed 1V. (1667-1675). Als dessen Nachfolger Sulaiman IIl. den Thron bestieg, mußte Ahmed aus seinem Ante weichen. ging zunächst nach Igypten und lebte später abwechselnd in Mekka und Medina. Lr ist miz/1702 in Mekka als Abt des Mewlewi-Ordens gestorben. Von seinem arbeitsreichen Leben zengt eine ganze Reihe von Werken rer'schiedenen Inhalts, darunter auch eine Gedichtsammlung. Dasjenige aber, was seine Stellung in der literatur begründet hat, ist seine Universalgeschichte des Islams von den ersten Anlängen bis zu seiner Zeit, das ist bis zum Jahre 1083/1672. Er bezeichnet sie als صحائف الاخبار d.i. Historische Bläter. Ohne Zweilel laben ihm die reichsten Literaturschätze in arabischer, persischer und tïrkischer Sprache zur Vertïgung gestanden. Das Verzeichnis der Quellen, die er in seiner Einleitung I 6,7 auf\%ählt, ist so reich, wie es ein anderen Forscher schwerlich jemals gehabt hat, noch haben wirl. Fr hat seine fieschichte in arabischer Sprache abgefabt, sie ist dann innerhalb der Jahre I132/1719-1142/1729 von dem bekannten Dichter Nedin in das 'Tïrkische ïbertragen worden. Diese tïrkische Ausgabe liegt nir vor in dem dreibändigen Druck Stambul I $285 / 1868$ !.

Der Wert seiner Narhrichten ist der Wert seiner Quellen. Wo diese reichlirlı flieben. sehildert er in grober Ausfïhrlichkeit die Geschichte eines Landes, scine geographischen Verhältnisse, den Zusammenhang und die Entwicklung seiner Geschichte in einfacher, klarer Sprache, wobei er einen weiten Blick iiber den ganzen Islam und über alle Vorgänge seiner Zeit, wie z. B., um nur eines zu nennen, ïher die Fortschritt. der Portugiesen im Indischen Ozean, hekundet. Daß er gern die chronologischen Verhältuisse mit einer Art Geflissentlichkeit und Ausfïhrlichkeit vorträgt, dïrlte ilm als Astronomen nahegelegen haben. Wo seinr Quellen versagen, benerkt er ausdriicklich, dab sie entweder mu bis \%u einem gewissen Zeitpunkt reichen. oder daß sie ïberbaupt gänzlich fehlen, und dann begnïgt er sich eventuell mit einer kum"zen Nanenliste orler mit dem (ieständnis seiner Unwissenheit. Sehr geeignet wiire das Werk, mu dantus das chronologische und genealogische Gerippe der Islamgeschichte zu entuelmen, aber dieser Salche bedart' es in der groben Hanpt-

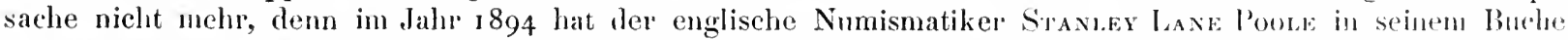
The Mohammadan dynasties, chronological and genealogical tables with historieal introductions die hauptsärbllichsten großen Dynastien wie Onajjaden, Abbasiden, Samaniden, Baberiden und andere in iibersichtlicher.

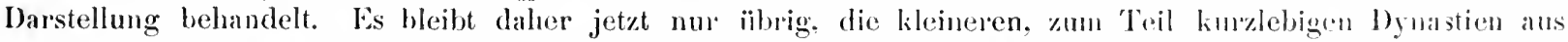
den verschiedenen Winkeln der Ishmischen Welt und ihrer (ieschichte zusammenzusuchen und sie nan Zeit und Lokal und eventuellen Zusammenhängen zur Darstellung zn hriıgen. Ifierfïr hat mir Mnnesigin Basehỵ das nötige Material geliefert. Den von Lane Poor.e aufgezählten nis Dynastien sind hir. noch 88 weitere

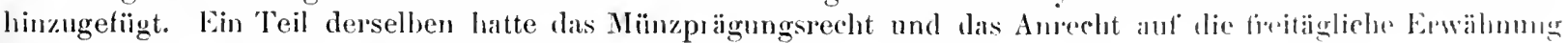

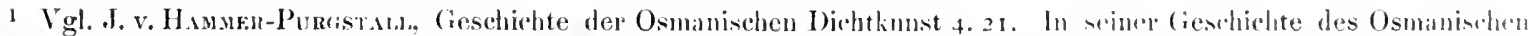

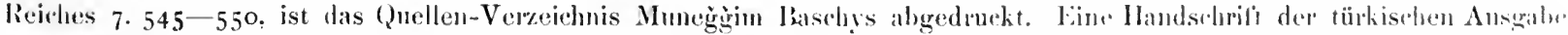

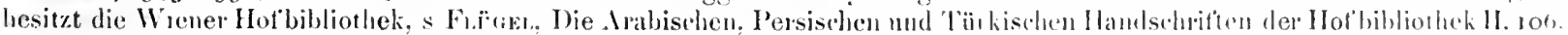


im Kanzelgebet. ron anderen ist es nicht bekanmt. Von den $9+$ Abschnitten dieser Schrift gibt die Nummer 30 eine Sanmelnotiz zu den kleinasiatischen Teilher'rschem vom Ende der Seldschuken- und dem Anfang der

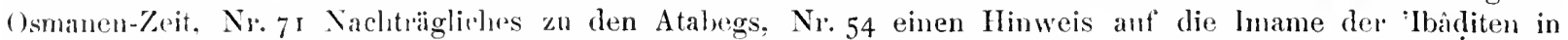
Oman und die Nummern 3o, 63, 64 Verzeichnisse von Männern. die in ihren Kreisen mit fürstlicher Macht anftraten, nicht aber als selbstïndige Fürsten angesehen wurden, die 'Tahiridischen Stattlalter von Bagdad sowie die Aghlabidischen und Fatimidischen Statthalter von Sizilien. Ich habe hier and da den Dynastien kure Notizen beigefïgt, welche dem Leser einige Fingerzeige fiir eine weitere Verfolging der Materie bieten mögen. olne aber hierin Vollständiges anzustrehen. Von Abliürzungen sind nur zwei gebraucht, MB = Muneğ̌̆in Baschy und LI'= ST. Lane Poole, The Mohammadan I)ynasties.

In kann diese Zeilen nicht schließen, ohne dem Bibliothekar an der Staatsbibliothek, H'n. Dr. Wartuen (iorrsriak lïr seine unermïdlichen Frenndesdienste in Bihliotheksangelegenheiten herzlichst zu danken.

Berlin. den 14. Mä1\% 1923.

Eunari Sachau.

\section{Inhaltsverzeichnis.}

\begin{tabular}{|c|c|}
\hline & sinite \\
\hline $\begin{array}{l}\text { Vorwort. . . . . . . . . . } \\
\text { Vemeichnis dre Dynastien }\end{array}$ & $\begin{array}{l}3-4 \\
4\end{array}$ \\
\hline I. Im Ostendes Kalifats & $5-12$ \\
\hline liann Frigin $\mathrm{Nr} \cdot 1$ & \\
\hline Girs voll Ghlulsšistiun 2 & \\
\hline Ians Biwand. Erste Sippe 3 & \\
\hline Zweite Sippe 4 & \\
\hline Dritte Siple 5 & \\
\hline Geschlecht Galawi 6 & \\
\hline Ilaus Giobira. Erste Sippe 7 & \\
\hline Zweite Sippe 8 & \\
\hline B:11111 Katis 9 & \\
\hline Ianu Inkenter 10 & \\
\hline Alislen. Fiste (imppe n & \\
\hline Zweite (implpe 12 & \\
\hline Britte (imple I 3 & \\
\hline Bamu Iljais 14 & \\
\hline (ieschlécht simgunt I 5 & \\
\hline $\begin{array}{l}\text { Die jürgoren Saffariden } 16 \\
\text { Ma munis } 17\end{array}$ & \\
\hline
\end{tabular}

II. Im Norden...... $12-16$

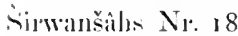

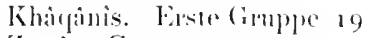

Cweite Guppe 20

Bat1u !I:ǐim 21

Banu Fialdai! 22

Isan Mussitil 23

Saliniije 24

Bamu Manginialk 25

Bitiniden 26

Diutšmend 27

D)ıิ-Al yadıijije 28

Rimur Rannal!an 29

Rleinasiatisehe Teilfürsten zo

III. In der Nitte.... 17-20

bialdis Nr. $3 \mathbf{I}$

liann Sihn 32

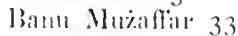

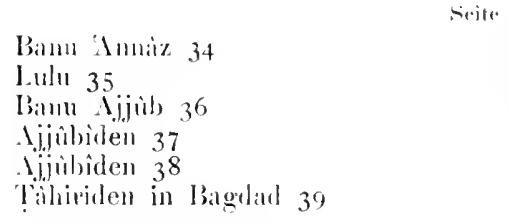

IV. In Siiden....... 20-24

Banu Ulaaidir N'. 40

Bann Mûsì 41

Biunu Falita 42

Bann (aitida 43

Bann Muhamua 44

Banu Tabatabà 45

IInsainî Ferifen. Easte

Gimple 46

\%weite (impe 47

Tscherliessen 48

Riumlî Lewend 49

Zaiditische Iname 50

'Jiidkische Stattlalter von Jemen 5 I

belienscher der Insel Lit 52

Beberischer dir Insel

Ilurumz 53

()man 54

$$
\text { V. In Westen...... 24-26 }
$$

Billu Rustau Nr. 55

lianu Midrat 56

Zijiniden 57

Ihanu Zakillijjii 58

Laun Q Qidi 59

Banu Animar 60

Bann Nuzanî 61

lann Wattis 62

$\mathrm{K}$ (olbitiselie Statthalter von Sizilien 63

Aghlabidisthe Statthalter rou

Sizilien 64
VI. Zeit iler.Seldsclumken, Atabeg. ...... 26-28

Suwinkisal liurden Nr. 65

Nachkommen des Sàm b.

Whardan 66

Itabegs 67

A tabegs 68

Freigelassene Sauǧars 69

kinechte Sanğans 70

Zal cinigen Byastien $7 \mathrm{I}$

Bam Khursid 72

\section{Zeit der C̈̈ngiziden,} IIchane ....... 28-29

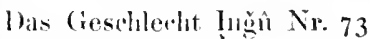

Das Geschlecht (uipàn 74

Dis Geschlerht 'Tughâtimur 75

lanı Tùluk 76

\section{Zeit der 'Timuriden} mul Indien .... : $\mathrm{O}-34$

Klans in Transoxanien Nr. 77

Sachliommen des Gehangir 78

Nachikommen ales Omar Sihaieh 79

Nachkommen von Sâmbli 8o

Nachliommen des $\Lambda$ bu Saíl $81.82,83$

Arghumis in sind 84

Tankhants in Tata 85

(iïnälašisis in Lahri 86

Klatlğis in Indien 87

Freigelassene der Ghoriden 88

Zwei Dynastien in Kasinî

89.90

Nachkommen Babers 91

Naukhinijje 92

Sirrije 93

(Bhakkar 94

Indices ........... 34-39 


\section{Im Osten des Kalifats. \\ (Nr. 1-17.)}

\section{Banû Ferộghûn (Ferị̂hûn) in Gî̀zăğân.}

A. H. ( $.370-401$.

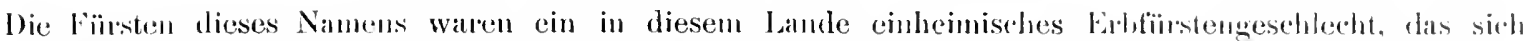

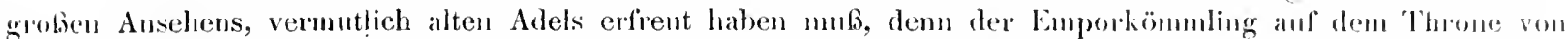
Chasua. Sebuktegin, hatte es fïir angemessen erachtet, sich mit dem seinerzeitigen Vertreter desselben zu ripschwïgern. Die Grenzen des Landes Cîzağân werden ron Jaquit in folgenler Weise beschrieben: Linn. Provinz von Baktrien, gelegen zwischen Merwalrid und Balkh. Die IJauptstadt war Jahridije. Als Mäz(ne

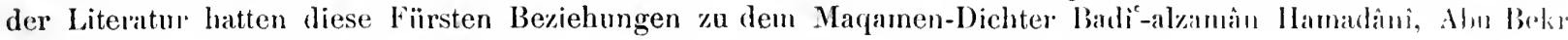

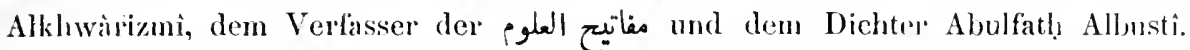

1. Abulluàith Muhammed b. Ferêghim war verschwägert mit Sebuktegin (366-387). lis ist gestorben in der ersten Zeit, nachdem dessen Sohn, der groß̉e Jamin-aldaula Malımid (388-421) sich Chomansus hemäehtigt hatte.

2. Abu Naşr Almad b. Abull!inith wurde bis an seinen Tod for von Malınind in der Stellung seines Vaters belassen. Dann wurde das Land von Malımìd annelitiert.

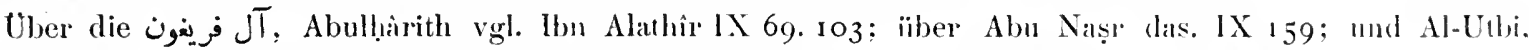
Kitàb-i-Yamini translated by Rfynombs S. 343 If.; ferner J. Marquar', Eranšahr S. 8o. MB II 270.

\section{I)ie Šâr von Ghaušistân.}

A. II. - - - 406 .

Das Land "Gharšistàn, eine Provinz ('holasans, grenzte im Westen an Ilerat. im Norden an Verwalprid, im Süden an Ghazna, im Osten an das Gebirgsiand Ghòr. Die beiden Stiidte des Lamdes waren Siurmin mnd Abšìn (Bašin). Die einheimisehen Fïrsten lïhrten den Titel Š̆r.

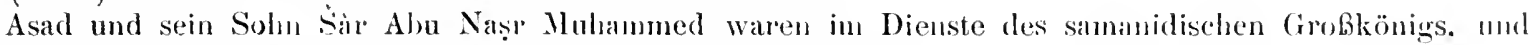
der Soln wurde ron ihm zum Statthalter von Gharšistin ernannt.

1. Sir Abu Nașr Muhammed machte bei wachsender. Schwäche des Samaniden-Reiches sich mabläingig,

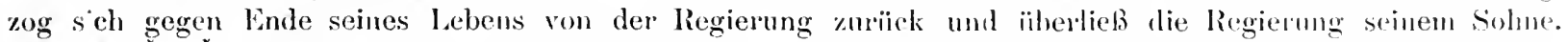

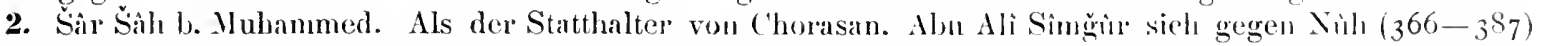
empörte, schickte er ein Ileer nach Gharšstân, wodureh Sirr Sỉh und sein läter genötigt wuden. sich in

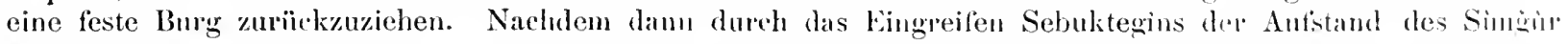
erledigt war, kehrten Vater und Soln in ihre heimatlichen Stellen \%urïck. Znerst gutes liurrornehmen mit Mahmio in Ghazna. Dann verlangt dieser, daß sio mit nach ludien zichen sollen. Šilh weigert sich trot/. des Zuredens seines Vaters. Malmund sehickt seinen Serasker Arslan Gidhib ins Land. Der Vater Mulammmol ergibt sich und wird in Herat interniert, wo er 406 starb. Der Sohn Sih verharrte in Widerstande. E. wird in seiner Festung von Arshan belagert, bezwungen nud in die Ciefangenschali abgefïlnt. wo er noch rol'

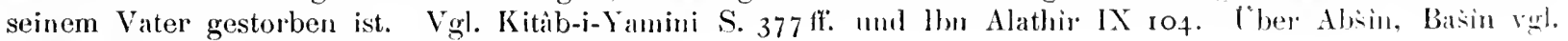
J. Marquar', EManšahı S. 79. Ill II 267-269.

\section{Die kaspischen Fürstentïmer. \\ Das Haus Bâwaml.}

Sein Ursprung wird znrïckgefiilut anf einen Bunder des groben Sasaniclen Anrismim, namens Kajis.

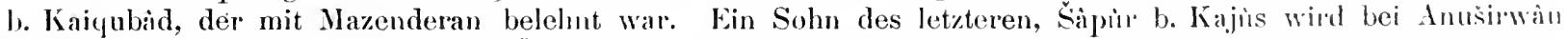
erzogen. Dessen Sohn, Bàwand b. Šipin, soll der Stammvater der Fürstengeschlechter dieses Namens seim.

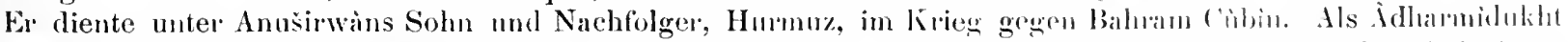
zur Regierung kam, zog Bâwand sich nach Tabaristan \%mrïek, lebte in froumer Znrï̌kgezogenlieit bui einem leuertempel bis A. II. 45 und wude daun vom Volke zum Herseher gewihlt. Das IIans Bawand bestelit aus drei Sippen und einer Abzweigung von der jüngsten Sippe. 


\section{Erste Sippe. Herrscher von Tabaristân (persisch Mâzenderân). A. H. 45-419.}

1. Bâtwand b. Šlıpir. Wird getötet von einem hei Bauersleuten erzogen. Nach acht Jahren tritt el hervor, tötet den Mörder seines Vaters und gewinnt die Ilerrschaft in Lande. A. H. 45-6o. Nebenregierung des لاوش von 6o-68.

2. Surkluîb b. Bìwand von 68-98. Zu seiner Zeit erobert Jěı̀ b. Almuhallab (98) die ebenen 'Teile des landes, wïhrend ron da an die Bawandis sich in den Bergen behaupteten.

3. Nihrmerdàn b. Surkhàb von 98 - 38 .

4. Surlkhàb, Soln von 3 , von $138-158$.

5. Ispahbad Šarwin. Sohn von 4, von I $_{5} 8$ - r 78 . Empört sieh gegen den lstanı.

6. Rustam, Soln von 5, von 178-203. I)ieser soll zuerst den Titel لملك الجبال "König der Bergea gefïhrt haben.

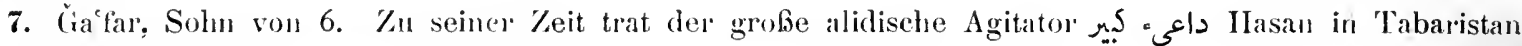
anl und gewann Anhang.

8. Qârin, Bruder von 7. Nahın znerst von dieser Dynastie den Islam an. † 273.

9. Rustam, Enkel des vorigen. Wird von Rebellen gefangengesetzt (302). Sein Sohn šarwin llieht zun Samanidisehen Großkönig, kehrt mit dessen Hilfe zurïek und befreit das Reich von den Rebellen.

10. Sarwîn, Soln von 9, von 302-337. Gegen Ende seiner Regierung von einem Samaniden angeariflèn, sehloß er ihn in einem Engpaß ein und lieb ihn nicht abziehen, da er ein Lösegeld von 30000 Goldstiicken nicht bezahlte.

11. Ispahbad Šahrjàr, Solın ron ıo, von 337-373. Der Bujide Fakhr-aldaula, Sohn des Rukn-aldaula, heiratete die Tochter des Marzubin Šarwîn.

12. Ispahbad Dàrâ, Bruderssohn von i i, von 373-380.

13. Ispahbad Šahrjàr, Sohn von r 2, von 380-415. Leistete Hilfe dem Qàbùs b. Wašngîr, dem Fürsten von Gumgàn $(366-37$ r und 389-403). Dann aber wurden sie verfeindet miteinander, ()âbìs besiegte und tötete ihn.

14. Ispahbad Rustam, Sohn von I3, von 416-419. Führte Krieg mit Alâ'-aldaula b. Kàkrija (Kàkwaihi), dem Herrscher von Ispahan von einer Seitenlinie der Bujiden (398-433), wurde von ihm gefangen genommen, aber wieder freigelassen, und regierte sein Land bis an sein Ende. Mit ihn ist diese Linie der Bìwand erloschen.

Uber einiges die Dynastenreihe 10-14 betreflende s. P. Casanova, Les Ispehbeds de Firim in der Jubiläumsschrift für E. G. Brownf, Cambridge 1922. S. I17-r26. Uber den Ursprung des Namens Bâwand S. J. Marq̨urt, Eranšahr S. I 28. MB Il 402.403.

\section{Zweite Sippe. In Tabaristan.}

A. H. $466-606$.

MB gibt über die Vertältnisse im Lande zwisehen den Ende der Herrsehaft der ersten Gruppe und dem Begimn der Herrschaft der zweiten Gruppe keine Auskunft.

1. Ispahbad IInsìm-aldaula Šahrjâr. Lebte in Verborgenen, wartend auf eine Gelegenheit, die Herrscbaft seiner Vorfahren wiederzugewinnen. Dies gelang ihm, als die Bujiden-1lacht zerfiel (um 447). Der große Seldschuke Muhammd b. Malikš̀h (498-51 I) grifl ihn an, wurde aber zurïckgeschlagen. Nach Friedensschluß heiratet ein Soln des Ispahbad, Neggnn-aldaula (s. Nr. 2) eine Tochter Mulammeds. Regierte von 466--503.

2. Neğmaldaula Qàrin, Solın von I, 503-5 I I.

3. Rustan, Soln von 2. Nach einem Jahr stiirzte ilın sein Oheim 'Alấ-aldaula mit Hilfe des Seldschuken Nuhammed b. Malikšith und sperrte ihn in eine Burg ein, wo el vergiftet wurde. Regierte nur ein Jahr.

4. Alà'-aldaula Alî, Vatersbruder von 3. Heiratete die W'itwe seines Bruders Neğnı-aldaula, die seldschukische Prinzessin. 'Tritt nach 2 r jähriger Regierung sie an seinen Sohn ab. Regierte 512-533.

5. Rustam Sàh-Ghìi, Sohn ron 4. Unternahm $55^{2}$ einen Feldzug gegen die Ismaelier in Alanuit. Ein längerer Krieg im Bunde mit Inaq. dem Statthalter von Gürŭğı̀, der sich gegen seinen Herın Sultàn Sanğar $\left(5 \mathrm{I}-55^{2}\right)$ erhoben hatte, geren die Gluuzz, der verlustreich endet 558. Ferner Krieg mit Mu'ajjad, Serasker des Sultans Arslan (556-573) um die Landschaft Quimis. $\because 55^{8}(560)$.

(i. 'Mli'-aldaula Hasan, Sohn von 5. Behauptet sich gegen Inaq von Giurğàn und gegen Mu'ajjad. Von seinen Leuten ermordet. Von $558-567$.

7. Ardašîr, Sohn von 6. Bestrafte die Mörder seines Vaters. Regierte 34 Jahre, von 567-6or.

8. Sams-almulik Irustam, Sohn von 7. Regierte 4 Jahre 60I-605. Wurde dann 607 anf Befehl des

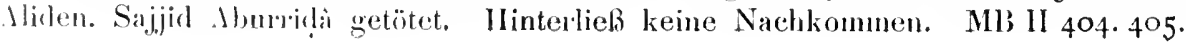


In der Zeit von 606-635 hielten sich die Bìwandiden, die im Stammbanm des Bàmandhanses bei MB II 403 anfgezühlt werden, im Verborgenen, bis

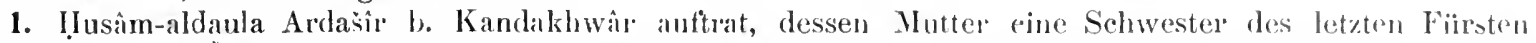
zweiter Sippe, des Samns-almulìk Rustam war. Mannsehaft um sich sammelte, sich in Anol niederlielì und dic Herrsehatt seiner Vorfahren zurïekgewann. Zu seiner Zeit wurde das Land ron Mongolenseharen unter den ersten Nachfolgern Cingizkhàns ïbermant. Regierte von 635-647. Er fiihrte den Beinamen Abulmulik.

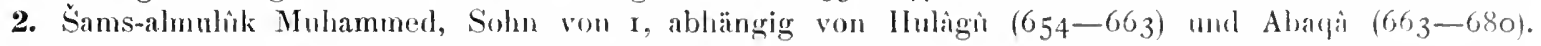
Inuligì befiehlt ihm, zusammen mit dem Fïrsten ron Rustamdâ die Festung Girdkuh zu erolsern; da ihm

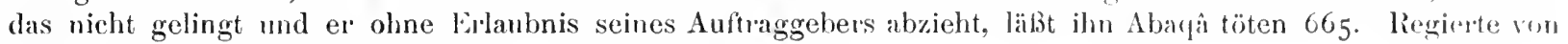
647-665. Nlit Erlaubnis Abayàs folgt ihm sein Bruder

3. 'Alâ'-aldaula 'Alî von $66_{5}-675$.

4. Tàğ-aldaula Jazdağird, Bruderssohn von 3. Unter ihm blïhte das Land. Amol soll 70 Nordresen gehal, haben. Von $675-698$.

5. Nașir-aldaula Sahrjâr, Solın von 4, von $698-7$ r4.

6. Rukn-aldaula Kaikhnsran, Bruder von 5 , von $714-728$.

7. Fakhr-aldaula Hasan, Bruder von 6. Zu seiner Zeit große Pest im Lande. Er war verheiratet nit der Schwester des Afrâsiàb Ğalàwî. Dieser und seine Schwester versehworen sich gegen ilıreu Gromahl Hasan und ließen ihı durch zwei Söhne Afrâsiâbs im Bade ermorden. So war das Ende des IIauses Bàwand, nachdem es 705 Jahre iiluerstanden hatte. Regierte 728-750. MB II 405-407

6. Das Geschlecht Galâwî. Herrseher in einem 'Teil von Mâzenderân. A. H. 750-909.

1. Afrâsial, der Mörder des letzten Bàwandiden der dritten Sippe. Verkehrte viel mit einem herïhnten Heiligen, Sajjid Qiwâm-aldîn Maŕăsî und heuchelte Fröınmigkeit und Buße. Als er dann den wachsenden Einfluß des Heiligen fürehtete, wollte er ihn vernichten, begab sich zn ihm in sein Kloster, find ihn aher von seinen Anhängern umgeben und wurde getötet dureh einen Pfeilscluh. Regierte 750-760.

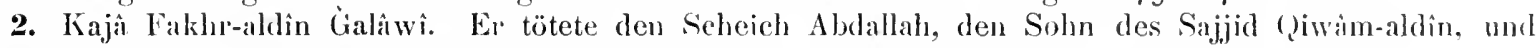
zur Rache dafiir ermordet das Volk ihn sanıt vier Söhnen.

3. Kajâ Guštìsp. War verheiratet mit einer Schwester des letzten Biłandiden der dritten Sippe, Hasaun. Wurde mitsamt sieben Kindern ermordet.

4. Iskender Alšilkhî b. Afrisialy. Nach dem Tode seines Vaters (unter 1) floh el nach Herat und wendete sich an 'Timur $(77 \mathrm{I}-807)$. Mit dessen Hilfe kehrte er zurïek und herrschte wieder im Lande. Als er sich aber dann gegen 'Timur empörte, schiekte dieser ein Heer gegen ihn, das ihn gefangennahm und tötete. Die nächsten Schieksale dieses Hauses unhekannt. Dann trai

5. Emir Hasan Kajâ auf, der Nachkomme eines Lubràsp b. Afràsiâb Jlğalìwî. Nachdem er cine Zeit-

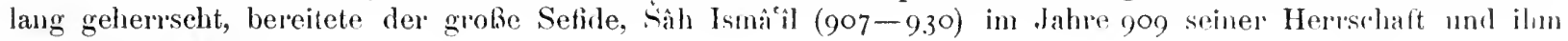
ein Ende. MB II 407.

\section{Das Haus Gâobâra, Herrscher von Gûhn und Rûjjàn.}

Diese beiden Landsehaften sind die westliche kistreckung des Kaspischen Gebirges. Riijan (auch Rustamdâr und Rustamàbàd genannt) grenzt im Osten an Mazenderan und wird auch zu Mazenderan gerechnet. Gîlàn fällt vom Gebirgskamm zun Meer hinab, seine Hauptstadt ist Fìmen (SSW von liescht). Die siïdliche Abdachung ist Dailem mit dem Vorort Rübàr. Der Ursprung des einheinischen Fïrstengesehlechts wird \%u-

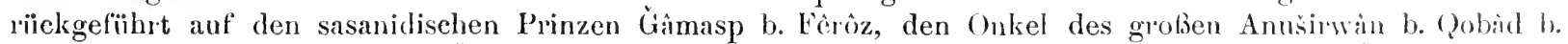

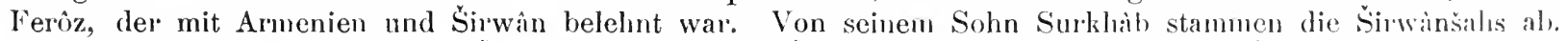

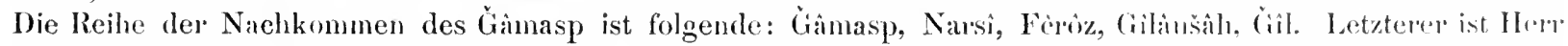
von Tabaristan und Rüjàn, regiert von A. H. 25-40 und wird der Stammvater zweier Fürstenhäuser durch seine beiden Söhne Dibinje und Bädispin.

\section{Erste Sippe. Dâbûjẹe, Fürsten von Gúlân. Residenz Fûmen. A. 1l. 40-141.}

1. Dâbî̀je von $40-56$.

2. Farkhân Kebìr, Soln von r. F̈̈hrte zuerst den 'Titel Ispahbad. Zn seiner Zeit eroberten die Muslims Teile von Tabaristan. Von $56-73$.

3. Dirmilır, Sohn von 2. Starb nach wenigen Monatein.

1 Uber den Ursprumg des Namens Dibûje s. Marquart, Emañahr S. 132. 
4. Sirrìje, Bruder von 3. Von 73-93. Trat die Herrschaft al) an seinen Bronderssohn.

5. Ispahbad Khnršid. Y/a seiner Zeit eroberte Jezid b. Muhallab Tabaristan und Ğurğàn, und erbaute die Hauptstadt von Ğurğin. Im Jahre 137 erhob sich ein Zoroastrier namens Sanbâd. Fliehend vor den

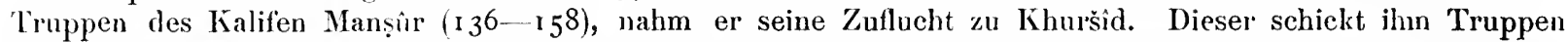
unter einem Manne namens 'Tiis entgegen, der den Sanbàd tötet und sein Haupt an Manșiur schickt. Die von Sanbìd hinterlassenen Schätze nahm Khursî̀l an sich, und weigerte sich sie dem Kalifen auszuliefern. Darauf schickte Manșîr den 'Amr b. Al'alà' gegen ihn, dieser ver'wüstete das Land, eroberte die Schätze und nahm die Familie Khuršìds gefangen. Khuršîd selbst floh nach Dailem und ist dort r4I gestorben. Von 93-I4I. MIB Il 393. 394.

8. Zweite Sippe. Bâdûspân, Fürsten von Rûjân. Residenz Rustandâr. A. H. 40-857.

1. Bàdispàn. Vor ihin hatte ein Bruder von ihın regiert. Darauf ging Bàdûspàn nach Rủjàn und ließ̉ sich dort nieder. Das Volk erivählte ihn zum Landesfïrsten. Regierte von 40-75. 2. Khùrzàd, Sohn von 1. 75-105. 3. Bâdùspàn, Sohn von 2. Vertrieb die Muslims aus seinem Lande. Nachdem das Geschlecht seiner Vettern Dâbuijje erloschen war, nahm er deren Land Gîlàn in Besitz. I05--145. 4. Sahrjâr, Sohn von 3. 145-175. 5. Dindàr Ummìd, Sohn von 4. 175-207. 6. Abdallah, Sohn von 5. Zu seiner Zeit wurde der Alide Hasan b. Zaid Herrscher von Tabaristan. 207-241. 7. Frêdûn b. Qairin, ein Vetter von 6, 8. Bàdìspàn, Sohn von 7. Nr. 7 und 8 regierten zusammen 18 Jahre, von 24I-259. Beide lınldigen dem Aliden Hasan b. Zaid. 9. Sahrjar, Sohn von 8. 259-274.

10. Hezìrsendìn b. Bundàr b. Š̀rzìd b. Bàdùspàn (Nr. 8). Von 274-286. Zu seiner Zeit war der I)ailemite Asfàr Herrscher in Tabaristàn und Gự̆àn, und sein Heerführer war Mardàwîğ, der Sohn einer

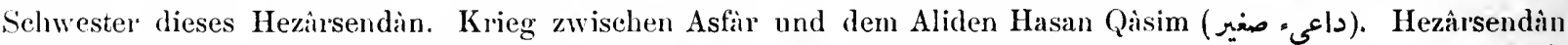
wird von Hasan ïberlistet und getötet. Dafïr greift Mardàwî̀̆ den Hasan an und tötet ihm. Dies soll 3 r6 geschehen sein.

11. Šahrjầr b. Samšîd b. Hezâr'sendàn. Von 286-298.

12. Abulfadl Muhammed, Sohn von I I. Von 298-31 2. Schwierigkeiten mit dem Áliden Sajjid Ğáfar.

13. Ispahbad Ilusâm-aldaula Zerrînkenter, Neffe von i2. Von 31 2-347.

14. Saif-aldaula, Enkel vou 13. Von 347-374. 15. Il usăm-aldaula Ardašîr, Sohn von 14. Von 374-409. 16. Fakhr-addaula Nimwer, Neffe von i 5. Von 409-44r. 17. 'Izz-aldanla Hezârasp, Sohn von 16. Von $44 \mathrm{I}-48 \mathrm{I}$.

18. Ṡahrnùš, Sohn von 17. Verheiratet mit einer 'Tochter des Fürsten von Tabaristan, S̆àh Ghàî. Von, $481-5^{2} 3$.

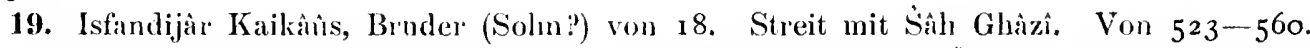

20. Zerrìnkemer Hezârasp, Neffe von 19. Streit mit Ardašì Š̉ih von Tabaristan um $55^{2}$. Von 560 bis 586 . Ermordet von einem Vetter.

21. Zerrînkemer b. Khastìn خستان, Sohn von 19. El besteigt den Thron (in Rinjàn) mit Hilfe des Fürsten von 'Tabaristan, Ardašì Săh (s. Nr. 7, Das llaus Bâwand, zweite Sippe), und dieser ernennt einen P'ascha Ali zum Statthalter des Landes (während Ninderjährigkeit des Zerrinkemer?). Nachdem er dann erlahren, daß \%errinkemer mündig geworden, wollte er ilm die IJerrschaft des Landes ïbergeben und ilın mit sciner Tochter verheiraten. Opposition im Lande. Man tätet den Ali und setat Bîsutìn auf den 'Thron. 1)anı kommt Ardašir mit Ileeresmacht, tötet die Mörder des Ali, und Bisutin flieht nach lindbàr. Ardašî. zicht sich nach Tabaristan zurïrk, und Zerrinkemer regiert im Lande. Von 586-61o.

22. Bisutin, Sobn des Zerrinkemer. Von 6ro-620. 23. Fakhr-aldaula Nimwer, Soln von 22. Von $620-640$.

24. II usìm-aldanla Ardašir, Bruder von 23. lskender, Bruder von 24. Ilerrschte in dem Gau Nâtil

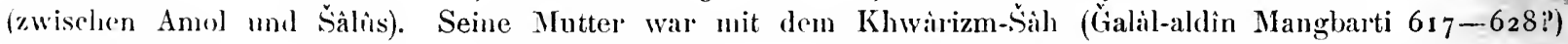
verwanlt.

25. Isfandijà Sahrâkam, Bruder von 24. In r I. Jahre seiner Regierung bestieg der Qâàn Mangù deu Thron d. i. 646. Regierte von 635-67 I.

26. Isfandijâr Fakhr-aldaula, Sohn von 25, von 67I-70r. 27. Malik liai Khusrau, Bruder von 26, von 701-712, 28. Malik Muhammed Ṡahrjàr, Sohn von 27, von 712-717. 29. Naṣîr-aldaula Sahrjär, Bruder vou 28, von 7I7-725. 30. Tì̆galdaula Zijàd, Bruder von 29, von 725-734. 31. Gaalal-aldaula Iskender, Sohn von 30, von 734-76r. Erbaute die Burg Kucìid 746 (?). 32. Siàh Ghàzi Fakhr-aldaula, Biruler von 3I, von 76r-78I. 33. Adlud-aldaula Qubad, Sohn von 32, $780-80 \mathrm{I}$. Fiel im Kriege von Lankì dureh die Iland des Aliden Fakhr-aldin. 34. Sa d-aldaula TṬis, Oheim von 33. Zu seiner Zeit zog Timur nach Mazenderan: 'Tis unterwarf sieh ihm und wurde in seiner Herrschaft belassen. 


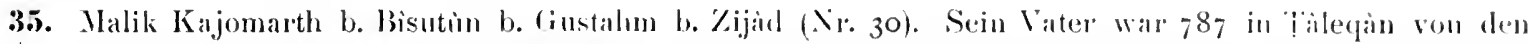
Ismaeliern ermordet. Bevol Malik Kajomarth zur Regierung kam. war er fïr 'Timur (77 807 ) Burgvogt von Nirr. Verstrickt in Beziehnngen zu den Eukeln Timurs, den Söhnen des Omar Saikl, war er eine Zeitlang in Schira\% getangen. Dann kehrte er zn seiner Ilerrselaft ïber Rustamblir zuriack, eroberte anch Ninr

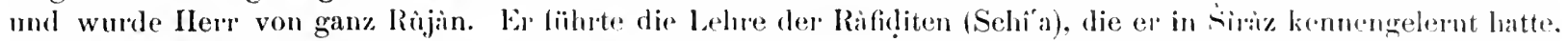
in seinem Lande ein, die Lehre, die später von dem Grinder der Scfiden-Iynastic, Ismáil ans Arbabil (907 bis 930) zur Reichsreligion Persiens erhoben wurde. Malik Kajomarth starb 857 . Von seinen söhnen ist

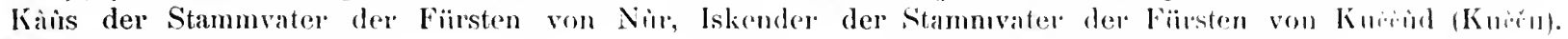
MB II $394-39$ s.

\section{Fortsetzung des Geschlechts Bàdìspân.}

\section{Eirstes Geschlecht.}

\section{Die Banu Kân̂s, Fïrsten von Nûr. Residenz die Burğ Nîr. A. II. 875-956.}

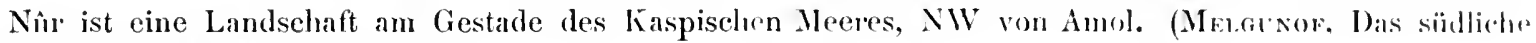
liler des Kaspischen Meeres S. 2 ro).

1. Malik Kins b. Gajomarth war in Norr der Nachfolger seines Vaters. Verfeindet mit soinen läidern. die sich an einen von ihnen. Iskender (s. unten $\mathrm{Nr}$. I) ansehlossen. Regrierte 875-88 (?).

2. Ciehangir, Sohn ron r. Regierte 33 Jahre.

3. Gajomarth, Solnn von 2. Sein Bruder Bahman empört sich gegen ihn und tötet iln.

4. Bahman, Bruder von 3. Sein Bruder Bisutin erhebt sich gegen ihı und tïtet ihn.

5. Bisutin, Bruder von 4. Tötet seine Onkel und Briider. Bricht in das Reieh es bis auf die Burg. in der der Landesherr sich hält. Zicht in sein Reich zurörck, wird von einem Weibe ermordet 9 I 3 .

6. Bahman, Sohn von 5. Heiratete die Schwester des Fïrsten von Gîlin. Ahmed Khan und die Schwester Jes Emir Abdalkerim, des Fürsten von Mizzenderan. Regierte 9r6 956.

7. Gajomatth, Sohn vou 6. War dem groben Sofiden Siah Tahmisp (9.30 984) untertan.

8. I'wais. Nielıt mehr selbständiger Fürst. Bekam yon Sih Thahmisp einige Lehen. MIB 11398.

\section{Zweites cieschlecht.}

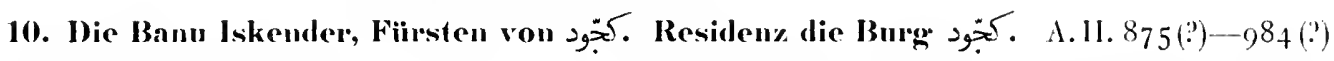

Die dussprache des Landesnamens ist nugewib. MB II 399 selureibt كجّ und sagt. die bessere Aussprache sei كجّ ohne Dal. Eine westlich an Nirr (s. Nr. 9) angrenzende Landschaft am Kaspischen Meer heibt

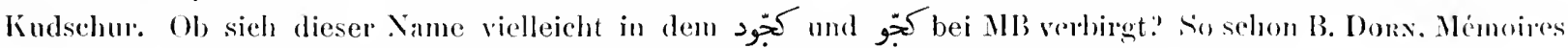
de lacadimie impériale de St. P'itersbourg tome XXIll $\left(18_{77}\right)$, S. roz.

1. Iskender b. Gajomartlı. War eine Zoitlang in Gelangensehaft seines linders liais von Niur.

2. Malik liağaldaula, Sohı von t.

3. Malik dšrat, Soln von 2. Bisution v'on Ninr will sein land gewinnen, schlielst Ašraf in eine Burng

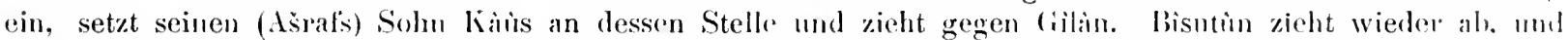
dšat wird wieder lrei, indessen sein Soln Kains macht ihn mit Erfolg die Regierung des Landes streitig.

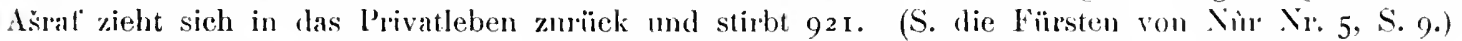

4. Malik Kinis. Heiratete die Tochter des Fïisten Ahmed von Gilin. Verfeindet mit seinen heiden sïhnen Gijomarth und Ciehingir. In Jahre 950 vergiftet von seinem Solu Ciehingir.

5. Malik Gajomarth, Solın ron 4. Gestorben 963 .

(i. Malik Ciehangir. Heiratete die Schwester des Fürsten Alumed Sultan ron Giliun, und rmpörte sich

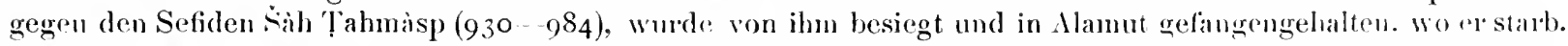

7. Malik Muhanmed, Sohn von 6 War dem Sah Tahmisp tributpflichtig. lm lahre $95^{6}$ wall der lïirst thmed Sultan ron Gilin aus seinem Lande vertriehen, und seficlisehe Statthalter regierten dis liund. Xun wollte: Malik Mulammed Gilan fïr sich gewinnen, empörte sich gegen lahmasp umb rïsteto zum Kivege.

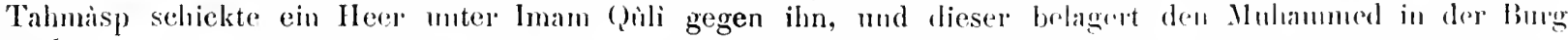

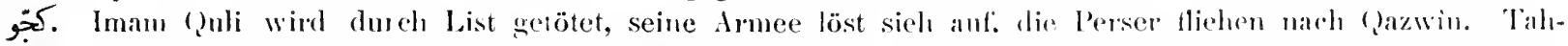
mâsp schickt eine nene drunee unter einem Muad in Jahre 983, der den Malik Muhammed in der leste كجّ belagert. Mitterweile stirbt Tahmasp (984). Unruhen in Persien. Hier brielut MlB ab. MlB II 399. 


\section{Aliden in den kaspischen Ländern. Drei Gruppen.}

Im Jihre 250 braeh in Kufa ein von Jahjâ b. Omar geleiteter Aliden-Aufstand unter dem Kalifat von Nusta in aus. Nach Unterdrïckung desselben zerstreuten sich die Aliden in viele Länder, und gelangte ein Hasan b. Zaid nach Tabaristan. Dies Land wurde als Tähilidiselıes Lehn fïr den Lehnsherrn Muhammed b. Abdallah b. '! ihlir durch einen christlichen Beamten verwaltet. Unter diesen Umständen gelang es den Aliden, Linluh im Lande zu gewinnen und einem der Ihrigen die Huldigung zu versehaffen. Vgl. LP i 27.

\section{Eiste Gruppe.}

\section{Die von Hasan abstammenden Aliden, Fürsten von 'Tabaristân. Residenz Amol.}

A. H. $250-300$.

1. Hasan b. Zaid, genannt gegen die 'Tìhiriden. Wenn er geschlagen wird, flieht el' nach Dailem, kehrt aber allemal in sein Land zurï̈ck. Sucht auch Gurğ̀ân und Rai zu gewinnen. Regierte von $25 \mathrm{I}-2 \gamma^{\circ}$.

2. (Ji im-billagq Muhammed b. Zaid, Bruder von I. Herrschte in Tabaristan und Gurŭgin. Führte Kriege mit Risfí b. Harthama. Verlor Land und Leben im Kampfe mit dem Samaniden Ismâîl (279-295). Regierte von $270-287$.

3. Mahdi Hasan b. Zaid, Enkel von 2. V'erschwindet nach 290 in Privatlehen. T'abaristiu in der Iland samanidischer Statthalter (bis zor).

\section{Zweite Gruppe.}

A. H. $301-318$.

\section{Die von Ilusain abstammenden Aliden, Fürsten von 'Tabaristân. Residenz Sârija und Amol.}

1. Hasan b. Mli I'ṭ̂nš von der Linie Husain hatte mit Mluhammed b. Zaid (s. erste Gruppe) an der Sichlacht teilgenommen, die Muhammeds Ende bedeutete, und hatte in ihr eine Kopfwunde erhalten, in deren Folge er sehwerhörig wurde. Daher Hasan der Sehwerhörige (uṭišs). Nach jener Schlaeht floh er nach Dailem, blieb dort Jahre, bekehrte viele Menschen zu seinem Bekenntnis (der Zaiditischen Schia) und wurde mächtig. Führte Kämpfe mit den Samanidischen Statthaltern Muhammed b. Hàrùn und Ibn Sưlìk und gewann die Herrsehaft ïber 'Tabaristàn. Er' islanisierte das ganze Gebiet vom Spidrìd bis Amol. $\rightarrow$ 304.

2. Ahmed und Gáfar, Söhne von r. Kriege mit den Samaniden, für welche Sìmğùr Aldawàti Ġurğàn besetzt. Almed und Ġáfar fliehen nach Astrabad, dann nach Sàrija. Damu setzen sie den Màkàn b. Kàlî Jailami als Statthalter in Astrabad ein. Die beiden Fïrsten Ahmed und Ga far starben, jener 3r 2 , dieser 3 r 3 .

3. Abu Ali Muhammed, Sohn des Almed Abullunsain. Wird von Mìksin b. Kiali besiegt und gefangengesetzt, gewinnt aber die Freiheit und sein Reich Tabaristan zuriick. ${ }^{\prime} 3$ r5 an einem Stmrz vom Pferde beim Polo-Spiel.

4. Abu Cualfar Ilasan, Bruder von 3. Cietötet $3 \mathbf{r} 7$.

5. Ismî́îl, Sohn eine! Tochter des Màkàn b. Kâlì, die mit Giáfar, einem Sohme des IIasan Vṭ̂nšs verheiratet war (s. muter $\mathrm{N}_{1}, 2$ ). Starb vergiftet nach kurzer \%ait (3I8).

\section{Dritte Gruppe.}

\section{Anhang zu den Ihusainî-Aliden von Tabaristân.}

A. II. $304-35^{6}$.

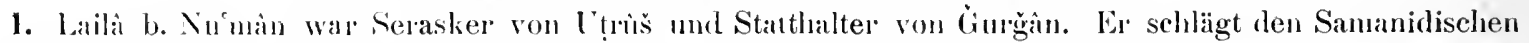

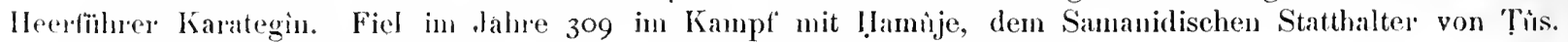

2. Sirtụin Bihsûuân Dailamî. Einer von den Heerlührern des Utrî̀̌s.

3. Nlàkân b. Kâlì. Wurde um 3 ro mächtig in Astrabad. Kämpfe nit den Simaniden, mit Asfàr, einem

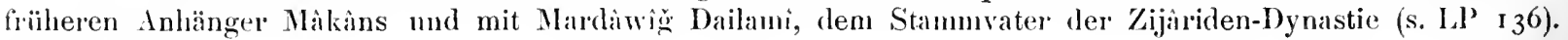
$\checkmark 011310-329$.

4. IFasan, Bruderssohn von 3, in Sîrija. Ifeiratete die'Tochter des Bujiden Rukn-aldaula (320-366). Von $329-356$. Die Kerrschaft geht ïber an die Bujiden und die Zijàriden.

Uber viele der hier aufgezählten Fürsten in kaspischen Ländern finden sich maneherlei Nachrichten bei E. Browne, In abridged translation of the history of 'Tabaristan ete. by Muhammad b. Al-IIasan b. Isfandiyar, l.ondon I905. MIS II 4 IO -418.

\section{Die Banı Iljâs in Kemmân.}

A. H. $317-357$.

1. Der Grïuder der Fantilie war Abu Alî Muhammed b. Iljiss b. Elisa , ursprünglich ein Dienstmann des samanidischen Großkänigs Naṣı b. Ahmed (3oI-331). In dem Streit des Großkönigs mit seinem Bruder Abu

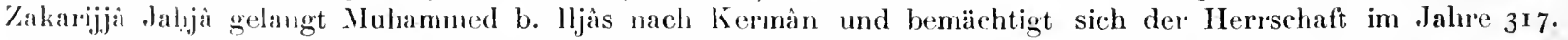
Er hat mit verschiedenen Feinden zu kämpfen: wenn sie das Land besetzen, flieht er nach Segestan, und wrmu sie alzzielen, kommt er zurïck. Sein größter Feind war Murizz-aldaula $(320-356)$. der eine der drei 
großen. Bujidischen Bröder, der zu Zeiten Kermàn beherrseht. Mit solehen L'utribrechungen hat Muhammed b. Iljàs das Land von 317-355 regiert. Eo latte drei Söhne Elisal, Iljais und Sulaimàn. Nach. Streitigkeiten

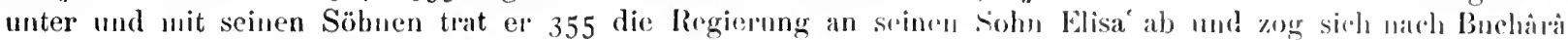
zurïck, wo er 356 starb.

2. Elisa b. Muhammed, Nachfolger seines Vaters, fïhrte Krieg mit dem groben Bujiden Mr!mb-aldaulau

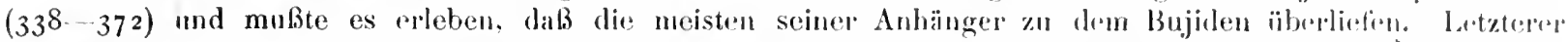

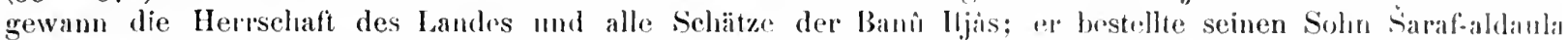
Abulfawàis zu seinem Vertreter. Elisae muläte das Land rä̈men, foh nach Buchara, 3.57, wurde zunächst von dem Sananiden Manșì b. Nìl! (350-366) gut aufgenommen, dann nach Khosirizu verbanut, wurde augenkrank, blendete sich selbst und starb $35^{8}$.

3. Sulaimàn b. Mubammed zicht mit einem Heer, das ihm der Simanide gegeben hatte, nach Kernin. um die von seinem Vater und Bruder innegehabte IIerschaft wieder»ngewinnen. In Kampf mit dem bujidisehen Regenten des Landes wird Sulaimân geschlagen und samt Verwandten getötet. 359. F"ïnf .Jahre später', $3^{64}$. versuchte ein Vetter Sulaimans, Husain b. Ali, die verdorene Provinz dem Bujiden wieder zu entreiben, ahe vergebens.

Uber die Geschichte des Abu Ali Muhaumed und seines Sohnes Vlisá vgl. Ihm Alatluîl VIll 241-24t; $432-434$. $\quad 11311263-267$.

\section{Im Samaniden-Reiche.}

\section{Das Geschlecht Sîmğn̂n in Chorasan.}

A. 11. c. $330-387$.

Dies lieschlecht aber es hat zu Zeiten Teile von Chorasan, zu Zeiten ganz Chorasan mit fïrstlicher Machtrollkommenheit beherrscht.

1. Sîmğ̀ir, der Stanmvater des Geschlechts, war Sklave des Samaniden Ismii il b. Ahmed (279-295). wurde in Verwaltungsdienst verwendet und hieß daher سيمجور دواتى, der Tintenfaßn-Simğhr. Er bekam von seinem königliehen Herrn mit der Freiheit den Namen Abu 'Imrin' und wurde zum Gouverneur' des Landes Segestan ernannt. In dieser Stellung ist er gegen Ende der Regierung des Samaniden Nașr b. Ahmed (30r-331) gestorben.

2. Ibràhim b. Simgìr folgte seinem Vater, wurde aber 333 Serasker und Statthalter von ganz ('horasan. Nachdem er diese seine Stellung verloren hatte, lebte er bis an seinen Tod in dem Lande Kúhistin (vermutlich ist das Gebirgsland in Sïdosten Persiens gemeint), das ihn als persönliches Lehn verlielıen warl.

3. Abulhasan Muhammed b. Ibrähin folgte seinem Vater im Jalure 355, Statthalter von Chorasan im Dienste des Samaniden Manșir b. Niı!! (350-366). Gefeiert als Mäzen der Literaten. Gestorben 377.

4. Abu Ali Muhammed 'Imàd-ildaula, Sohn des vorigen, folgte seinem Vater, empörte sich aber nach einiger Zeit gegen seinen samanidischen Herrn Nùh b. Manṣ̂r (366-387), geriet nach kriegerische»n Unglïek in die Gefangenschaft seines Herrn, von dort in die Gelangenselaft des Nișir-aldinn Sebulitegin von Ghazna und ist dort 387 gestorben.

Ein Bruder des letzleren, Abulyàsin. versuchte in verschierlenen ciegenden das dilürk seimr. Fanilie wiederherzustellen aber ohne kirfolg.

$$
\begin{aligned}
& \text { Simğin .............. † c. } 330 \\
& \text { Ibrâhim b. Sim ğ̀ir ....... c. 330-355 } \\
& \text { Abulhasan .......... 355-377 } \\
& \text { Abu Ali ........... 377-387 }
\end{aligned}
$$

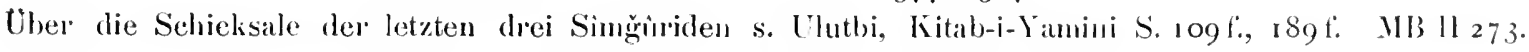

16. Die jiingeren Safhâriden in Segestan, Hauptstadt Zerenğ.

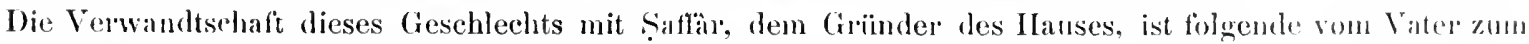
Sohn: Lath Alṣathàr - Ṭâhir - Ḱ̉halaf - Muhammed - Alumed. Dieser

1. Ahmed wurde 3 ro von dem samanidischen Großkönig Naṣı b. Ahmed (zor-331) zum Statthalter von Segestan ernannt, da das Land in Unordnung war und es schien, daßs das Volk an chesten cinem salliariden gehorehen werde.

2. Khalaf b. Ahmed, Protektor der Literaten Abulfath Bustî, Abù Bekr Khwànizmî, Bandí-alzamàn Lamadiun i. Nach versehiedenen Kriegen, auch mit dem eigenen Sohn Tâhir, fällt seiu Heè ab zu Malımind von Ghałna. Klualaf starb 399, sein Land wurde von Malımid ammektiert.

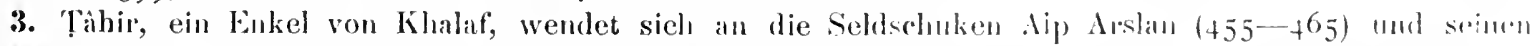
Solın Malikš̀̆h $(465-485)$ und gewinnt mit deren IIilfe die väterliche I'rovinz zurïck. (iestorben 479. 


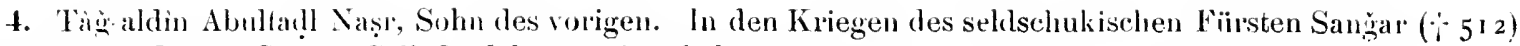
kämpfte er auf dessen Seite. Soll 8o Jahre regiert haben. $\div 559$.

5. Sims-aldin Abulfatl! Ahmed, Sohn des vorigen. Ermordet seine Brüder, wird von seinen Uuteıtanen getötet. $\because 562(?)$.

6. 'Tà̆galdin, Soln eines Bruders des vorigen. 'Tàğ-aldîn war von dem vorigen (Nr.5) geblendet. Von rinem Khwirizm-Š̉b gegen Ende seiner Regierung aus einem Teil seines Landes verdrängt. Soll 50 Jahre regiert haben: also da er 6 I 2 gestorben ist, von $5^{62}-6$ r 2.

7. Iamin-aldaula Sahrinsìil, ein Enkel des vorigen. Wurde von einem Fidàwî der Bàtiniden erstochen.

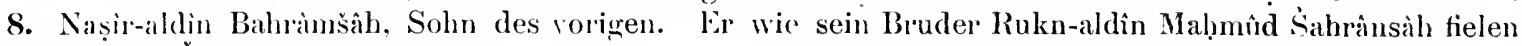
im Kampf gegen C'ingizkhàn (603-624).

Cber Khalaf b. Ahmed und seine Beziehungen zu Samaniden und Glaznawiden s. Alutbî, Kitab-i-Yamini S. 5 Iff. und 27 Iff. MIB Il 423-428. Sauvaire, Numismatic chronicle r 88 I, 137 ff.

\section{Die Ma'mûnîs in Khwârizm.}

A. II. $385-407(?)$

1. Khwinizn war pine l'rovin\% des Samaniden-Reiches, welches dort rertreten war dureh den Statthalter Ia'mîn J. Muhammed. Wie andere Statthalter suehten auch dieser und sein Geschlecht bei dem Rïckgang der Samanidemmacht sich unabhängig zu maehen. Er lesidierte in den von Jezìd b. Muhallab gegrïindeten Ġmrg̀nijje, während gleichzeitig ein letzter Sproß des alten einheimischen Gesehlechts der Khwàrizm-Ş̧́hs, namens Abdallah, in der Stadt Kâth residierte. In den kriegerischen Wirren, welche die Relsellion des Statthalter's von Chorasan, Abu Alì Sìmğìr, verursacht hatte, wurde Abdallah von Ma'minu getötet, 385 , der ıun seiner:eits den alten einheimischen Titel Khwàrizm-Sâh innahm (s. Derrímerr. Histoire des Samanides par Nirkhond S. I $84 \mathrm{ft}$.). Maimìn $385-387$.

2. Ihm folgte Abulhasan Ali b. Ma'min, dessen Schwester mit dem großen Malımuid von Ghazna verlheiratet war.

3. Ihm folgte Abul'abbâs Màmin, Bruder des vorigen. Auch dieser war mit Malımid verschwägert. lm lahre 407 verlangte Mạ̣mìd, daß in Khwârizm das Kanzelgebet in seiucm Nanen gesprochen werde. Abul'abbàs willigte ein. aber die limire seines landes empörten sich dagegen, töteten ihn und setzten einen Bruderssohn ron ihm.

4. Abul!̣arith Mulıammed b. Ali, auf den Thron. Nun zicht Maḅnùd nit Heeresmacht heran, um seinen Schwager zu rächen. Er bestraft die Rebellen. gefangene Khwàrizmier fiilurt er fort und postiert sie an den Grenzen lndiens. Seinen Kämmerling Altuntas̀ macht er zum Statthalter des Landes (408).

V'ber das Ende der Ma'mini-Dynastie vgl. meine Schrift, Zur Gesehichte und ('hronologie von Khwàrizmn in den Sitzunguberichten der Wiener Akadenie I873, Juni, Heft 74. S. I4ff. MlB Il 271. 272.

\section{In Norden. (Nr. 18-30.)}

18. Die Širwânšâhe, Fürsten von Širwân.

A. H. $183-44$ O.

(Vgl. ïber den Ursprung dieser Dynastie oben S. 7.)

Jezid b. Mazjad Aliaibanî. Bruderssoln des Mán b. Zàida, eines Zeitgenossen des Kalifen Omar, war Haruns Statthalter in Armenien. Er elwab sich das Verdienst um seinen Herrn, daß er im Jahe 178 den Aufstand des lbn Tarî Saibini in Mesopotamien niederschlug. und wurde zun Lohn dafïl 183 zum Statthalter von Adherbaiğàn, Sirwan und Bäb-alabwaib ermannt.

1. Jezid b. Mazjad Alšaibànî von 183 - 185 .

2. Khàlid b. Jezìd, Sohn von $x$, wird 205 von Jảmin emannt. Der Kalif Mútaşim setzt ihn 220 ab und setzt Af̧̌n an seine Stelle. In jener Zeit trat Bâbek in Adherbaiğgin auf. Der Kalif IVàthiq setzt den Khilid 227 wieder ein und entsendet ihn, die Revolution des Stathalters Islyic b. Isma'îl von Tiflis zu unterdrüicken.

3. Muhanmed b. Khàlid, Sohn von 2. Mit der Provinz Bab-alabwàb vereinigt er Adherbaiğin, Armenien und Arràn in 242. Gründet die Stadt Khaira خيرة.

4. Haitham b. Khalid, Bruder von 3. Mit dem Tode von Mntawakkil gerät das Kalifat in Verfall 247 Der Statthalter nimmt den Titel Šinwìnših an.

5. Muhammexl h. IJaithan. Siohn ron 4 . B. Haithan b. Muhammed, Sohn von 5 . 
7. Ali b. Haitham, Soln von 6. Lir und der llerrseher von Bih-alabwib werden 300 von den Barbaren, den Sarir, Shandin und Khazaren geschlagen. Beide Herrseher werden gefangen. Ali wird wieder frei und kehrt 305 in sein Reich zuriick.

8. Abu 'Tihir Jezid, Vetter vou 7, vou 305-337.

9. Muhammed, Solnu von 8, von 337-345. 10. Ahmed, Sohn von 9, von 345-37o. 11. Mulaummed,

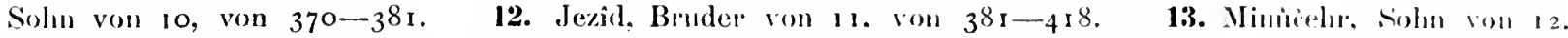
Kämpfe mit den Sarir und den Län (Alanen) in 423. Ermordet $425 \mathrm{im}$ Streit mit seinem Brnder Ali. 14. Ahu Manșìr Ali, Brnder von r3, von 425-435. 15. Kubid, Bruder von I4. von 435-441. 16. Buklitillassal.

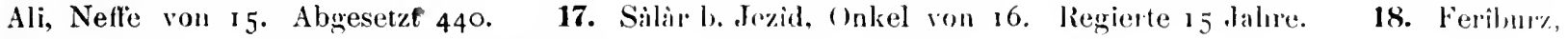
Sohn von 17 . 19. Feridin, Sohı von i 8.

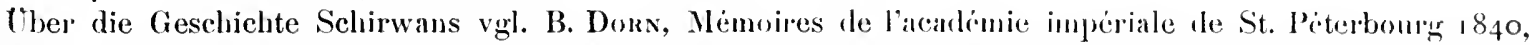
Beiträge \%ur Geschichte der kaukasischen Länder und Völker. I. Versuch einer Gesehichte der Schilwanschalıe. MB III $172-175$.

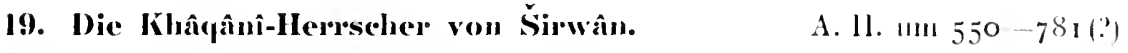 Erste Gruppe.}

Der erste Fïrst dieses Geschlechts, das sich vom Sasaniden Ann'šrwìn ableitete. fïhrte den 'Titel Khingin. Sie sind gegeniiber den Sirwinsiths (s. S. 2 r) eine jïngere Serie von Laudesfïrsten. MB 111 177 weif von ihnen nicht mehr zu berichten als folgende Namenreihe: 1. Minuciahr. Regierte um 550. 2. Ferrukhziul.

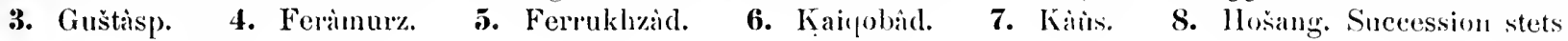
von Vater auf Solm.

20. 'Zweite Gruppe.

A. H. $78 \mathrm{I}-953$.

1. Schaikh Ibrihim, Vetter von Hošang, dem letzten Fürsten der ersten Gruppe. L̀ muterwarf sich

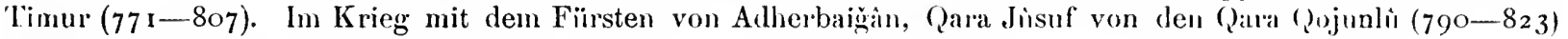
wurde er gefangen. Von $78 \mathrm{I}-82 \mathrm{I}$.

2. Sultîn Khalîl. Sohn von I, von 82 I-868.

3. Ferrukhjasìr, Sıhn von 2. Mit Hilfe von einem Solın des I'un Inasan von den dy (Qujunlii $\left(87 \mathrm{I}-88_{3}\right)$ besiegt er den Sefiden Schaich IIaidar und tötet iln. Zur Rache dafiir wird er 906 von dem Sefiden Sîh Ismíil (907-930) geschlagen mid getötet. Von 868-9o6.

4. Behranu Beg, Sohn von 3. Regierte I Jahır.

5. Ghàzi Beg, Bruder volı 4. 6 Monate.

6. Malımid, Sohn von 5. Aligesetzt vom Volk.

7. Schaich lbrîhim, Onkel von 6. Scin Vorgänger ron einem Sklaven ermordet. Er verjagt die Perser. Von 908-930.

8. Sultan Khalỉ, Sohn von 7. Schw:egersohn des Sefiden Šilı Ismíil (907-930). Von 930--942.

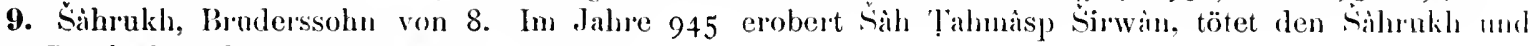
gibt das Land als Lehn seinem eigenen Bruder.

10. Burhàn Alî, Sohn von 8, tritt auf in Jahre 95 r. Kämpft olne Erfolg mit dem sefidischen Statthalter Alqasss Mirza und regiert 2 Jahre mit Hilfe des tïrkischen Sultans Sulaiman (926-974). Dann gewiunen die Per'scr wieder die Oberhand.

11. Mirza Abu Bekr', minderjähriger Solnn von ro. Wird nach Dagestan gebracht. kommat in Alter ron 20 Jahren zu den Tscherkessen, dann nach der Krim. wo der Tataren-Khan Danlat (iirài $\left(95^{8}-9^{8} 5\right)$ ilın freundlich aufnimmt (im Jahre 978). Die Tärken unter Lala Mustalia Pascha erobern šrwain 987 und versehen den Mirza Abu Bekr mit dem nötigen Einkonımen. MB 111 I 77-178.

\section{Die Banu Hâšin, Ilerrscher von Bâb-al’abwâh.}

I. I1. $255-457$.

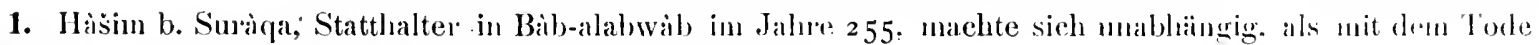
des Mutawakkil die Kalifen-Maclit zerfiel. Von 255-27r.

2. Amr, Sohn von I, regierte I Jahr.

3. Muhammed, Bruder von 2. Krieg mit den Khazaren 288 . ln 292 niumt der l'ürst ler Sallir den Muhammed gefangen, läßt ihn aber wieder frei. Von $272-303$.

4. Abdalmalik, Bruder von 3, von 303-327.

5. Ahmed, Sohn von 4. Wiederholı abgesetyt und wieder eingesctet. Von 327--360.

6. Maimin, Solın von 5. Eine Zeitlang verdrängt durch einen fanatischen Prediger Musa aus (iilau. der die jungen, bei Maimin befindlichen Russen unit Gewalt bekehren wollte. In 385 brelinl ter die in seinen Machtbereich befindlichen Georgier zum 1slam. Von 366-387.

7. Muhanmed, Bruder von 6. Nach ro Monaten getötet. 
8. Laškalì, Soln von 6. von 387 (388:) -39I (?392).

9. Manșin': Brnder von 8. Finfall der Russen, die aber auf dem Rïekzuge ron Manșìr gesehlagen und ihrer Bente beranbt werden. im Jahre 423. Zweiter Einfall der Russen und Alanen, sie werden aber zurïekgesehlagen. Von 391 ('392)-425. Wal verheiratet mit der Toehter des Fürsten der Sarîr. Bukhtîsìie.

10. Abdahualik. Sohn von 9. Unruhige Regierung von 9 Jahren. Von 425-434.

11. Manșir, Sohı von ro. Unruhige Regierung. Ermordet. Von 434-457.

12. Abdalmalik b. Laškari, mit Hilfe des S̈irwânsâh anf den 'Thron gekommen, abgesetzt.

13. Maimin b. Maușin. Ende der Dynastie. Mll III 175 - I77.

\section{Die Bam Šadlâd, Ilerrscher von Arrân.}

A. H. $340-468$.

Arrins llauptorte Nakhiewin, Denirc|apu, Genğe, Tillîs und andere. Die Bewohner werden jo Lesgrier

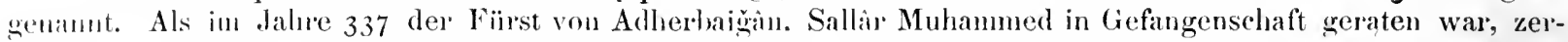
streuten sich seine Leute mo ein jeder suchte sich in irgendeinen Lande mabhängig zu nachen. Dazu achörte anch

1. Muhammed b. Šaddad. Regierte als unabhängiger Fïrst bis gegen 344. Gegen Ende seines Lebens verlor er sein Reieh.

2. Abulhasan Laškarî, Sohu von r. Trat im dalıe 360 ant und wubte das ganze Reieh wieder in sciner Iland zn vereinigen. Von $360-368$.

3. Marmubin, Bruder you 2. Erselılagen von seinem Bruder Fa!!l 375.

4. Fadl, Binder von 3. Baute eine große Brïcke ïber den Araxes. V'on 375-422.

万. Abulfitl! Misis. Solm von 4. Yon $422-425$.

6. Làskarî Ali b. Musa, Soln von 5. Von 425-440.

7. Nišsirwàn, Solın von 6.

8. Abul'uswâr S̈àdir b. Faḍl. Als der Seldsehuken-Sultan Alp Arslan (455-465) im Jahre 457 Armenien und 'Teile von Kleinasien erobert hatte, machte er den Abul'uswir' zu ihrem Verwalter' daselbst. Starb 459.

9. Fac!l b. šmis. Wird helassen von Alp Arslan. † 466 .

10. Farlliun, Sohn von 9. Empört siel gegen seinen Vater. Kam sich nieht länger als 2 Jahre halten (466-468). ilp Arsian annektiert das hand.

Der hier unter Nr. 8 genannte Abul'uswàr dïrfte gemeint sein in der Seldsehuken-Chronik von Bondǎrî ed. Houtsma. S. 3 I Anm. f: NIB II $506-508$.

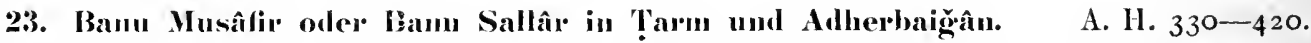

Tarm (Tàım) ist ein an Dailem grenzendes Gebirgsland nördlich von Qazwîn, dessen Landesherren den Titel Sallar fühten, und von denen einige die Stellung unabbängiger Fürsten einnahmen.

1. Sallàr Muhammed b. Musâtir Aldailemi, urspmünglich ein Serasker des Dailemiten Mákàn b. Kâlî̀ und dessen Statthatter in Tarm. Wurde selbständig durch den Verfall der Macht Mâkàns. 2. Sallâr Marzubàn,

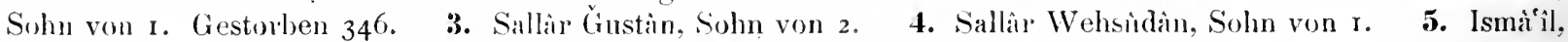
Sohn von 4. 6. Ibrähim, Sohn von 2. 7. Marzubàn, Sohn von 5.

Vgrl. die Gesehichte dieser Dynastie von (co. Huart, les Misatirides de l'Adherbaïdjin in dem Jubilämmsband V. G. Browne, Cambridge 1922. S. $228 \div 256$ und MIS II 505. 506.

\section{Die Saliqijje, Ilerrscher von Erzermu.}

A. H. ? -598 .

1. Enì Saliø. Anfing seiner IIerrschaft nnbekannt. Herrscher in Erzerum. Fïhrte Kriege mit.den christlichen Georgiern 7 ك.

2. Malik Muhammed, Soln von I.

3. Malik 'Ali'-aldin, Soln von 2, Eude dieser Familie 598. Der hier' genannte صلبق diirfte identisch sein mit الملك صلتق بن على بن ابن القاسم صاحب ارزن الروم, der von Ibn Alathîr IX, 126. 185. 209 in den Jahren $548,55^{6}$ und 560 eiwähnt wird.

\subsection{Die Banu Mangû́čak, Herrscher in Erranğân und líunâkh.}

A. H. ? $-46 \mathrm{r}$.

1. Enir Manginiak. Wurde $46+$ von dem Seldschuken Alp Arslan $(455-465)$ mum Statthalter diese4 (iveliete ernanut.

2. Aliá-aldin. 3. Fakhr-aldin. 4. Alì'-aldin. 5. MLüaffă-aldìn. Diese Söhne von 1 regierten nacheinander. Ende ilner llerrsehatt 464.

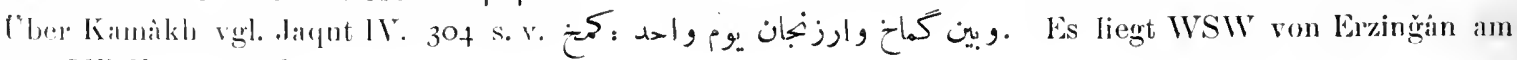
limpluat. NIB II 577.578. 
26. Die Oberhäupter der Bâținiden oder Isuntiliden in Maumut.

A. II. $483-654$.

1. IIasan Sabbil! gewinnt 483 mach vielen Wanderungen die Burg Alamut und besteht dort die Angriflir der Seldschnkenfïrsten Barkijarok, Muhammed und Sinnğar. $\because 51 \%$.

2. Sein Stellvertreter oder Kalif, Kajai Buzurg Ummîl. Unter ihn dringen 520 dir Bàtinis in S!rien ein und besetzen Bànijâs. $\because 532$.

3. Sein Sohn Kajai Muhammed. Läbt seine Armee in ('horasan einfillen, die aher wird von cinmu Statthalter des Landes rernichtet. $\because 557$.

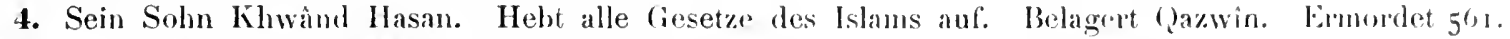

5. Sein Soln Khwând Muhammed. ${ }_{5} 62$.

6. Sein Soln Khwind Galirl-aldin. Kehrt zur Sumna zurïck. Läßt sieh vom Kalifen Nàșir (575-622) mit den Ländern seines Machthereiches belehnen. Verbrennt die Bächer des Lasan Sabbah. I’nterwirft sich ('ingizkhin (603-624). $\because 638$.

7. Sein Sohn Khwànd Ali'-ildin. Kehrt zur Ketzerei seiner Vorlahren zurrïck. Von $638-673$.

8. Sein Sohn Khwand Rukn-aldaula. Sein Vexier der Philosoph Nasir 'Tissi ( $\because 672)$. Vernichtung den Bhiṭinîs durch Huligì $\left(654-66_{3}\right)$. $\because 654\left({ }^{\circ}\right)$.

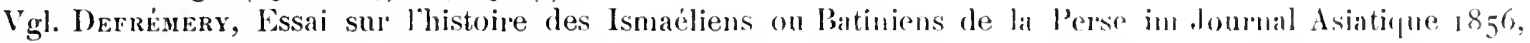
V. sirie, tom. VIII, S. $353 \mathrm{fr}$. MIB II $468-477 \cdot 478, \mathrm{I}-3$.

27. Die Dânišmend, Herrscher im ästichen Kleinasien. Residenz Siwas. 1. 1. 464-570.

MIB II 575. 576 gibt unter Hinweis aul die Versehiedenheit der Therlieferung folgente in einigen Stiieken von L 156 abweichende Darstellung.

1. Dânišmend lebte als Lehrer in Adherbaiğàn unter den 'Turkmanen und unterrichtete die Kinder'. Als 455 Sultan Alp Arslan gegen Kleinasien und Georgien zog, schlossen sich die Turkmanen-liegs ihm an, unter ihnen Dinis̀mend. Da er sich auszeichnete, verlieh ihm Alp Arslan Tokat, Neocaesareia, Siwas, Albistan, Malatia und alies Land, was er noch von den Christen erobern werde, ohne Verpllichtung zor Stener\%alılung an den ()herherrn und mit Erbberechtigung (ür seine Söhne.

2. Gü̈nïšstegìn, Sohn von I. Kämpfte crfolgreich gegen die Christen.

3. Muhammed, ältester Sohn von 2.

4. Jikghy Arslan, Bruder von 3. Folgte im Jahre 537.

5. Ibribìm, Bruderssohn von 4 .

6. Ismấ-ill, Sohn von 5 .

7. Dhì-Alnin, Bruder von 6. Folgte 564 .

In dem Stammbaum bei MB II 575, auf den Rande, wird Damišmend lrezeichnet als w und sin Geschlecht in folgender Weise angegeben: Dinišmend, sein frohn Gümüštegin, dessen Söhne Jaghy Arslin

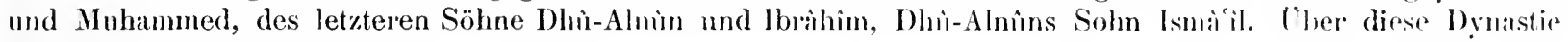
vgl. Ibn Alathîn IX (s. Index).

\section{Die 'Turkman-Dynastie Dhû-Alyadrij.je, Ileprschè von Mlloistân und VIar'aš.}

A. II. $740-920$.

Dies Gesehlecht leitete sich ab) von Anuširwän. Sie zelteten als IIirten im Gelbet von Mar as.. Malalia. Aintâb, Kharput und lisisn-Mausuir.

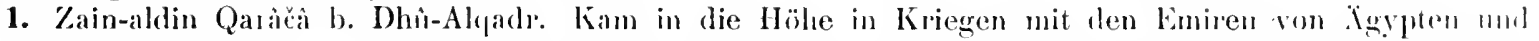
Syrien. Besetzt Ablastin بلستين in 740. Kampf mit Jelbughì, dem ägyptischen Statthalter von Aleppo. Li. fiilırt Krieg gegen Armenien. Wird im Kanpf gegen die Xgypter gelangen und gretötet.

2. Khalil Beg, Solun von r. Intertänig gegen Kgypten. Erwarb Mar'aś. Malatia und Kharput. Fintwrict aul' Betreiben Agyptens. Regierte 34 Jahre.

3. Sili Beg, Bruder von 2. Krieg mit den Ẍgyptern. Regierte 12 dahre. Ermordet.

4. Nâșir-aldin Nuhammed Beg, Bruderssohn von 3. Fïgte ("äsareia und Tripolis seinrm liviche hinzı.

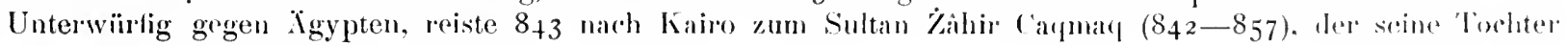
heilatete. Von $802-846$.

5. Sulaimin Beg, Sohn von 4. Seine 'óchter, Sittî Khatinn, war mit den tïrkischen Prinzen Muhammed Khàn, Solu des Sultans Muràd, verheiratet, die in Adrianopel eine Moschee baute. Von $846-858$.

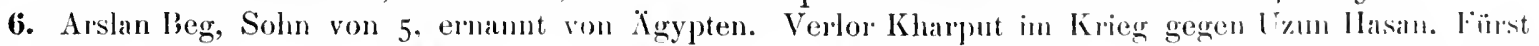

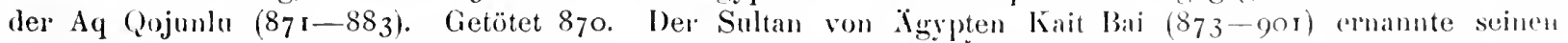

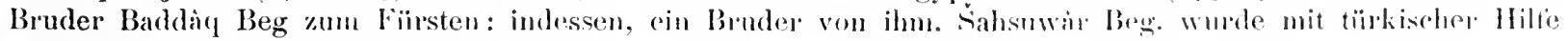
Nachfolger des Arlan Beng. 
7. Sahsuwir Beg. Krieg mit den Ägyptern. Wird getangen und getötet von den Ägyptern. Von $858-864$.

8. Sih Baddà, Bruder von 7 , aufgestellt von den Ägyptern, während sein Bruder 'Alâ'-aldaula mit IIilfe der Tïrken die IFerrsehaft erlangt. Baddàq geht in Xgypten zugrunde.

9. 'Alâ'-aldaula. Kampf' mit dem Sefiden Š̉h Ismấîl (907-930). Lr fält im Kampt gegen die Türken unter Sinin Pascha wïhrend der Regierung des Sultans Selîm (918-926). Regierte 40 Jahre.

10. Ali Beg, Enkel von 9, angestellt von Sultan Selìn. Er begleitet letzteren auf seinem Eroberungszuge nach Syrien und "Igypten A. II. $923=$ A. D. 1517. Infolge einer Intrige am tïrkischen Hof mitsamt seinen Kindem ermordet. AB III r67-17 r.

\section{Die 'Turkman-Dynastie Bamu-Ramadân, Herrscher in Cilicien. Residenz Adana.}

A. H. $780-970$.

1. Almmed Beg b. Ramad̦in besetzte Adana 780 und lebte bald in Frieden, bald in Krieg' mit Xgypten. Lifolgreicher Kampf mit 'Timur Beg, dem Statthalter von Aleppo. Von $780-8 \mathbf{r} 9$.

2. Ibrihim Beg, Sohn von I. Der Sultan von Ẍgypten setzt ilın ab und ernennt an seiner Stelle einen sciner Isrider, den

3. IIamza Beg, fiel im Kriege.

4. Diłìd Iseg, einer der Söhne von Ramaḍin, fiel 885 im Kriege.

5. Khalîl Beg, Sohn von 4, baute in Adana eine Moschee und eine Medrese. Von 885-9rg.

6. Malmutu Beg, Bruder von 5, begleitete Sultan Selim auf seinem Zuge nach Syrien und Agypten und tiel in Kampfe 922.

7. P'irì Beg, Bruderssohn von 6, hegleitete Sultan Selîm auf dem Zuge uach Agypten bis zu dessen Riickliehr. Baute viele Bauten in Adana. Gestorben 970.

8. Deswis Beg, Sohn von 7 , angestellt von Sultan Suleiman $(926-974)$. Regierte 6 Monate.

9. Ibràhim Beg, Bruder von 8.

10. Nuhammed Beg, Siohn von 9. MB III i 7 I. I 72.

\section{Kleinasiatische 'Teilfïrsten.}

A. H. 1111 700. 800 .

$\%$ dem von LP 184 gegebenen Verzeichnis kleiner Iynastien, die in Kleinasien um die Zeit des Untergangs des Seldsehukenreiches von leonium (700) anfkamen und nieht lange darauf von der aufsteigenden (Ismanenmacht (699 Regierungsanfing von Osman I.) einverleibt wurden, bietet MB III 3 I. 36 folgende Beitriige:

Mu'in-aldin l'arwìne hatte zwei Söhne.

1. Sinope.

Mn în-aldin b. Muein-aldin Sulaiman. Dieser Sulaiman gehörte zu den Dienern der Seldschuken von lconium, und nachden der Sultan Ruku-aldin (Yylyc̀ Arslan hauptsächlich mit seiner Ililfe Sinope erobert hatte, verlieh er es ilm und seinen Kindern zu erblichem l.eln. Nach seinem Tode trat sein Sohn im lahre 676 die Ilersschaft an und gewann Stïrke durch Beziehungen zu der llkhani-Dynastie (Abaqa 663-68o). Ciestorben 696.

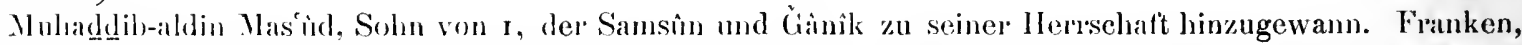
dir in Sinope landen, nehmen ihm 698 gefangen und bringen ihn nach Europa. Er kaufte sich frei und kam in sein Reich zurïck. Starl) 7oo, und sein Reich ging über in die IIand der IIerrseher von (Qasțamûnî. MB III 3r.

\section{Il. Cianik}

(ein Sinciak in Qastamuni, sïllich von Trapezunt).

1. (qobid ()ghlu. Zog mit Timur (804) gegen Sultan Muhnumed (805-824). Der Familienname bei Mll unbekannt.
2. Ṭišin ()ghhı.
3. Cimmaid Beg.
4. II usain Beg.

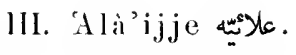

Ilerrscher Latiff Beg, war seldschukischer Abstamınung. Sein Reich wurde von Gedik Ahmed Pascha fïir den Sultan erobert.

IV. Siwas.

()âdi Burhàn-aldin war eine Zeitlang Herrscher von Siwas. Fiel in einem Kampf.

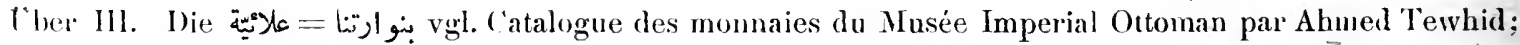
section des monnaies Mlusulmanes, IV. partic S. $426 \mathrm{ft}$; iiber. IV. Siwas daselbst S. 442 . MB III 36 . 


\section{In der Mitte. (Nr. 31-39.)}

\section{Die Baridis iuı Irât.}

A. $11.323^{--3} 36$

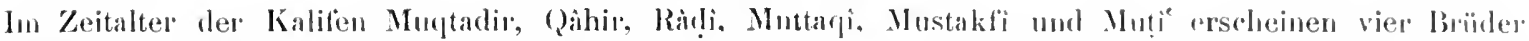
dieses Namens, Abu Abdalah Alhusain, Abu Jîsuf da qüb, Abulhusain Abrallab und Abullasan Ali, vun denen der erste, zweite und vierte als unabhängige ILerscher in Wasit und Basıa residierten.

1. Als Staatsbeamter in Bagdad erlangt Husain 316 die Provinz Aḷwiz fiir sich und andere Provinzen fï̈ seine Brïder. Sie überstehen den Sturz ihres Gönners Ibn Muqla, errafien Geld mnd sammeln Kíregsvolk, schicken keine Steuern nach Bagdad, machen sich unabhängig mit List, Gewalt, Urkundenfälsehung.

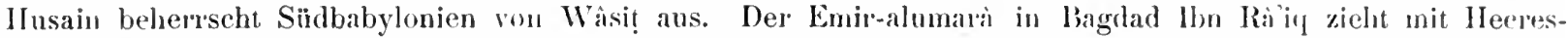
macht gegen Wasit, ihn zu unterwerfen, wirl aber von ihu ïbertölpelt. Nun ernennt Ibu Rảin ibn zu seinem Vezier; IIusain nimmt zwar an, gebt aber nicht selbst nach Bagdad, somdern schickt einen Vertreter. Sein Bruder Jåqub wirl Stathalter von Basa. Der liviede dauert nicht lange. Ls folgen große Kämpfe zwisclien den Vertreteru des Kalifats und IIusain; seine Feinde dringen vor bis gegen lasia. Husain erbittet Ililfe von dem ersten großen Bujiden, dem Beherscher der Persis, Imàdaldaula. Dieser schickt ihm seinen Bruder Mu'izz zur Hilfe. Mu'izz und llusain vertreiben die Bagdader 335. 336. Das Ende dieser societas lennina ist aber, raß Muizz in Alıwaz beibt und Husain auf Wisị beschrankt wird. Der Kalif Ràrlî ernennt rlen IIusain zu seinem Grobvezier; er nimmt an, geht aber nicht nach Bagdad, 327 . In den Kämpfen des Jahres 328 häit er sich uben anf und zielıt an 2. Ramadàn 329 mit seiner Armee in Bagdad ein. lir erprebt den Kalifen viel Geld; indessen seine Soldateska meutert gegen ihn, plïndert baglad, und er selbst flieht naclı Wäsit. Im folgenden dahıe schickt er seinen Butuler Abdallah mit den 'Truppen wieder nach Bagdad, wo diese von neuem gräulich hansen. Der Kalif holt den Hamdaniden in Mosul zur Hilfe herbei; die Bardis werden in ihren Sïden zurïcligejagt. In $33^{2}$ versucht Husain von neuem sein Gliirk durch eine Ver-

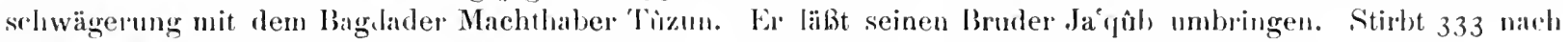
zelııjälıriger Regierung.

2. Auf Husain (Abu Abrallah) folgte sein jïngster Bruder Ali (Alulhasan). Ein Aufstand seiner' 'l'uppen.

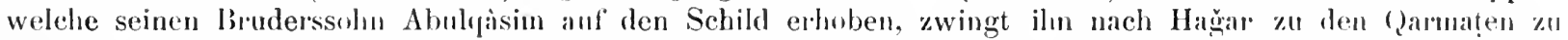
fliehen. Diese kommen ihm zu Hilfe, loelagem liasra. ziehen aber ohne Frfulg wieder ab. Verhandlungen zwiselıen den beiden baridis. Abulqasim bleibt in basia: Ali geht nach liagdad und geht im dortigen lutrigenspiel elend zugrunde, 333 .

3. Als dritter folgt A buly à im (Abdallal). Ë besiegt eine Versehwörung, rlie gegen ihn von ,lanis, einem Freigelassenen seines Hauses, mit einem dailemitischen Machthaber angezettelt war. Abulqàsim blieb anf' Basıa beschränkt, denn Wâsit war in der Gewalt des Bujiden Mu'izz, der seit 334 in Bagdad herrschte. 335 Kampt" zwischen den Truppen des Müizz und des Abulquisim. Der letztere unterliegt. In 336 erobert Muizz auclı Basıa. Ali flieht nach Ilağar zu den ( armaten und verschwindet dort.

Es war verlängnisvoll fiir die Bardiss, dab ilı Auftreten gleichzeitig war mit den des gröberen lie-

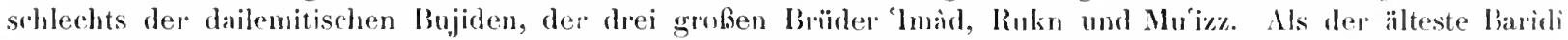
die llilfe der Bujjolen aus der l'ersis herbeirief, leitetr er damit den Untergang seines cigenen fieschlechtes ran.

$$
\begin{aligned}
& \text { Alı Abrallah Allusain...... 323-333 } \\
& \text { Aluiliasan Ali .......... } 333 \\
& \text { Abulquisim.............. 333-336. }
\end{aligned}
$$

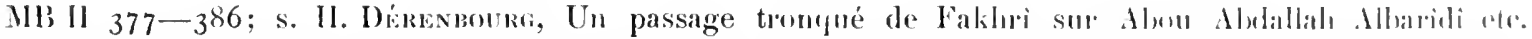

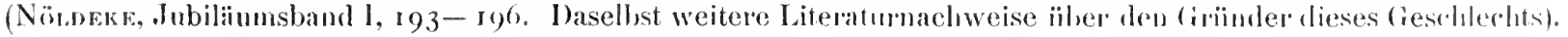

\section{Bauı Ṣ̌̂hîn in Albatẩị.}

1. II. $338-374$.

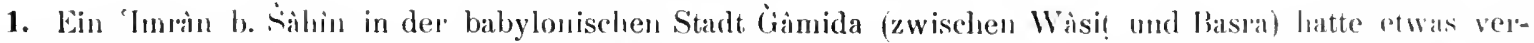
brochen und floh daher, um der Strafe zu entgehen, in die Sumpt- und Rohrwildnis des siidbabylunisehen r'berschwemmungsgebietes (Albațił!), wo er von Fischen und Wasservögrln lebte. Bald sammelte cr gleirlıe Kumpane un sich, bildete eine Räuberbande und machte die Straben der nngrenzenden (icbiete unsirher.

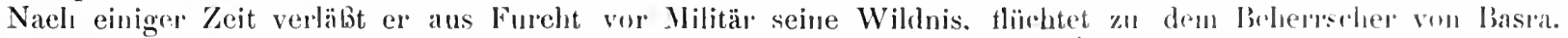

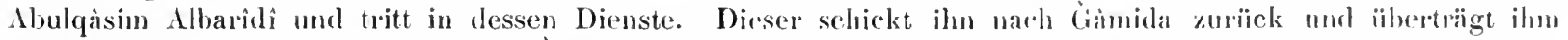

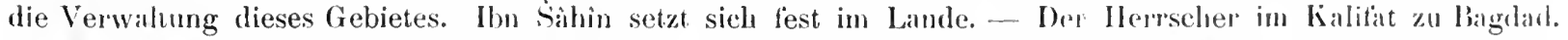

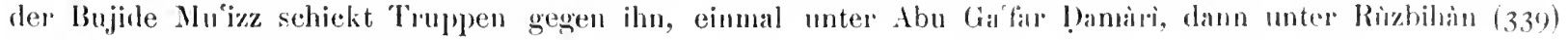


und zuletzt unter Muhallabi, alle ohne den gewïnschten Erfoly. Mu'izz sieht sich genötigt, mit ihm zu verhandeh. Die Gefangenen werden von beiden Seiten ausgetauscht und Ibn Šahìn als Herr von Albatẩilı anerkannt. In 344 plïndert Ibn Sâhîn eine Karawane, welche die Steuern von Abwàz naelı Bagdad zu Mu'izz bringen sollte. Nach weiteren Zwischenfällen zieht Mu'izz in eigener Person gegen ihn zu Felde, erkrankt unterwegs, kehrt zuriick nach Bagdad und stirbt bald darauf (356). Sein Nachfolger Bakhtijàr setzte den Kampf gegen Ibn Šihin fort, gelangte schließlich bis an sein Hauptquartier, fand es aber leer; der Feind hatte sich mit Sack und l'ack irgendwohin in Sicherbeit gebracht. Die Bagdader Truppen meutern; Bakhtijâr muß unterhandeln, und Ibn Šâhîn blieb, der er war, der Herrscher von Albatââị̣. Er starb A.H. 369 .

2. Ihm folgte sein Soln Abulhasan Husain. Der derzeitige bujidische Herrscher im Kalifat Adud-aldaula schiekt von neuen ein Heer unter dem Vezier Nuṭahhir gegen den Sumpflönig 369, aber wieder vergebens. Der Sumpfkönig siegt. Er wịd nach dreijähriger Regierung von einem neidischen Bruder 3. Abulfarağ ermordet. Die Truppen wollen aber von dem Mörder nichts wissen, töten ihn und erheben seinen Bruderssohn 4. Abulfară Muhammed, Sohn des Abulhasan Ḥusain, auf den Schild, 373. Da dieser noch unmündig war, bemächtigte sich der Chef der Soldateska, Mużảffar der Herrschaft, tötete alle Anhänger der Familie Ibn Š̉hîn und erklärte sich zum Herrscher von Albațầih auf Grund eines gefälschten Diploms. Ein letzter unmündiger Sproß der Banu Šìhin wurde mit seiner Mutter nach Wàsit geschickt.

\begin{tabular}{|c|c|}
\hline 2. Abulbasan Husain, Soln von $1 \ldots$ & $370-37$ \\
\hline $\begin{array}{l}\text { 3. Abulfarağ, Sohn von I } \ldots \ldots \ldots \ldots \\
\text { 4. Abulfarağ Nulianmed, Soln von } 2 .\end{array}$ & $\begin{array}{l}373 \\
373\end{array}$ \\
\hline
\end{tabular}

Mll 11 386-389. Uber das Ende dieses Hauses s. Ibn Alathì IX, 2 r. 22.

\section{Banu Muzalfar in Albaṭ̂àih}

A. 11. $374-410$.

1. Mùatlar b. Ali regierte im Lande nach dem Ende der Banu Sähîn mit lisfolg und starb 376 . Ihm folgte sein Brudersohn Muhaddib-aldaula Abulhasan Ali, der von dem Kalifen belehnt und mit dem Titel besehenkt wurde, auch mit dem Bujiden Behà'-aldaula versehwägert war. Der Abbaside Qâdir wird auf der Flucht vor dem Kalifen 'Tầi bei 2. Muhadgdib aufgenommen. Rebellion im Innern, Muhaddib muß vor einem seiner Oftiziere außer Landes fliehen. Nach seiner Rückkehr tritt er wieder die Regierung an und sendet dem Bujiden Belä'-aldaula jährlich 50ooo Denare.

Muhaddib erkrankt. Die Großen wollen seinen Sohn Ahmed zum Nachfolger machen; dem aber tritt sein Sehwestersolnn Abdallah entgegen und bemächtigt sich der Person des Ahmed. Muhaddib stirbt 408 und jener 3. Abu Muhanmed Abdallah tritt die Regierung an. Frmordet seinen Vetter Ahmed. Drei Monate später starb Abdallalı an Diphtheritis. Die Großen erwälılen einen Freund des Mulıaddib zun Nachfolger, den 4. Ilusain b. Belsr Alšarsibì, der zwar vom Kalifen anerkannt, aber 4ro abgesetzt wird und danit verschwindet.

$$
\begin{aligned}
& \text { Muziaflar b. Ali ............... } 374-376 \\
& \text { Muhaddib-aldaula Abulhasan Ali .... 376-408 mit Unterbrechung } \\
& \text { Abu Mulaumned Abdallah......... 408 (drei Monate) } \\
& \text { Ilusain i. liekr Alšaràbî ......... 408-4 ro. }
\end{aligned}
$$

III $11,389-390$. Dis Einde der Dynastie etwas anders bei Ilm Alathir 1X, 22.

\section{Banu 'Annâz Kưdî in Ịulwân mnd Qarmîsîn.}

Zı den kleinen Dynastengeschlechterı der Bujiden-ZZeit gehören außer den Hasanwaihids (Hasanujje) und Kàkwahids (Kikịje) auch die kurdischen Banu Annâz, welche in einem Teil des westliehen Zagros i zo Jahre geboten haben. Der Gründer des Geschlechts, Aluulfat!̣ Muhammed war ein Dienstmann des Bujiden Behâ'aldaula (379-403). Gegen Ende der Bujiden-Dynastie (c. 452) machte er sich mabhängig und regierte noch 20 .Jahre. Der Stammbaum ohne Regierungsdaten wird in folgender Weise angegeben:

1. Ahulfath Muhammed b. Annầz. 2. Abulmầnìl Muhalhil, 3. Ahnššauk Fàris, 4. Surkhâb, Söhne des

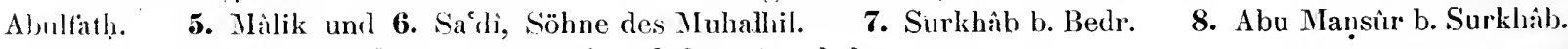

Von diesen sollen Nr. r, 3, 2, 4, 6 und 8 regiert haben.

Der Stammbaum der Hasanwailirds (LP I $_{3} 8$ ), welche nach MB Il 503 in Dînawar residierten und über

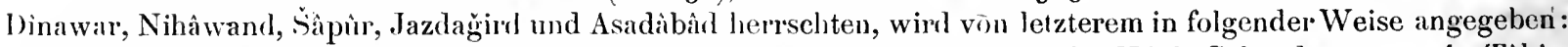

1. !lıısanawaihi (Hasanûje). 2. Abunneğm Berlr. Solun des r. 3. Hilâl, Sohn des 2. 4. 'Tàhir, Sohn des 3. 5. Bedr, Sohn des 4 .

Als ihre Regierungszeit gibt MIB II 503 die Jahre $350-440$ an und ihre Rigentenreihe in folgender Weise: Hasanawaihi, Alıuneğm Bedr, llilìl Bedl, Bedr, Ṭ̂hir, Bedr. Ober Abulfatlị Muhammed b: Annàz siehe Ibn Alathin IX r 58 , der auch ïber ihn and sein Cieschlecht Weiteres berichtet. 


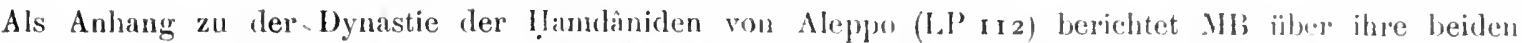

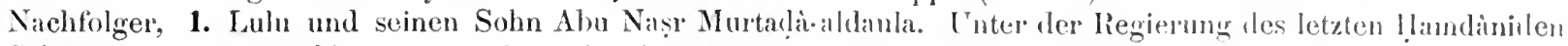

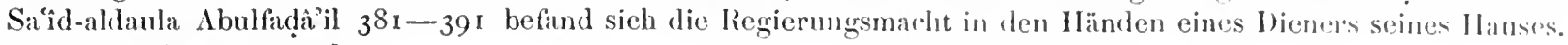
des Lulu, der 399 starb.

2. Sein Sohn und Nachfolger Abu Nașr ließ das Kanzelgc bet lï̈r den fatimilisclen Kalifen !bakim (386-41 ) halten und erhielt von ihm den Titel Murtadataldaula, in des Folgezeit aber wurde der Friedle zwischen Al'pp" und Ägypten gestört. Diese Gelegenheit benutzten Beduinen, unter einem Schaich Sälił Aleppo anzugreifin.

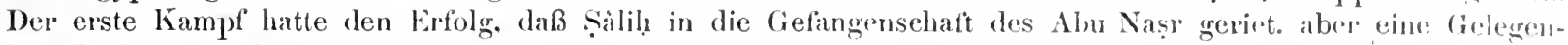
heit fand zu entiliehen. Durch den zweiten Kampf geriet mmgekehrt Abu Nași in die Gefangenschalt des

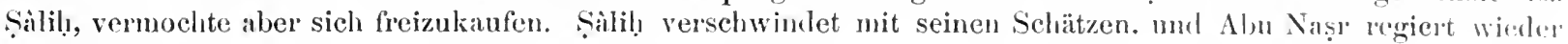
in Aleppo.

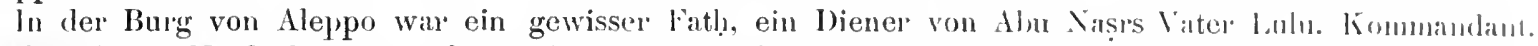
Aher Nașr hegte Verdacht gegen ihn und wollte ilun durch einen seiner eigenen biener namens Sinriur ansetzen; indessen Fath, unterrichtet von dem, was ihn droht, versagt den Geliorsan und läht sich durch kriu Mittel aus der Burg heranslocken. I lieser Fat! ließ wieder das Kanzelgebet tïr llikim von Xgypten halten,

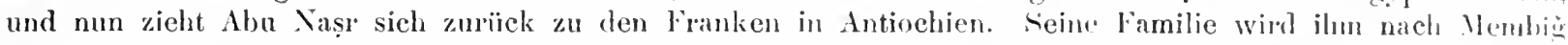

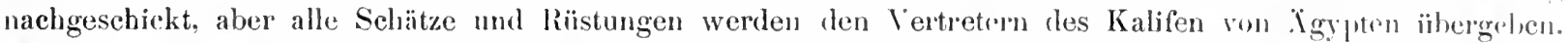
Aleppo wird ägyptisch und gerät nach einiger Zeit (4'4) unter die llerrschaft der Mirdaisiden (t.P' II4).

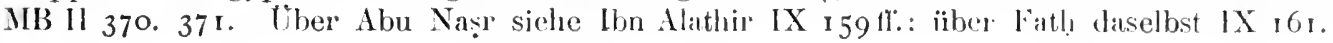

\section{Banı Ajjônb 1. Šấlî in Baalbek.}

A. $11.533-644$.

Zu den kleineren Reichsbildungen, welche ans dem Reieh des großen Atal)eg 'maid-aldlin \%engî (52 I-54I). des Beherrsehers von Mesopotamien und Syrien, teils dureh Verwandte, teils dureh Dienstlente hervorgegangen

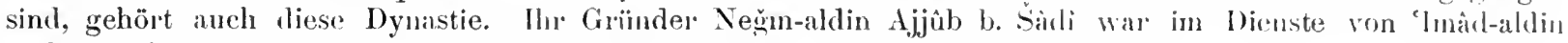
und von ihm mit der Verwaltung von Baalhek betrat. Reihenfolge der Regenten:

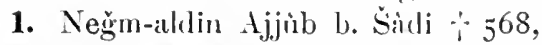

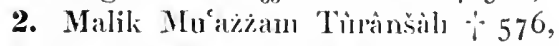

3. Malik Manșurr 'Izz-aldin, Bruder'soln von 2. $\therefore 578$,

4. Malik Amğad Mağd-aldin Bahrâmšìh, Sohn von $3, \therefore 027$.

5. Malik Sàli!̣. Biutler von 4, $627-644$.

MB 623-624. Ygl. Ibn Alathir XI 225. 259. 3 I 0.

\section{A.jônhidische Herrschaft in Kerak.}

1. II. $5^{8}+-66$ I.

Der Bruder Saladins. Malik ídil, eroberte Kerak 584 und ließ sich darin nieder. Als er daun einige Zeit nach dem 'Tode Saladins Beherrscher von Damaskus geworden war', 592. Z̈̈berlieb er Kerak seinem Suhn:

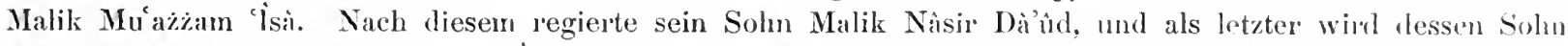

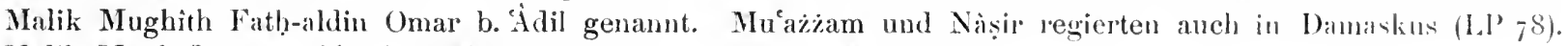
Malik Mughith erlag 66r lem Mamlukensultan Baibars. MB 11624.

\section{A.joúlnidische Hemschaft in !̣ișn-Kêt.}

A. H. $629-930$.

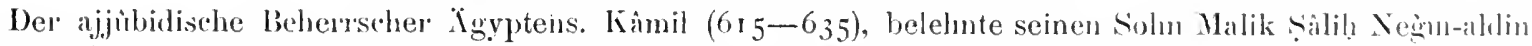
Aj.jìb mit den Provinzen Amid und ḷiṣn-Kêf. Nachdem Malik Sililı sich von dort nach I)anaskus und Agypten begeben hatte, ibergab er 636 semen Solne Malik Múazian Turan die Heruschalt ïber Ilișn-Kif.

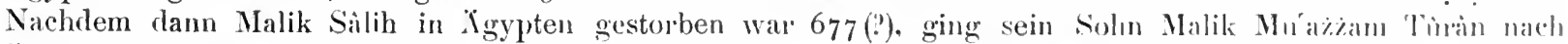

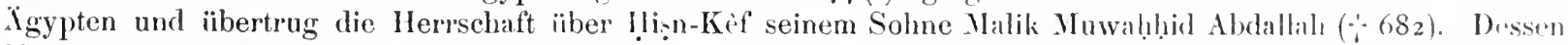
Nachkommen haben bis 930 in Ilișn-Kèt regiert. Die Reihentolge dieser Ilerrscher ist bri VIH whe \%eitangaben in folgender Weise iiberliefert:

Malik Kàmil Abı̀ Bekr, Sohn des Muwalı̣id - Malik Àdil Muğìralklin. Solın des vorigen - Malik

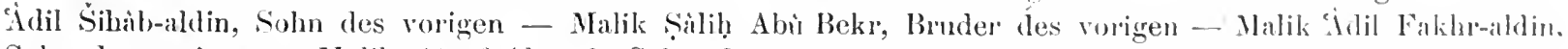
Sohn des vorigen - Malik Asral' Ahmed, Sohn des vorigen - Malik Kàmil Khalit. Suhn des rorigren Malik Kinnil Ahmed, Soln des vorigen - Malik Âdil Khalaf b. Muhammed b. Mšralt. M11311 624. 625.

\section{Die 'Tâhiridischen Pröifeklen von Bagralad.}

1. II. $2 \mathrm{I}+\mathrm{t}-300$.

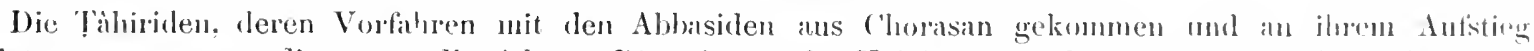
beteiligt gewesen, waren die ersten. die sich rou Dienstlenten der Kalifen zu mächtigen Herren und unahhängixw 
Ilerschem emporgesehwungen hahen. Der eine Zweig der Fanilie beherrselte von Herat aus die Provinz Chorasan (LI' r28). während ser andere das grobe Amt des Stadtpräfekten von bagdad immelaate. MB gibt die lieihe der letzteren in folgender Weise:

1. Islầy b. Ibrahim b. I'usain. ein Bruderssohn 'Ṭhhirs, des Grïnder's der Familie und ersten Stattlailters von Chorasan, wurde amm Präfekten ernannt. nachdem Abdallal, b. Tïhir (2 If) Statthalter von ('homasan geworden war. Er besiegte 218 die Bibekis in Medien. $\because 235 \ldots \ldots \ldots \ldots \ldots \ldots \ldots \ldots 214-235$

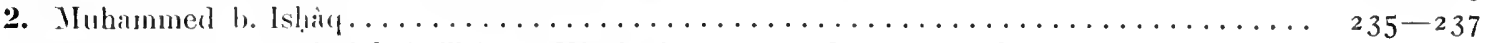

3. Mubammed b. Abdallah b. Tiahir. Wird ahgesetat und an seine Stelle .......... 237

tritt

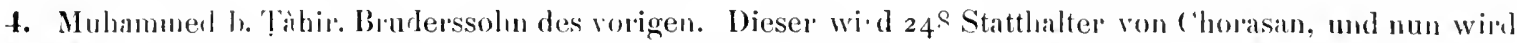

3. Mulanmed b. Abrallalı zum zweitenmal Präekt. $\because 253 \ldots \ldots \ldots \ldots \ldots \ldots \ldots \ldots 248-253$

5. Abu Almed Ubaidallalı b. Abdallah, Bruter des vorigen. das erstemal ......... $253-255$

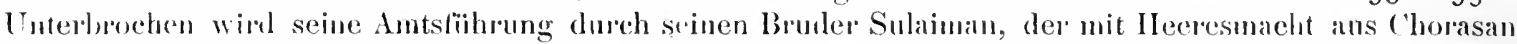
kommut und dir l'rälektur fïr sich nimmt.

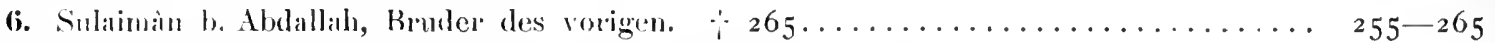

5. Ahı Ahmed 'Uhaidallah b. Abdallah, zum zweitenmal Prailikt............. $265-271$ ?

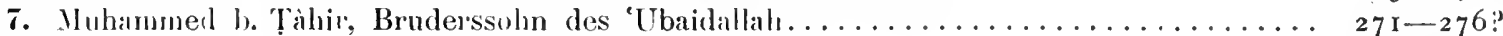

7. Abu Alımed Ubaidallah b. Abdallah, zum drittenmal ................ $276-300$

Mancherles Nachrielıten ïber die T'ihhiriden, sowohl die Statthalter von ('horasan wie die P'räfekten von Bagrlad gibt das Klosterbuch des Sabušti (s. meine Beabeitung Berlin I919. Abhandlungen der Akademie) und vorher die Schrift von G. Rothstern in dem Jubiläunsbande Nördeke I S. I 55 ff. IIB II $241-244$.

\section{Im Siiden. \\ (Nr. 40-54.)}

\section{Die Bam Chaiḍr, Aliden vom Stamme Hasans, Herrscber in Mekka mud Jamâma. Residenz Mekka und lliğr. \\ A. H. $251-35$ o.}

1. Ismaitil Saträk b. Jisuf Alulaidir. Er entficlute einen Aufitand $25 \mathrm{r}$ gegen den Kalifin Mustain $(248-251)$ und vertrieb dessen Stathalter in Mekka. Wr plïndert Mekka, ïlserfällt Medina, zurïekkehrend belagert er Mekka, brandschatzt Gidda. kämpft mit den P'ilgern auf 'Alatit und plïndert síe. Stirbt nach einem Jahr.

2. Abu Abdallah Muhammed. Bruder von 1. Der Kalif Mutarz (251-255) schickte ein Heer gegen ihn. Juhammed setzt sich in Jamâma fest. $† 316$.

3. Nuhammed, Bruder von 2, fiel in Kampt mit den (Yarmaten.

4. Hasan. Bruderssohn von 3. 5. Abu Ciafar Almed. Sohn von 4. 6. Abu Abdallah Mluammed, Sohn von 5. 7. Muhammed, Bruderssohı von 6. Die Qammaten benächtigen sich des Higàz. Ende der Dynastie.

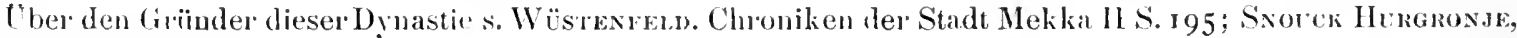
Mekka S. 47 . MB HI $428-43$ O.

\section{Die Banu Mn̂sâ, Alidische Herrscher in Mekka md Medina.}

A. I1. $350-453$.

Nach dem lirlöschen der Dynastie der Banu Uḷaidir machte sich ein anderer Alide

1. Dà'ìd 1. Musa zum Herrscher ron Mekka und Medina.

2. Sein Bruiler Mulımmed. 3. Sein Solm Ihusain.

t. Sein Sohn Muhammed 'Thà ir.

5. Sein Solın Husain b. Muhanmed. 6. Sein Solın Abu Haisin Muhanmed. 7. Sein Bruder Abu Cia laı Muhammed.

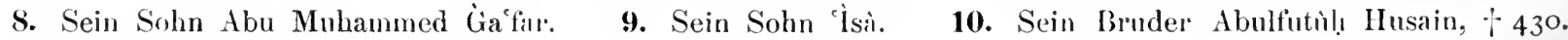
11. Sein Sulın 'Tà̆ğ-almáầlî Š̉ukr.

l'ber einige Mitglieder dieser Familie s. Snouek Hengronde, Mekka S. 59.60. MB II 508.

42. Die Ilawâšim oder Bann Falita, Alidische Herrscher von Mekka. A. H. 460-598.

Ein anderes alidisches Geschlecht entıiß den Banı Mìsâ die Herrschalt ïber Mckka.

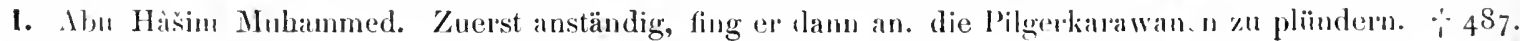

2. Sein Sohn Falitil, $\odot 5 \mathbf{r} 7$.

3. Sein Sohn IIàsim, 517-527. 


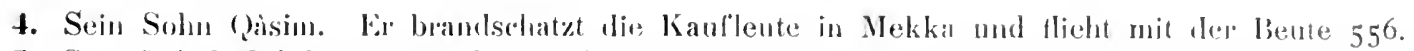

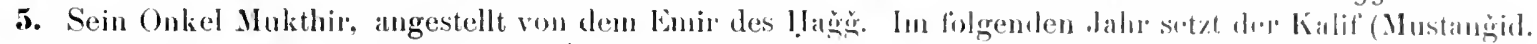
$555^{-566)}$ ihn ab und setzt seinen Onkel 'ísil an dic Stelle.

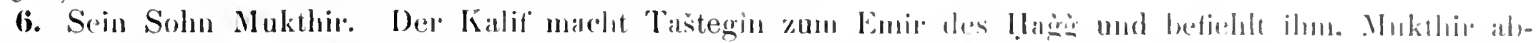

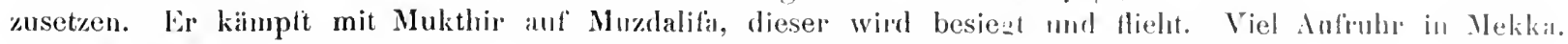
Dann wurde

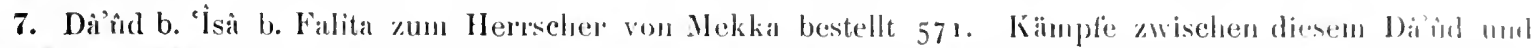

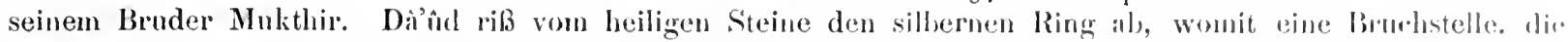
ein Qarma! mit seiner Keule gesehligen hatte, verdeekt worden wal. Daraufhin reaktivierte der Kalif' (Mustadi.

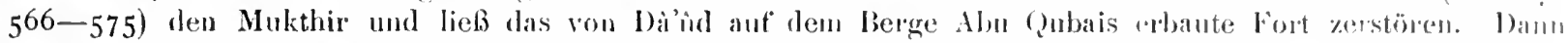

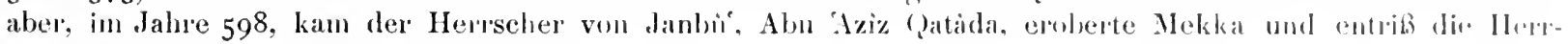
schilft dem I)ầíd. Encle der Dynastie.

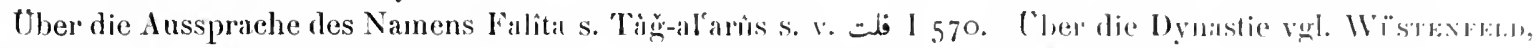

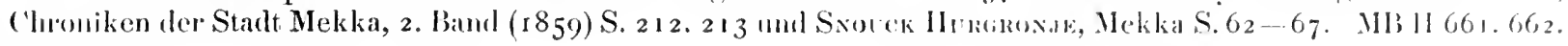

\section{Die Baun Qatâda,} Alidische, von IIasan ahstammende Ilemischer von Mekka.

A. II. 598 bis \% \% \%eit voll

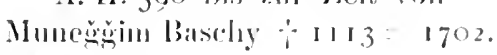

1. Abu Aziz Qatâda. Den Verfall des Hauses Hawišm henutyend, embert cr Westalralien bis Jemen mit türkischen Truppen und Beduinen. Sein Sohn Hasin ermordete den Bruder scines Vaters mud dann seinen Vater selbst.

2. Hasan. Ermordet auch seinen Bruder, den Herrn von lanbu'. In zweitfolgenden lahre \%icht der aj.jubidische Sultan ron Arabien Mas'iud herin und entreißt ihm die Iferrschaft. Hasin muf fliehen und gelnt in der Fremde zugrunde. Die IJerrschaft ron Mekka war eine \%eitlang in den Iländen der Rasuliden von Jemen (s. Ll' 99). Im Jahr 629 machte dann der Herrscher von Jemen, Maśĭds Solm, Nirr-aldin den Sohn des Hasan,

3. Rägị! zum Fürsten von Mekka. Nun schickt der ajjubidische Sultan von Igg pten, Kimil (6r5-635), ein Heer, das Mekka belagert und den Rišgilı zwingt, nach Jemen \%u fliehen. Nür-aldin in Jemen gibt ihn ein Heer, er kehrt zuriick nach Mekka und verjagt die Igypter. Letztere kommen aber zum zweitenmal mod vertreiben den Ri ğilı.

4. Serîf Abu Sâîl, ein Eakel von Qatîda. 5. Sein Onkel Šerif Gammì, 65I, verjagt nach rinem

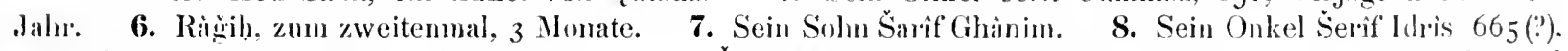
vertreibt seinen Vorgängrer. Getötet 669. 9. Šerif Abu Numìj.j. regierte 5o Jahre. 10. Rumaitlaı und قميصه (Aussprache:'). zwei Brïder, Kinder von Nr. 9, regierten in Gemeinsehaft. Sultan Baihars ron Tgypten kımmt mit den IIagig nach Mekka. fïhrt diese beiden als Gefangene nach igypten und setzt

11. Muhammed und Abughaith an ihre Stelle. Streit zwisehen den heiden. In $70+\mathrm{k}$ ommen Rumaithal und (Yumajijișa aus Igypten zuriick und herrsehen wieder in Meklia.

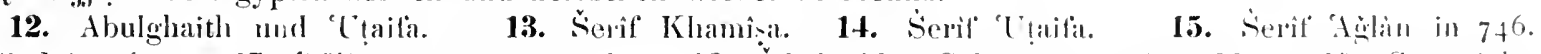
16. Sind in 760. 17. Ağlàn zum zweitemmal. 18. Sihàb-aldiı, Sohn von 77 bis 788 . 19. Secin Sulı!

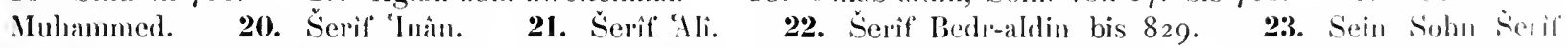
Zain-aldin, zahlt Tribut an Tgypten und ïbelibi Tgypten den Zoll, der von den aus Indien kmmmenden Schiffen erhoben wurde.

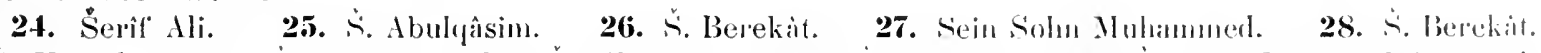

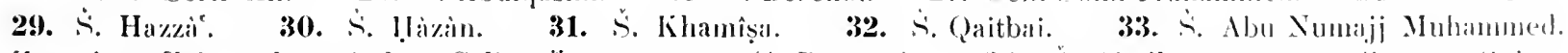
Zan seiner Zeit mobert sultan Selim Igypten, 922 (A. I). I5 7). 34. S. Ahulhasan, angestellt von Sultin

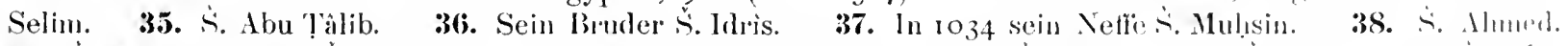
39. S. Masûd. 40. S. Abdallah. 41. Sein Soln Muhammed. 42. S. Nimi. 43. S. Zaid. 4t. S. Sild.

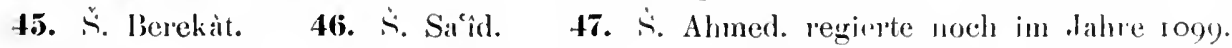

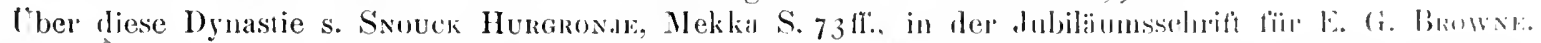

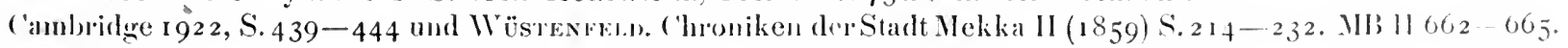

\section{Die Bann-Muhanna', Herrscher in Medina. $\quad\left(95^{8} 3-6.1+3\right.$.}

1. Abu Falita, Alide vom Gesehlecht Husains. Kämpfte auf der Seite von Sialadin bei der Eubruns von Jerusalem $5^{83}$ und in anderen Kiriegen. Vorgesehichte der Familie unbekannt.

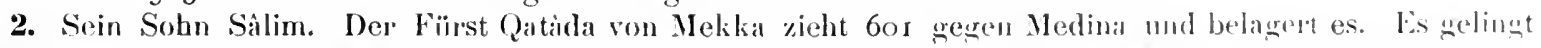

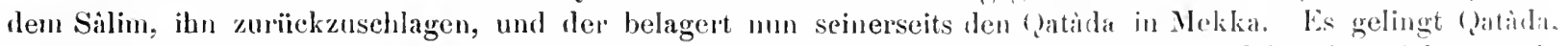
die Truppen Sâlims zu sieh herüberzuziehen, infolgredessen mub Silim abziehen. In Jahre 6ra zieht ()atridal 
wieder gegen Medina, zerstört ihre Dattelpflanzungen, während Sälim in Syrien bei dem Ajjubiden Malik Âdil Abı Bekr (635-637) war. Letzterer stellt ihm ein Heer zur Verfïgung, er zieht damit heimwärts, stirbt aber unterwegs.

3. Sein Nefle Ciammiz. † 704 .

4. Sein Sohn Manșir. 5. Sein Sohn Ațijja, regierte 57 lalıre. 6. Nughair, Bruder von 5. 7. HibatAllâh. 8. Muhammed. $\subsetneq 788$. 9. Gamàl aldin. 10. Sein Neffe Thàbit. 11. Sein Bruder Ağlàn. 12. 'Uıair. 13. Ağlân. 14. Hasan. 15. Ağlìn. 16. نhıl (?). 17. Màní. 18. Wathabân. 19. Sulaiman. 20. Sein Bruder نيlol. 21. Sein Sohn Zuhair. 22. Daigham A.H. 874 . 23. Qusaitil b. Zuhair. 24. Zuhri. 25. Sein "Sohn Hasan. Regierte zur Zeit von Muneğğim Baschy $(f$ I I $3=$ I 702$)$. Der Grüuder dieser Iynastie heißt mit vollem Namen 'Izz-aldin Abu-Alfalita ( Qâsim b. Alınuhanna' Nl'alawî Allụsaini, s. Ibn Alathî̀ XII ı. MB II 665.

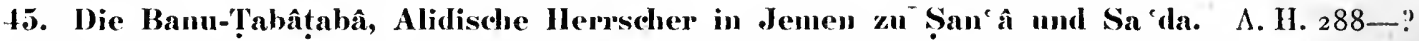
Von der Darstellung bei LP 102 gibt MB folgende, stark abweiehende Form.

1. Jaḷja Mhâdi. Nimmt Mïnzreetit und Kanzelgebet in Anspruch. Von 288-298.

2. Sein Sohn Murtalya Muh:mmed. Von 298-320?.

3. Sein Bruder Alumed Alnàir.

4. Sein Solın Ilusain Almuntakhal). † 329 .

万. (Yàsim Mukhtàr, Broder von 4. Getötet von Abulyảsim Ilamadàni.

(j. Muhammed Alhâdi, Brïder vơn 5 .

7. Ciafar Alrašî, Bruder ron 6. Ende der Dynastie.

Ober den Ursprung des Namens 'T'abitabâ s. Triğgal'arùs I S. 353. MB II 430. Uber die Zaiditén und

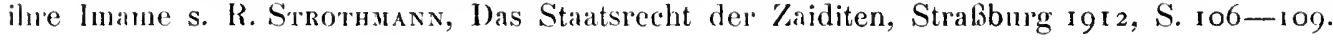

\section{Die von Husain abstammenden Šrifien, Imame von Jemen.}

\section{$Z$ wei Cruppen.}

\section{Eiste Gruple.}

A. H. $600-$ ?

1. Maușin Abdallah. Seine Vorfaluren waren 6oo, vor den Abbasiden fliehend, nach Jemen gekommen und hatten dort gegen das Ende der Ajjübden-Herrschafic Macht gewonnen (LP 98). Residenz San`à. +614. Scine Nachkommen führen alle den 'Titel šerif.

2. 'Izz-aldin Muhammed. Kämpfe mit den Rasuliden (LP' 99).

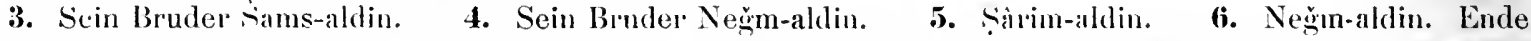
des Geschlechts. Iliermit ist zu rergleichen LP Ioz (R'ssid lmans von 593 ab). MB 1 II 20.

47. Zweite Ciruppe.

A. H. 600-?

Imane in demen, die \%ur Zeit Muneğgom Baschys $(\because$ r I $3=$ I 702$)$ noch vorhanden waren. Sie tauchen atul mit 600 .

1. Manșîr Ahdallah (s. erste (iruppe r). Von 6oo-6r4. Seine Nachkommenschaft sonderte sich in zwei Gruppen, die obengenannte und die hier folgende. Sie fiihren alle den Titel Iman.

2. Ahmed. Bis $九 u m$ Jahre 646 hatten die Kaiditen keinen Imam aufigestellt, im genannten Jahr erwählten sie Ahned zum lmam. Fïhrte Ḱriege mit den Rasuliden (LP 99). Das Volk spaltet sich in zwei Parteien, in diesen P'arteikämpfen fällt Ahmed.

3. Abu Mnhmmed IIasan. Serife und /aiditen huldigen ihm. Heftige Parteikämpfe. Hungersnot. $† 683$.

4. Jaḥjà b. Muhammed. Angefeindet ron den Husaini-Š̉erifen. Eifolgreiche Regierung in Sanấâ, wo sein Grab als wundertätig verehrt wurde.

5. Husain fand keinen Gehorsam.

6. Ibrâhìm b. Ahmed 6ךo. Einige Stämme Jemens und viele Șerfen huldigten ihm. Führte Kriege nit dem Rasuliden-Snltan von Jemen (s. LP 99). Gerät in Gefiıngenschaft des letateren und bleibt dort.

7. Mu!ahhar b. Jalıjà. Ihur huldigen die S̈erifen 674. Kämpfe mit dem Rasuliden-Sultan Muajjad (6,6-72r LP 99). Auch Kämpfe mit den Oberhaupt der Zaiditen, Šerif Dầìd. +697 .

8. Sein Sohu Muhammed. 9. Sein Sohn Mutahhaı. 10. Sein Sohn Săâlut-aldin. Seine Geschichte ist MlB nicht bekannt. MB $11120-22$.

\section{Tscherkessen als Herrscher in Jemen und Ḥiğâz.}

A. $922-927$.

1. Euir Inusain Kurdi. Die Portugiesen werden mächtig im Indischen Ozean und besetzen die lnsel Hurmuz. Der Sultan von Guğeràt, Mưaffar Š̉ah (917-932). und der Sultan von Jemen, Âmir b. Abd-Alwahhâb 


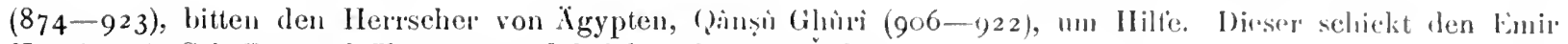
Husain mit Schiffen und Truppen und belehnt ihn mit Gidda.

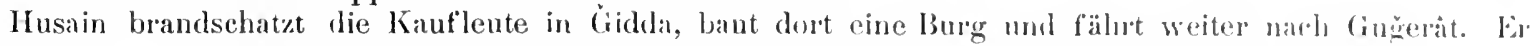
kann gegen die Portùgiesen nichts ausrichten, fäht zurïck und landet in Bandal Kamran in .Jemen.

Er verlangt Lebensmittel von 'Ámir, dem Landestiirsten, und wird abgewiesen. Nin buseliliebt er, Jemen

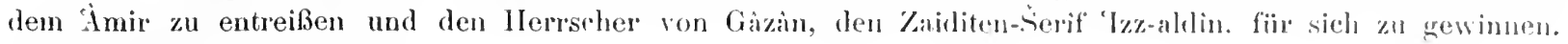
Diese schließen sich ihm an.

Die Kgypter hatten Kanonen und Gewehre. nicht die Jemener. Husain besiegt die Jemenr' und besetzt 922 die Stadt \%ebid, die gepliindert wird.

Husain läßt seinen Sklaven P’urspaii in Zebid zurïck unł segelt nach Iden, das er vergeblich belagert. Er segelt dann nach Ciiddiı.

Mittlerweile erobert Sultan Selím Igypten mo macht der Tscherkessenherrschaft ein Ende 923. Li

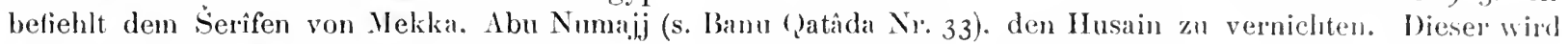
auf das Meer hinausgelockt und dort ersäult.

2. Emir I'urspâi herrscht in Jemen. Er nimmt dem Sultan X̂́mir die Stadt Ta'izz ab 923, und plïndert sie.

Er läßt einen seiner Leute اقب̣̂ (Aqbâi) in Ta izz und zieht gegen die Feste مقران (?), wo die Schätze des Sultans Âmir lagen. Letzterer aber wubte seine Schätze in Sicherheit zu bringen.

Er zieht gegen den Stamm der Banu Ammâr, wirl vou ihnen in die Flucht geschlagen.

Er zieht nach Şan à und kämptt mit Sultan Ảmir und seinem Brudes Abd-Almalik. Die letzteren wurden besiegt und getötet und ihre Familien gefangen. Dies ist das Ende der Jemenischen '? ähirilen-Dynastie (s. LI' ror).

P'urspài verweilt zwei Monate in Șan ä, plïndert die Stadt und zieht beutebeladen zur Küste. Wirl unterwegs von Einheimischen angegrifien und aller seiner Schätze berabt, erreicht Zelid mit Mühe und Not 922. Purspaii hat nicht einmal cin ganzes Jahr regiert.

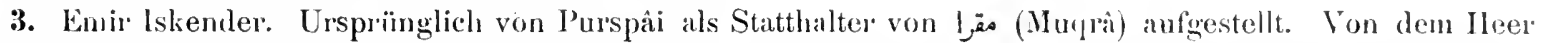

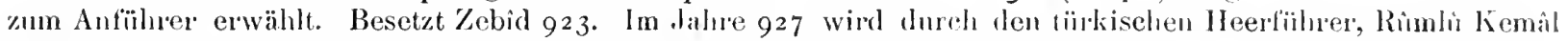
Beg, den Iskender und der 'l'scherkessenherrschalt in Arabien ein Ende bereitet.

Vgl. Snouck Ilurgronse, Mekka S. roz. Uher Muqrai vgl. Ilandini ed. D. H. Mülsen S. rof: iiber Giakin (statt liazin der Ausgabe) s. das. S. 73. 120. MIB 1112 I4-2I7.

\section{Die Rûmln̂ Lewend, Herrscher in Jemen.}

A. 11. 927-"

1. Kenâl Beg, Janitschar, war mit Sultan Selim $5_{5} 7$ nach Xgypten gekommen. Lir besetzte Zebirl und las das Kanzelgebet im Namen von Sultan Sulaiman im dahre 927. Wurde ron den Lewend getötrot 930.
2. Iskender Beg 930.
3. Husain Beg. +932 .
4. Rumlu Mustiafì Beg. † 934 .
5. Khalr-aldin IBeg.

$\because 935$. 6. Musțafí Beg. Berrihrungen mit hudien. 7. Sajjicl Ali Beg. Einige Monatr. S. Isliender. Beg regierte 6r/2.Jahre und starb 943. 9. Ahmed Beg Nákhutlì. Ende der Lewendijje.

Uber die Lewend, tïrkische Marinesoldaten aus Kleinasien, s. Znkersen, Geschichte des osmanisclwa Reichs in Europa 111 (1855) S. 307. NB 111 217-222.

\section{Die Zaiditischen huane von Jemen.}

A. Il. $922-10,38$.

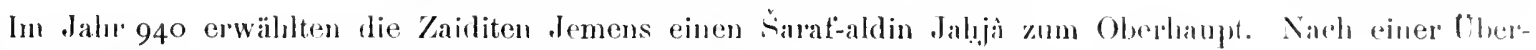
lieferumg soll Mahdî-lidin-Allah der erste dieses (ieschlechts gewesen sein, nach andere.

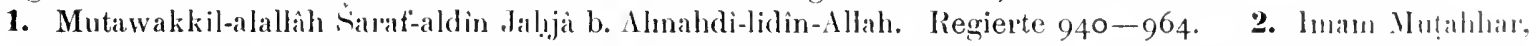

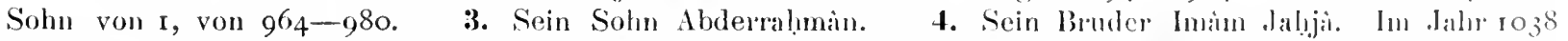

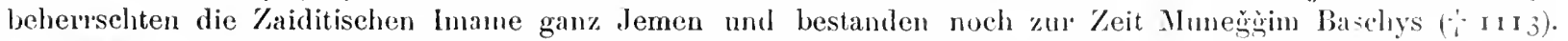

MB Ill 222-238, gibt eine ausfïhrliche Geschichte Jemens in diesem Zeitram, vermutlich nach zwei

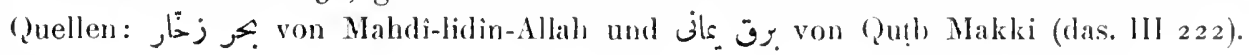

\section{Die tiinkischen Statthalter von Jemen.}

A. II. $945-\operatorname{ro} 3$ s.

1. Behrâm Beg. 2. Mustafa Beg wurde 947 von Sultan Sulaiman zum Statthalter von Jemen rruanut. Von 947-952. 3. Uwais Pascha von 952-954. 4. Farhad Pascha von 954-956. 5. Crslemir Pascha. 956.957. 6. Mustafa Pascha zum 2. Mat von 963-967. 7. Qara Mustafí Pascha, 967. S. Malumiul Paseha, 967-972. 9. Rị̣̂ân P'ascha. Zweiteilung der Provinz Jemen. 10. Mlurał l'asehı, 973. 11. Hasan Pascha, 975. 12. Othman Pascha, Sohn des Vzdemir. 13. Masan Paseha zum 2. Mar, 976. 14. Behrâm Pascha, $976-982$.

MB III 238-257, gibt eine ausfïhrliche Schilderung der Verhälnisse temens unter den tïrkischen Stathaltem. 


\section{Beherrscher der Insel Lâr.}

A. $11594 \cdot-973$

Làr im l'ersischen Meer zwischen der Stadt Sîràf and der Insel Qais. Ein Teil der Bewohner soll sich ableiten von einen Perser Namens roo d. Fl. \%uerst den Islam angenommen haben.

1. Qutb-aldin-Mu’ajjad, genannt باقوى ديو. Regierte 45 Jahre. Von 594-638 (?). 2. Kàlinğar, 32 Jahre. 'Trat die Herrschaft ab an seinen Sohn. Von 638-670 (?). 3. (2utb-aldin, r9 Jahre (670-689:). 4. Ali'-almulk ron 689-72I. 5. Kâlingiger Il., 72I-733. 6. Saif-aldin, 733-775. 7. 'Alä'almulk Karkin, Sìl genanut. trat 789 die Herrschaft an seinen Sohn ab. Von 775-789. 8. Mubairiz-aldin Nuhammed von 789-840. 9. ()uṭb-allin, 840-86r. 10. Ğahàušìh, 86ı-883. 11. 'Alà'-almulk. 12. Hàrin. 13. Wuhammed Bę̣, 937-940. 14. Nưirwàn, 940-948. (ietötet von einem Fidì'î. 15. Ibrăhim Khàn von 948-973. Den Sefidenkönigen Pursiens untertan. Tber das Ende dieser Dynastie ist Munesigin Bascly nicht muterrichtet. MB 11666.667.

\section{Herrescher der Insel Hurmuz.}

A. H. $671-972$.

Ursprïnglich lag die Ortsehaft auf der Kïste. Als sie aber daun in den Tataren-Stïrmen verwiistet war, siedelte die Bevölkerung ïber nach der lnsel. I)ie Herrschaft beginnt $6_{\rceil}$, ihr Ende unbekanut.

1. Maḷmìd Qalhâtì. Ursprïnglich Statthalter im Dienste des Salghariden Atabegs der Persis (LP' 173), machte er sich bei dem Verfall dieses Fïrstengeschlechts unabbängig im Jahıre 67 I.

2. Enuir Nuṣııut. 3. Rukn-aldin.

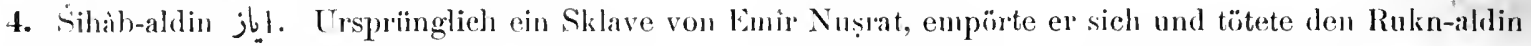
und setzte sich an seine Stelle. $\because 716$.

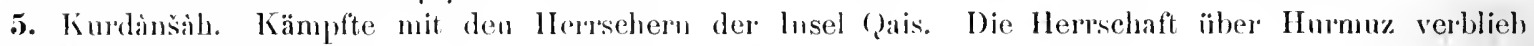
in seiner Nachkommenschatt.

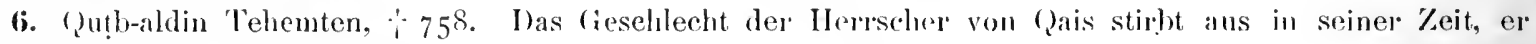
beliommt viele ihrer Besitzungen.

7. Tiumsinsils, von $75^{8-788 .}$

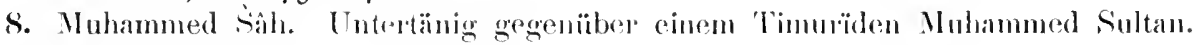

9. Fairìzšàh, $\because 839$.

10. Saif-aldin. Von einem brutler verdrïngl, flicht er zu Sihrukh (807-850).

11. Sein Bruder Turinsih, von 840 an.

12. Sihrib-aldin. 13. Salghar Silı.

14. Tirrin Silh. Die Portugiesen besetzen die meisten Hïfen von Ifumm.

15. Silhabraldin. Die P’ortugiesen besetzen die Insel جرو in lahr 928.

16. Muhammed Silh.

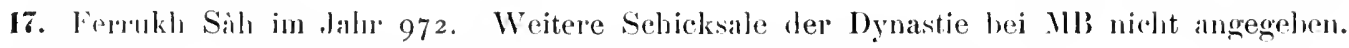

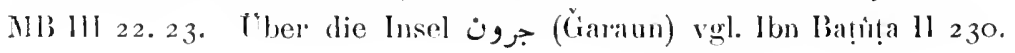

\section{OMıิıิเ}

Die Reihe der 'Ibiditischen Landesfürsten von Oman fiil' die \%eit von 75 I lis 1868 ist verzeichnet hei Baber, Ilistory of the limans and Sejjids of Oman ete. Tramsiated by G. P. Banger. London 1871 . Introductom and analysis S. 'XXV.cXXVl.

\section{In Westen. \\ (Nr. 55-64.)}

\section{Banı Rustam in Tâhart (Algier).}

A. II. $138-297$.

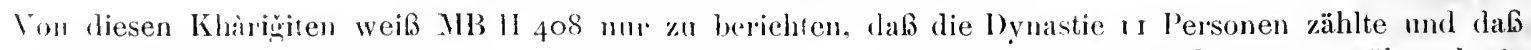
sie von r $38-297$ (su zu lesen) regierten. Ihn Alathir 8, 38 nibt dieselbe Regierungsianer an, während sie

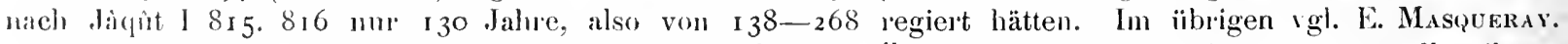
('Mroniqu d'Abou Zakaria. Alger s 879. und meine Schrit "Ober eine Arabische Chronique von Zanzibar" 


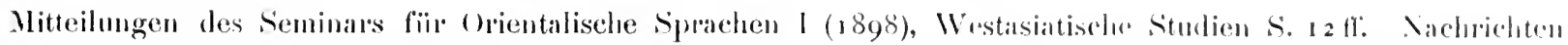

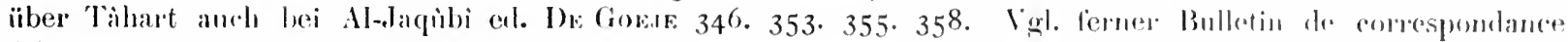
Africaine 1885 p. $30.36 .38 \mathrm{~m}$.

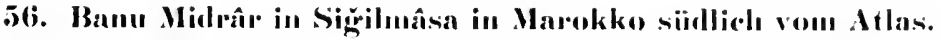

1. 11.155297 .

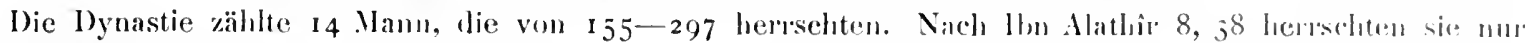
I 30 . Ialure, also von $155-285$, wïhrend or ihr Ende unter den breignissen des dilnes 297 berichtet. Buiden Dynastien, sowohl den Banu Rustam wie den Banu Mirlmir, wude ein linde bereitet dureh den Griinder des

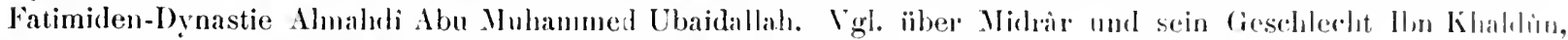
Histoire des Berbires, trad. DE S S LANE 1262 ff". MB II 408.

\section{Die 'Zijâniden oder Bann Abd-Alwâdd, Herrscher in 'Tlemse'n.}

$1.11 .621-9011 \%$

Nit der Daıstellung von MB Ill 19 ist diejenige bei LP 5 r zu vergleichen.

1. Jagmorasan b. Abd-Alwadd Alzaniti Alberberi. Bei zunehmenter Schwäche der Almohaten-Horlorhat

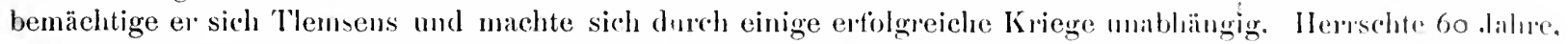

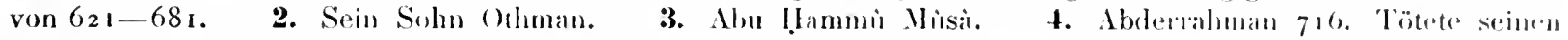

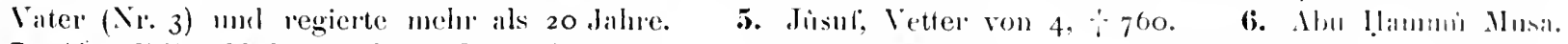
7. Abu Zijàn Muhammed. 8. Abrl-Alwiluid.

9. limir Muhammed.

10. .11m-11willid.

11. Limil.

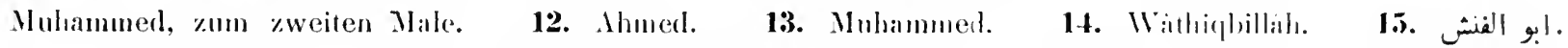

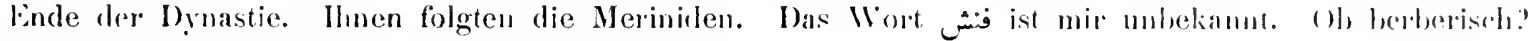

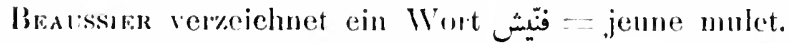

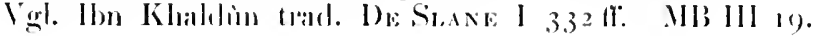

\section{Nordafrikanische 'Teilfüirsten aus der Zeit der Hatṣiden (625-9-41).}

I.

\section{Die Banu Kakarij.jâ auf' de.r luscel Giarlıa.}

lïuf Personen, Statthalter in Dienst der Hafsiden, die gegen Ende der Iterrschalt dersebhen unal)hïngig wurden. Sie regierten 37 Jahre. Anfang und linde ihrer. IIrr'selaift unbekinnt.

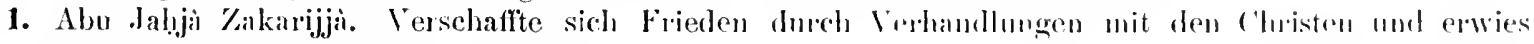
sich gehorsam gegen den Sultan der Tïrlici.

2. Sein Sohn Jaḷji. Bemïhte sich. die Insel Ciarla \%u behaupten.

3. Seine drei Söhne Si̊id, Ahmed und Sälil regierten gremeinsam. Die Franken eroberten ihre Insel. die ihnen aber ron dem tïrkischen Kapudanpascha l'ijila wirder ahgenommen wurde. (buer letateren fauch

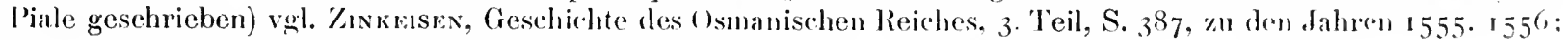

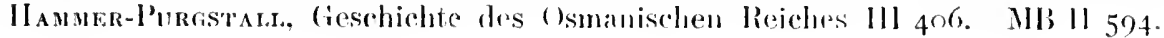

\section{II.}

\section{9). Die Banı Qậ̣i in Zawâta und Káakan (Kóko).}

Fïnf Personen, deren Anf"kommen und Ende unbekannt ist.

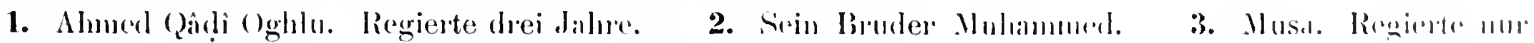
in Kaukau. 4. Ahmed. 5. Sein Solm Mubammed.

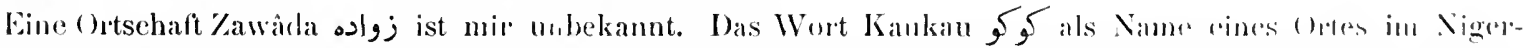

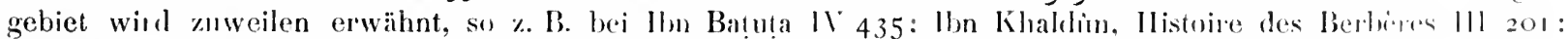

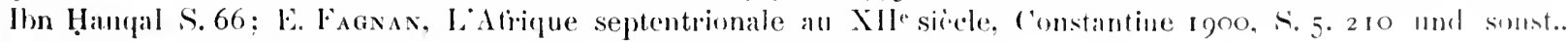
MB II 595. Uher زوارة s. Altiğinî in lommal Asialic 185r S. 121. 122.

III.

60. Die Banı 'Ammâı in 'Tripolis (Afrika).

1. Limir Thâhit b Ammar. Sellständig geworden durch die Sichüiche der llatsiden.
A. $11.724-803$.

2. Mulammuned.
3. Thaibit.
4. Abu Bekis.
万. Sirin Vefir: linir Mli.
6. 7. Aahiji und Abd-.llwiluicl
gemeins:illl.

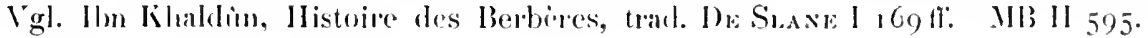


IV.

\title{
61. Die Banu Muzanî, Herrscher von Biskra, dem Hauptort des Landes Zâb.
}
A. H. $740-804$.

1. Emir Ali b. Muzani.

2. Hasan.

3. Alimed.

4. Ali.

5. Abulabbais.

Vegl. Ibn Khaldin I 124 fl: MB II 595 .

62. Banu Waṭ̂as, Herrscher in Marokko.

A. $11.876-956$.

1. Abu Zakiırijjji Jalịji.

2. Schaich \%akarij.jì.

3. Muhammed.

t. Abu Juasanin.

5. Alimerl.

i. Muhammerl. 7. Abu Miasanin.

Diese IIerrscher stehen in der Mitte zwischen den Meriniden (Ende un 875) und den Šerîfen (Anfang 951). vgl. LI' 57,58 und 6r. IIP 11120.

\section{(63. Statthalter von Sizilien unter den Aghlahiden ('Tunis) 184-296.}

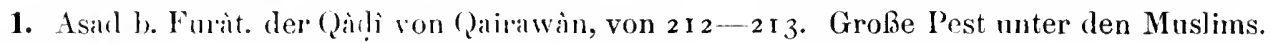

2. Muhanmed b. Abi-Alluwwirit.

3. Zuhair b. Aun, abgesetzt 2 r 7 .

4. Muhammed b. Abdallah $217-236$.

5. 'Ahbis

b. Alfa!ll $236-247$.

6. Sein Sohn Abdaliah, 5 Monate.

7. Khafäğa $247-255$.

8. Sein Sohn Muhammerl 255-257. 9. Ahmed b. Jaiquib $257-258$.

10. Gacfar b. Muhaumed b. Khafìga 258-?

11. Hasan b. Alabbàs. Abgesetyt von Ibraihim $(26 \mathrm{I}-289)$. 12. Muhammed b. Alfiulli.

13. Insain b. Ahmed $† 27 \mathrm{I}$. 14. Sawida b. Muhammed b. Khafäğa $\because$ nach 272 . 15. Ahmed b. Omar b. Abdallah. 16. Sein Sohn Abulabbais Ab̉dalıh. Kam 287 nach Sizilien. 17. Ahu Manșiu Zijàdat-Allah. 18. Muhammed Alsaraqùsi.

Dann folgen die Statthalter der Fiṭimiden (von 297 an). IIB II $216-222$.

64. Die Kellyitischen Statthalter von Sizilien

unter den Fâtimiden (297-567). Residenz Mazara. A. H. 336-444.

1. Ilasan b. \%aid b. Kelb, ernannt vom Kalifeı Manșìr $(334-341)$. Regierte 336-354. 2. Emir Ahmed. Sohn von 1, 354-359. 3. Linir Abulqusim Ali. Sohn von 1. Regierte r2 Jahre. 4. Sein Sohn Emir Gäbir. Abgesetzt 37.3. 5. Kmir Gáfar, Neffe von 4. Vom 373-375. 6. Sein Brutler Enir Abdallah. 375-379. 7. Sem Sohn Abultath Jìsut. 379-388. 8. Sein Sohn Gáfar. Abgesetzt. 9. Sein Bruder

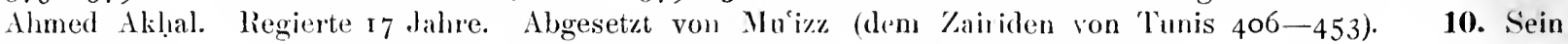
Bruder Hasan. linde dieser Statthalterreihe 428 . Folgen einige 'Teil-Stattlralter.

Vor dem lischeinen der kelbitischen Statthalter hatten die Aliden (d. i. der Grinder der FatimidenDynastic. Ubaidallah 297-322) im tahre 297 einen Ilasan b. Almed (näheres äber ilı nicht angegeben) zum Statthalter von Sizilien ernam, und nach ihm seien drei weitere Statthalter gekommen. So MB II 454, 7. 6. v. !. Cher Hasiul b. Almed vgl. Amari, Storia dei Musulmani di Sieilia II S. I 42 II: NIB II $454-457$.

\section{Zeit der Seldschuken. (Nr. 65-72.)}

\section{Atabegs der Seldschuken-Zeit.}

\author{
I.
}

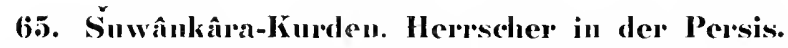

A. HI. $448-678$.

Kurden, die in den Bergen der Persis siedelten, kamen gegen Ende der Bujidenherrsehaft (gegen 448) in die

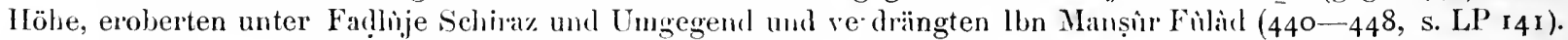
Sie wurden von dem Seldschuken $\mathrm{Al}_{\mathrm{p}}$ Aıslan in ihrer Herrsehaft gegen jälntiche Zahlungen belassen. Als sie aber diese Zahlungen verweigerten (im Jahre 464), schickte Alp Arslan den Nizhm-almulk mit Heeresmacht gegen sie. Sie wurden besiegt.

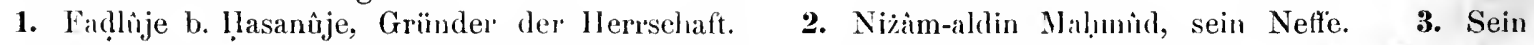
Solm Hezàrasp. †. Sein Soln Hasanìje. Kämpfe mit den Seldsehuken. 5. Seiı Sohn Muzaflar-aldin. 6. Sein Solın Qutb-aldin. 7. Sein Neffe Nizim-aldiı. 8. Sein Bruder Nuṣrat-aldiu. 9. Sein. Neffe Galàl-aldin. 10. Sein Bruder Bahà-aldiı im Jahıe 68r.

11. Seine Söhne Gijâth-aldin und Nìżm-aldin. Deren Macht war nur noch nominell. 


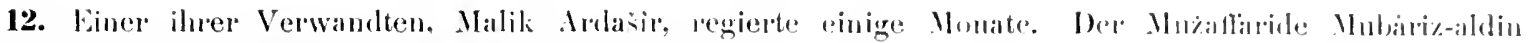
(713-759. LP' 249) bereitete ihrer Herrschalt ein linde.

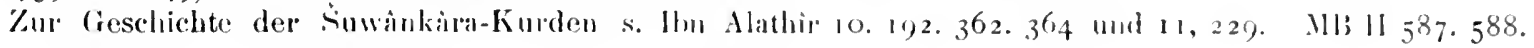

II.

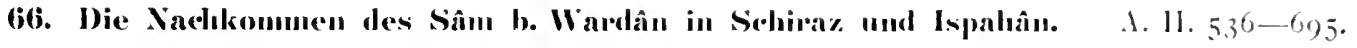

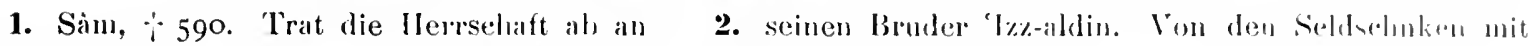

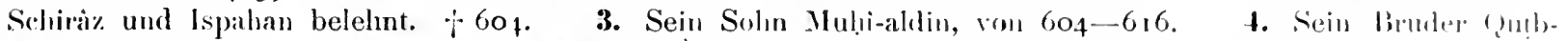

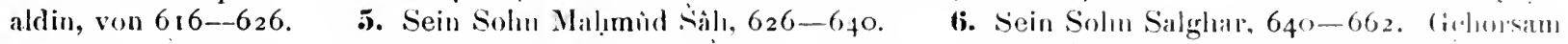

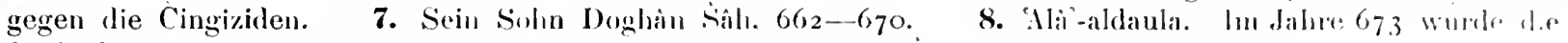
Stadt dezd dureh eine Flut zerstört. 9. Sein Bruder lusuf šilı. Ende der Dynastie.

III.

67. Atabegrs in Khồistân. $\quad$ A. 11. $547-591$.

1. Emir Gïntugdu اميركون طوغدى Soln.

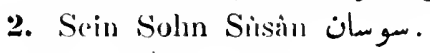

3. Eurir Siamla شara

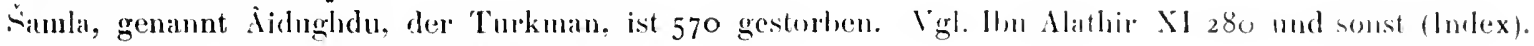
lir hate mehr als 20 Jahre regiert. MB 11582.

IV.

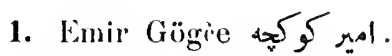

68. Atabegs in Ciebel, Hamadau und Ispahân. A. 11.591 -614.

2. Enir التغمش (Aitughmuš).

3. Emir Mangalî منكلى.

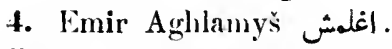

f'ber die (ieschichte dieser vier Iynasten vgl. Itun Alathir Xll 76. r 28 . 200. MB II $5^{81 .}$

\section{'Teilfüirsten in der Zeit des Seldschuken Sultan Sanğar (511-552).}

\section{I.}

69. Freigelassene des Sultan Sanğar, die in Chorasan 548-595 herrschten.

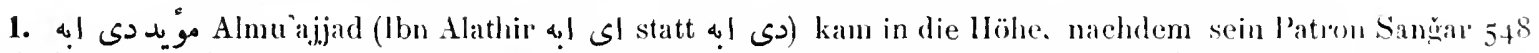
in die Gefangensclaft der Ghuzz geraten war. Zn seiner Zeit blutige Kämpfe zwisehen Schaffiten mo IIanefiten: die ersteren gewinnen. Geht жurunde 568 im Krieg.

2. Sein Soln Toghinših $\left(\because 55^{82}\right)$.

3. Sein Soln Sanğaršah $(\because 595)$.

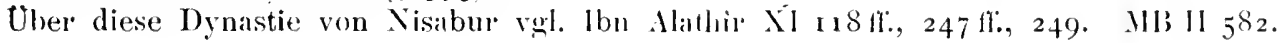

II.

70. Knechte Sanğars, die in einigen Gegenden Herrschemstellungen eimmahmen.

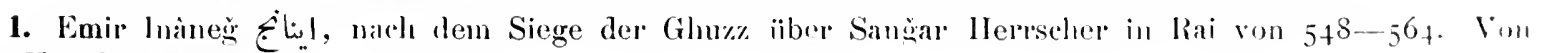
seinen Knechten getötet.

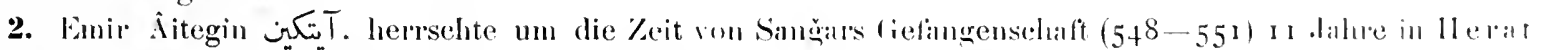
und Bìs̆an

3. Emir Salalil-aldin, Birł, Lmir ('horasans geherrseht.

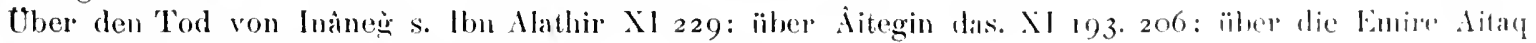
(Aithà) und Bughrategin s. Ibn Alathir Xl 173 . N13 II 582.

\section{Bemerkungen zu einigen Dyuastien.}

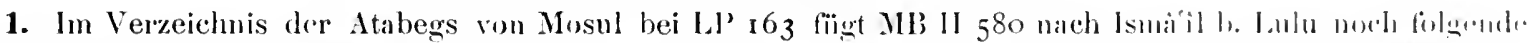

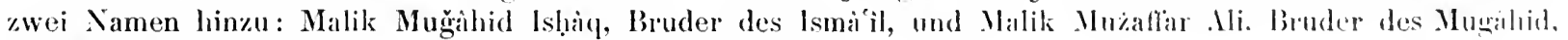
und gibt an, dah diese vier von $630-660$ regiert hïtten. 
2. Das Vermeichnis der Salghariden der Persis (LP 173) ist bei Mb $115^{8} \mathbf{I}$ in folgender Weise ïberliefert: Suncur. Takla, Zangî, Takla, Toghrul, Sa id b. Zangì. dem Sa di seinen Gulistan gewidmet; Abu Bekr,

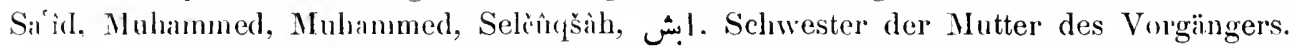

3. Die ( Juthugh Khins von Kerman (bei L.P ${ }_{179}$ ) werden von MB II $5^{8} 7$ in folgender Reilse ver\%eichnet: Burâr

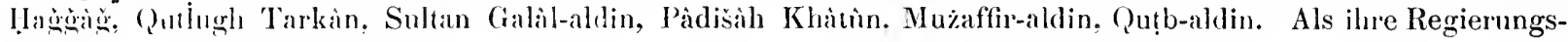
zeit wird 620-705 angegeben.

\section{Die Banu Khurschîl, Fiirsten von Klein Lûr.}

Von $570-$ ?

Dem Verzeichnis der Hazâraspiden, der Atabegs von Groß Lùr bei LP' I7, mag hier ein Verzeichnis der Fïısten ron Ḱlein Lì hinzugefïgt werden. Sie residierten in Khurramâbàd und kamen auf gegen 570.

1. Suğài-aldin Khuršî̀. Ursprünglich in Dienst des sedıschukischen Statthalters von Khìzistân, wird er ron diesem nach Klein Lin'istin geschickt mo ilm die Verwaltung des Landes ïbertragen (547). Nach dem Tode des rrsteren. 570, hersscht Khuršì unabhängig in Klein Lìristàn und erobert einige Teile von Khuristin dazn. Der Kalif lïßt ihn und seinen Bruder Nirr-aldin nach Bagdad kommen. Beide werden eingekerkert. Nirr-aldin stinbt im Kerker, Khnršîd wird wieder frei. kelıt 590 in sein land zuriick und stirbt 62 I.

2. Sein liruderssuhn Rustam. 3. Sein Broder Sinraf-ildin Abu-bekr.

4. Sein Bruder Geršisp.

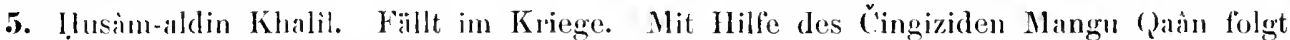

6. Sein Bruder Mas ind und regiert 18 Jahre. von 639-657.

7. Sein Vetter Tìg-aldin Sïh von 657-674. Wird getötet auf Befehl von Abacqa Khàn. Auf Befehl des letzteren folgen

8. Seine Vettern IIasan und Ilusain gemeinschaltlich von 674-689. Auf Befehl ron Kaikhàtû Khàn wird aus derselben Framilie ernannt

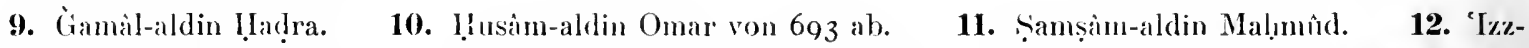
aldin Mulanmed, gestorben $716 . \quad$ 13. Seine Witwe Daulat Khitim. Sie tritt die Regierung an ihren Bruder

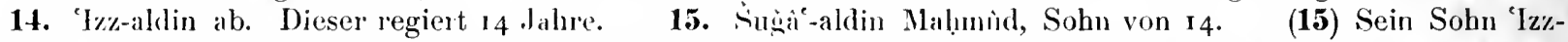
aldin Husain. Zu seiner Zeit erschien Timur. Lr wird von Timur bekriegt, gerät in dessen Gefangenschaft, wird alser wieder freigelassen und in sein Fürstentum entlassen. Wegen Differenzen mit den von Timur einšesetzten Bènten läbt ihn dieser töten.

16. Sajjijî Ahmed, Sohn von I5. IIielt sich eine Zeitlang im Lande verborgen, trat aber nach Timnrs Tode öflentlich hervor und führte wieder die Regiernng. Gestorben 810.

17. Ein linkel von 'Izz-aldin Husain namens Sih Husiin.

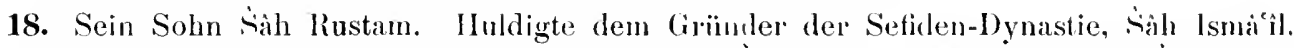

19. Soin Sohn Oghnz Khân. 20. Sein Brnder Ġehìngìr. 21. Sein Sohn S̈àh Rustam. 22. Sein Bruter Muhammadì Beg. 23. Sein Sohn Sahl Werdi. Nach einiger \%eit wird das Land von den persisehen Sefiden annektiert und von iliren Statthaltern regiert. Vol. Iloworitr. History of the Mongols III r 40.406 .754$. 113 II 598-600. Die geographische Scheidung zwischen Grob Lur und Klein Lur s. bei Le Strange, The lands of the Eastern ('halifite p. 200.

\section{Zeit dler Čingiziden. (Nr. 73-76.)}

\section{Das Geschlecht Inğón in Schiraz.}

A. H. $716-75^{8}$.

Der Stammvater Inğù war im Dienste der Hulaguiden Hüter des kaiserlichen P'rivatsehatzes in Schiıaz.

1. Saraf-aldin Šil Malmmid gelangte als IÏ̈ter des kaisendichen Schatzes in Sehiraz zu Macht und Ansehen. Wurde 736 anf' Befehl des Arpà Khàn, eines der letzten IIulaguiden, getötet.

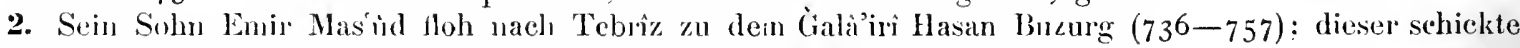
ilıı mit Bistî b. Cùpàn nach Schiraz zurïck, und dort wird Mas'ùd $7+3$ ermordet.

3. Lanir Sehaikh Abu Isḷiq. Von l!aifiz besungen. IHB 111 I 2 . I 3 .

\section{Das Geschlecht Ĉ̀̂ûan in Kleinasien und Adherbaiğân.}

A. II. $718-75^{8}$.

Die Coupàns waren sehr angeselıen bei den Mongolen, weil ihr Vorfahr Sarghìn einmal dem C'ingizkhàn, als er now Prinz war, das Lehen gerettet hatte, Drei Nachkommen ron ihm herrsehten in Kleinasien und Adherbaiginn 40 bahre lang. 


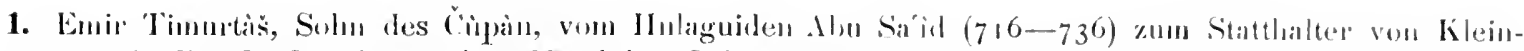
asien eruannt (718). Ließ sich mit dem Mamluken Sultan Melik Nișir (709-741) ein und wurdw vou ilum ermordet.

2. Sein Solm Sehaich Ilasan singhir. Eimordet 7 fr ron seiner Fran.

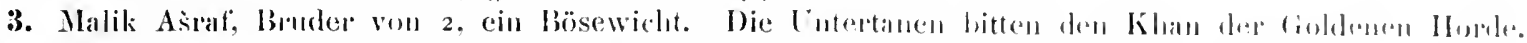

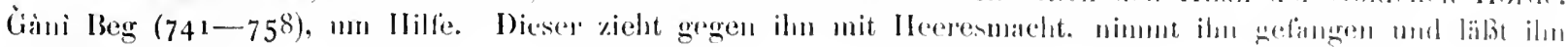
in Telriz enthaupten. IIB III $6-7$.

75. Das Creschlecht 'Tughâtimur in Mazenderan und Astrabat.

I. H. $7.37 \cdots 812$.

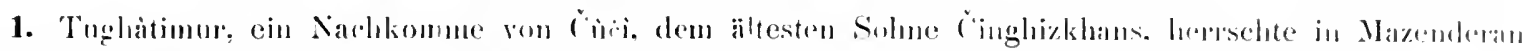

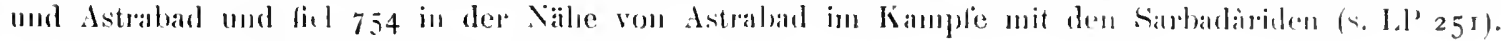

2. Sein Soln Lanjumin $(754-790)$.

3. Sein Suln l'irek Pandisils, emannt von Timur $(77 \mathrm{r}-807)$.

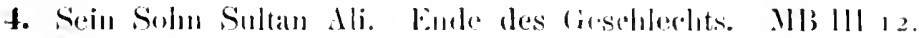

76. Die Baní Túluk, Fîrsten von Kinschgan.

1. H. $71,0 \mathrm{sig} 3$.

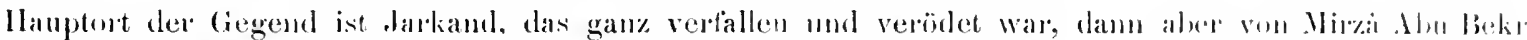
(s. unten $\mathrm{N}_{\mathrm{r}}$ 8) aufgebant und zur Residenz gemacht wude. Dieser regierte nach den ()ara Khiti-Fiirsten.

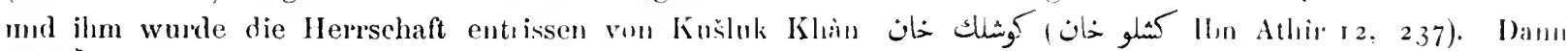

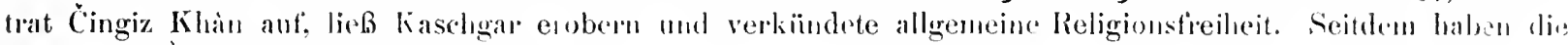
Emire der Cöngiziden das Land regiont.

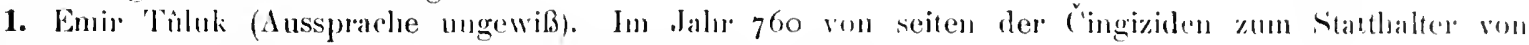
Kaschgar bestellt. Bestand vicle Kämp!e mit 'Timur $(771-807)$.

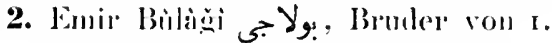

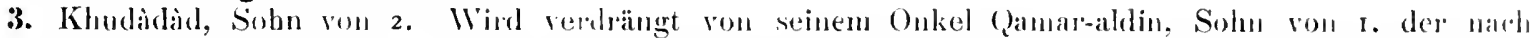
dem Tode des Landesfürsten, des letzten 'Tughlaptimur, die ganze Mongolei erobert und dessen Fanilie ver-

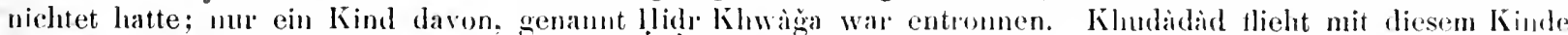

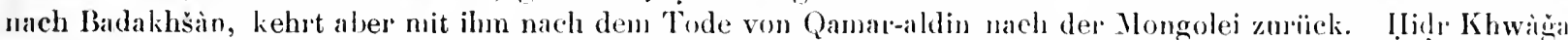
besteigt den Thron seines Vaters und ist dankhar gegen Khudadid. Dieser regiert als sellustindiger Fïrst und gewinnt noch zu den alten Besitzungen Khoten, Aysu, die Gebiete von sle und So. Xach dem Tindo

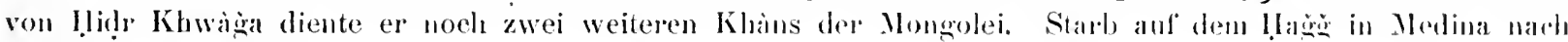
4ojährigrer Regierung.

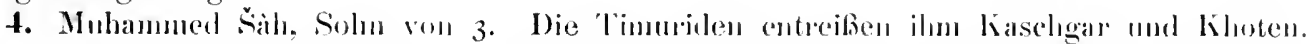

5. Emir Sajjid Ali, Sohn von 4. Er gewann Kaschear zuriek. nachdem es von dem Timuriden Llugh

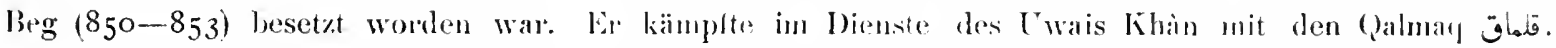

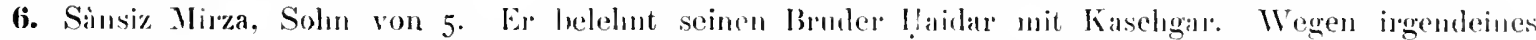

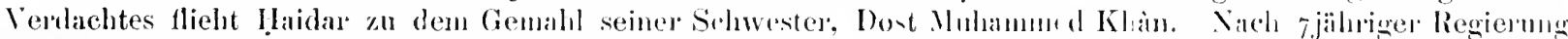

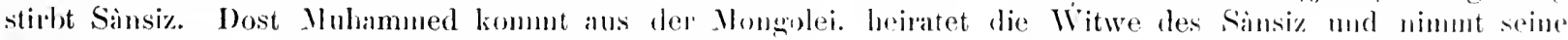
Kinder an sich.

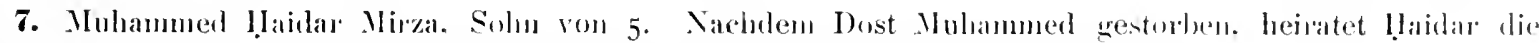
Wittwe seines Broders Sinsiz und nimunt dessen Sulm Abu Bekr an Solnes statt an.

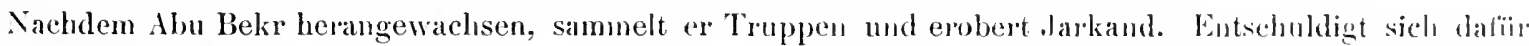
hei seinem Oheim Haidar. Dann erobent er Khoten. Es kommt zrm Kampf zwischen Onkel uml Xelti. Laidar und Abu beks. Des erstere wird geschlagen, geht nach Kinchgar und littet cinen Gnkel limus Khan

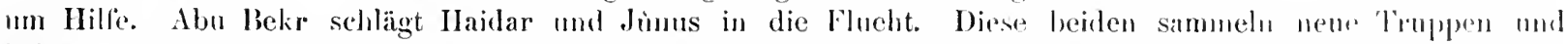
belagern den Abu Bekr in Jarkand. An Bekr macht einen Ausfall und besiegt seinr Gegner run nenen. Die Mongolen laufen davon. und anch Haidar und dimus diehen nach der Mongoled. Ilailar regierte 27 falure. von $866-893$.

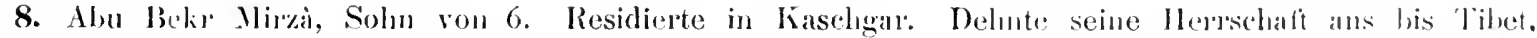

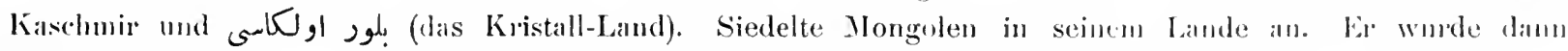
zuletzt depossediert ron dem Schaibaniden Abu Sacid Khän (937-970). floh in die (ielsirge Tibets und ist dort verschiwumden.

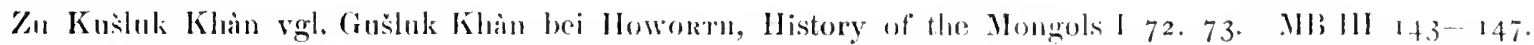

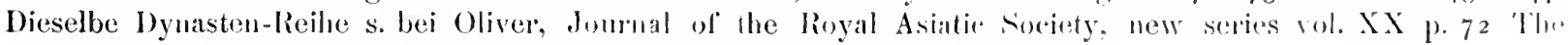
Chaghatai Moguls. Juwaini, Ta'rikhi-Jahningusha, Gibb Menorial r6. $46-52$. 


\section{Zeit der Timuriden und Indien. (Nr. 77-94.)}

\section{Drei Ḱhans in Transoxanien vor 'Timmr.}

A. II. $745-770$.

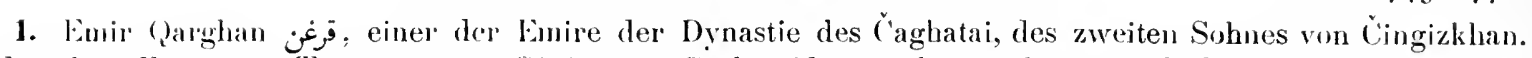
Der damalige Fïrst von Transoxanien. Gizèn, ein Caghataide, maehte sich so verhaßt, daß das Yolk den Lmir Qarghan zum Landesherm wählte. In den Kämpten zwischen Ghàìn und Qarghan fiel ersterer, uncl letzterer stellte den Danišmandča, einen Nahkommen von ()gotai, dem dritıen Solıne (ingizkhans, als Landesliïrsten auf. Qarghan wurde 759 von seinen leuten getötet. Vgl. LI' 242 unten.

2. Sein Solın linir Ahdallah. Nach kurzer \%eit tötete ihn das Heer und stellte an seiner Stelle seinen Sohn Tinur sih

3. Sein Neffe Emir Husain, 760. Verheiratet mit einer Schwest w von Timur. \%arst gutes linvernehmen \%wischen Husaju und Timur, dann Krieg. Die meisten Emire Husaius gehen äber zı Timur. und 77 stirbt die Frau Husains, wodurch das letzte Band, das ihn mit Timur verbaud, zerrissen war. Timur vernichtet den Husain und sein ganzes Fesehlecht. MB 11137.

\section{Timuriden. \\ 78. Nachkonunen des Ġehângîr, des ältesten Sohnes Timurs. \\ A. II. vor $776-$ nach $85^{\circ}$.}

Ygl. den Stanmbaum bei l.l' 268.

1. Mir\%a Ciehaingir. Ciesturben in Samarkand 776 .

2. Sein Sohn Miræa Muhammed Sultan. Seine Mutter war eine Torlhter des Padischah von Khwàrizm, Aq Sufi. Gestorben in Siwrî llisìr in Kleinasien.

3. Sein Br'uder Mir\%a I'ir Muhammed. Als 'Tinur starb, war dieser sein Soln Statthalter in Indien. Sein Vetter Mira Khalil besetzte Samarkand, I'ìr Muhammed zurïekkehrend besetzte Balkh. Krieg zwischen den beiden Verwandten. I'ir Muh, ïberlähit alle Geschäfte scinem Vezier Ali 'T'à, dieser empärtosich 8og und tötet seinen Jlermn mit allen Seinigen. ansgenommen die Söhne ()aidu und Sanğar.

4. Mir\%al Mnhammed Ġehingir b. Muhammed Sultan. Eist 9 Jahre alt, von Khalil Mirza auf den Thron gesetzt. Im Jahre 8I 2 erobert sein Grobonkel S̈ahrukh Transoxanien. Gestorben 826.

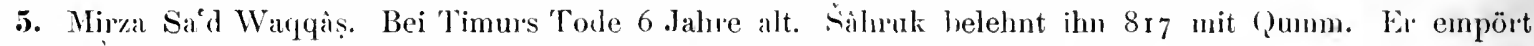
sich gegen Sihrukh, flieht nach Adherbaiğan zu (Qara Jusuf (l.l' 253) und stirbt dort $82 \mathrm{I}$.

6. Mirza Jahjâ, Bruder von 5. Sahrukh belehnte ihn mit einer Provinz und gab ihm einen Atabeg.

7. Nirza Qaidı. Săhrukh belehnte ihn mit Balkh. Er tötete den Ali Tì. den Möıder seines Vaters (s. 3). Wude belelunt mit Kandalıar, Ghazna und Kabul, wo el gegen Sâhrukh reb llierte. Von letaterem besiegt und refangen. starb er in der Gefingensehatt.

8. Mir\%a Sanğal. SHabrukh set\%te ihn 820 an die Stelle von Qaidu und gab ihm einen Atabeg bei. Cach einen anderen Lande versetzt. starls er 820.

9. Nir\%a Muhammed Sultan b. Ġehingir, der Soln einer Toehter des šbrukh. Von letzterem mit einer Provinz belehnt. starb er 842 .

10. Nirza Khalil Sultan, Bruder von 9. ebentalls der Sohn einer Tochter von Sährukh. Nach dem Tode des letzteren $(85$ ) sehloß er sich denı in Chorasan herrschenden Baibar Mliza b. Baismm(jur b. Ṡahrukh an, empörte sieh dann gegen ilm und kam dabei um. MB III 54. 55.

79. Nachkommen des Omar Schaich, des zweiten Sohnes 'Timurs. A. 11. 755-930(?')

1. Virza (1mar Sehaich. Verwaltete zuerst Andiŏgin und Turkestan. 755 mit der l'ersis belehnt, gefallen hei der Wstiirmung einer Burg 796. Vgl. LP 268 die Stammtatel.

2. Mirza Pir Muhammed, belehnt mit der Persis bis 812 (einige Jahre ausgenommen). Ermordet von Limir Ilusain.

3. Mirza Rustam, von Timur mit Ispahan belehnt. Streit mit seinem Bruder P'ir Mulammed. Bestrafte d'n Vürder des letzteren.

4. Miræa Iskender. Flïchtet nach Schiraz. Wird dort auf den Thron erhohen. Streit mit Sâhrukh, der ilın in Schiraz belagert, gefangennimmt und ilın in das Gelängnis sperrt, wo er geblendet wird.

万. Miřa Ahmed Mîrek, Statthalter im 1)ienst des S̈̈̀hrukh. Streit mit Ulug Beg. dem ältesten Sohn

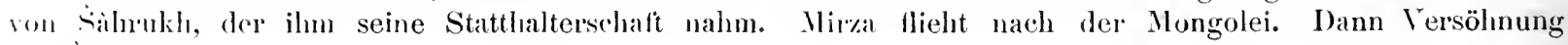
mit Sihroukh. 


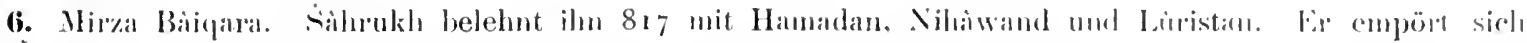

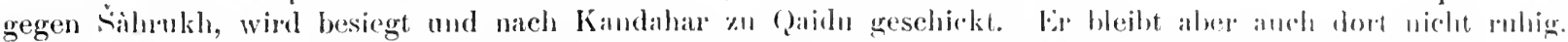

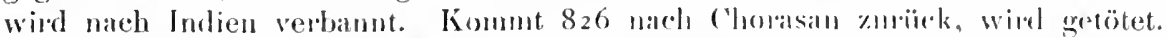

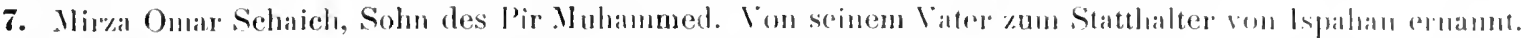

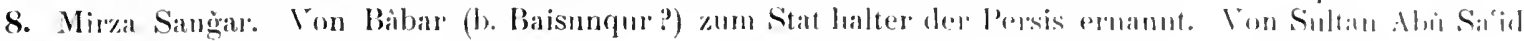
getötet in falure $863(\%)$.

9. Mirza Muzalta b. Baigara. Im Dienste von Silurukh

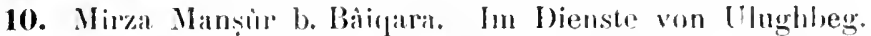

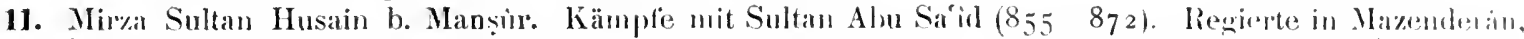

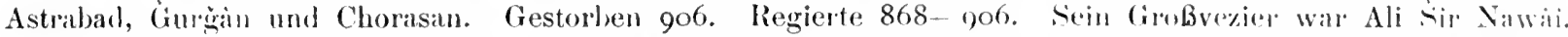

12. Sein Sohn Badí-alzaman. Limpörte sieh gegen seinen Vater. Vertriehen von dem Khan der. L'zhen,

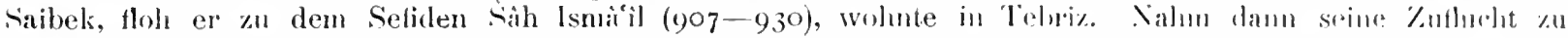
Sultan Selim (918-926), zog mit ilm nach Stambul und starb dort an ler l'est.

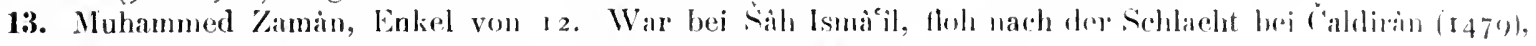
war eine kur\%e Zeit IIerrseher ron Balkh. Diann getötet. MB III 7074.

\section{Naclakommen von Sâhrukh, Jem vierten Sohne 'Timurs.}

A. $11.830(\%)-?$

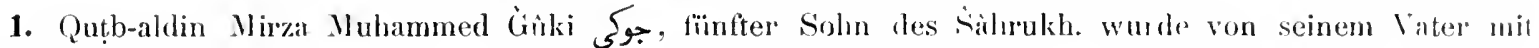
Germsîr und Khuttalin (einer rom oberen ()xus durelıströmten Landschaft mit der IJauptstadt IIulbuli) belelmb. Gestorben 848 .

2. Mirza Abn Bekr und 3. Mirza Qisim, beide Söhne ron r, verwalteten gemeinsam das l.elı ihres Vaters. Naeh dem Tode von Sàhrukh brachen Stürme aus, in denen sie zuggrundr gingen. MIl 11169.

\section{Nachkommen von Ahu Sa'îd (85.5-872), einem I'renkel 'Tinmurs. I. In Ghazna, Kâbul und dem ïbrigen Afghanistan.}

A. 11. ?-?

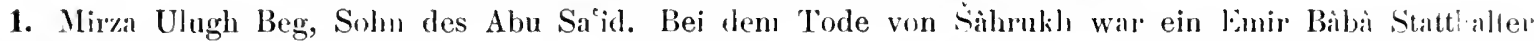
dieser Läinder. Nachdem Ahì Sa ìd zur Herrschaft geliommen, machte er Ulugh Beg zum Statthalter und Emir Baba zu seinem Atabeg. Letzterer rebelliert, nimut den Ulugh gefangen. Baba wird rou zwei lirintern ermordet, die sich der llersschaft bemächtigen. Dilranf sehickte Ahu Sat id ein Heer, um seinen Solm $\%$ befreien, worauf die briden mit drm l'rinzen fliehen. Lis gelingt einer Schar Afghanen, deu Jrinzen zm stehlın. Sie bringen iln nach Kabul und ïbergeben iln den Emiren des Vaters. Ulugh regierte 34 . Jahre.

2. Jiræa Abr-Alrazain, minderjäluig. Versehwand in den folgenden Unruhen. Folgen die Armhini.

\section{II. In Germsîr nud Kandahar.}

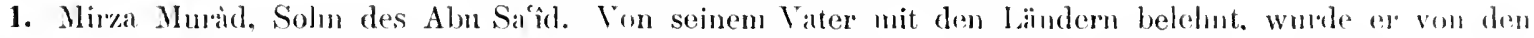
Eniren seiner IJerrsehaft beraubt. mubte flichen und vessehwand.

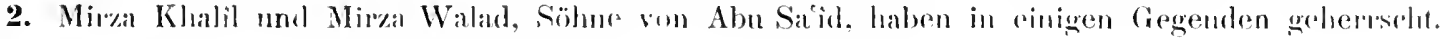

\section{III. In Badakhšîn.}

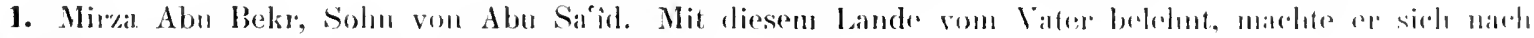
dessen 'Tode unablä̈ngig. l'iel im Kimpf mit Baiman"a.

2. Klàn Mil\%a, Enkel ron Abu Sâûl.

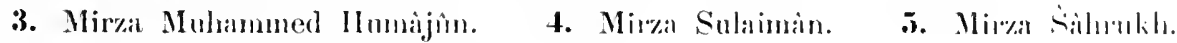

lhmen folgen die Uaheg. MB 11177.78 .

\section{Dienstleute von 'Timuriden.}

\section{Die Arghûnî, Ilerrscher in Sincl.}

1. Lmir Dhî-alnin b. Hasan. Sein Vater und Großvater vom Stamme Arghim waren Dienstleute T'imurs gewesen, er selbst im Dienste des Abu Sa ${ }^{\circ} i d(855-872)$, und dann von Sultan Ilusain in Ilerat ( $\left.i 912\right)$ mit Kabul und Kandahar belehnt. Machte siclı unablüngig unter Ilusain. Giestorben 905.

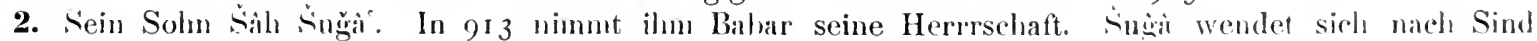
und herrscht dort 9 Jahre.

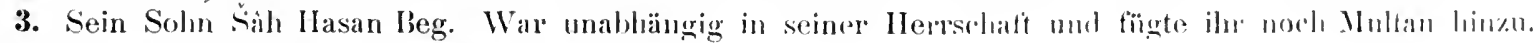
- Regierte 40 .Jahre. Gestorben 962. MB III I 20. 


\section{Nachfolger der Arghûni.}

\section{A. Die Tarkhânî, Herrscher in Tata unferı der Miindung des Indus. A. H.?-?}

I. Emir Isa Tarkhàn. Offizier im Dienste von shàh Hasan Beg Arghùni, machte sich in Tata unabhängig gegen dessen Eude. Er war unteränig gegen Humàjin und ließ dessen Namen im Kanzelgebet nennen. Regierte I 2 Jahre. $962-974$.

2. Sein Solın Mulammed Biti. Regierte zo Jahre.

3. Sein Solum Muhamned Paijende.

4. Sein Sohn Mirza Cimin. lieelıt bei Kaiser Akbar. Ende unbekannt. Uber die Geschichte der Arghini- und Tarkhini-Dynastion s. History of Sind by Mahomed Masoom, translated by G. G. Malert, Bombay I 855 S. 59 ft., I32 ff. Elhebliche Differenzen zwisehen dieser Quelle und MB.

\section{B. Die (Guinuîltâsí?).}

Sultan Malumind b. Gïñïltis (d. i. Steinherz). Sein Vater war Milchbruder des Arghuni Sìh Irasan Beg. llerrschte nach dem T'ode des letzteren eine Zeitlang in der Stadt Lahrî unfén der Mïndung des Indus,

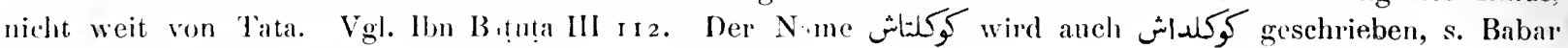

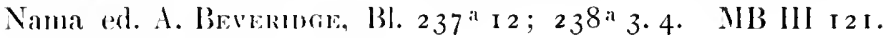

\section{s7. Die Dynastie Khalğ̣̂ in Indien.}

A. H. $602-801$.

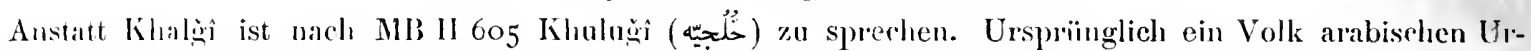
sprungs. dann aber mit Tataren vrrmischt, siedelten sie als Hirten zwischen Sind und Hind. Einige von ilmen waren in Dienst des Ghoriden Sihab-aldin Mahmid (? Mulammed, $\because 602$, s. LP 294). Mit dem Verfall del Macht der (ihoriden wuchs die Matht dieser Khalgis zur Unabhängigkeit heran. Ihre Residen\% war Lakhuawti in Bengalen.

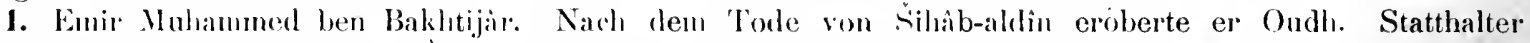
von Bengalen. 2. Mulammed b. siman. Fin Tymm. Von Anfständischen ermordet. 3. IInsim-aldin :Iwad.

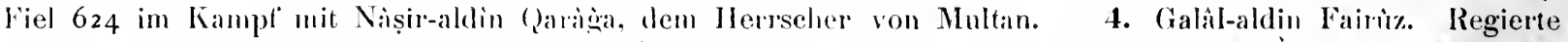

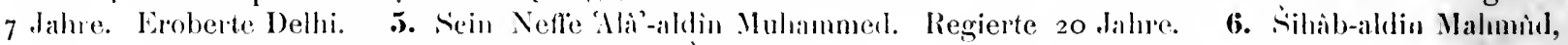
777 . 7. Scin Brolder Qutbaldiu Mubairak Sill.

Fïr die Fürsten 1-3 vgl. LP 306, 1. 2. 4. von den Statuhaltern von Bengalen; fïr die l'ürsten 4-7 rgl. LI' 299 die Reihe der Khalinis. MH 11605.

\section{Freigelassene der Ghoriden in Afghanistan und Indien.}

A. II. $602-624$.

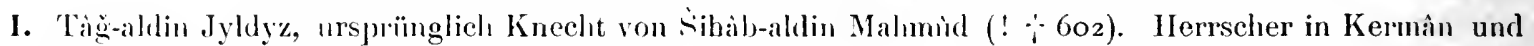
Ghazna, nach 6r2 anch in Multan. Geriet in Kıieg nit d^m Sultan von Delhi (S.ams-aldin Altamiš 607-633), wurde gefangen und getötet.

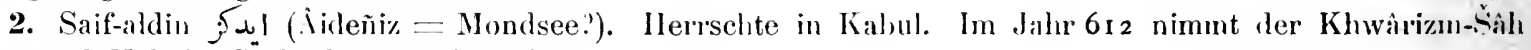
Glızna und Kabul. Säf-aldiı verschwindet.

3. Nișir-aldin قرج (Cubaila?' s. LI' 294) herrschte in Lahore, Multan, auch in einigen Teilen von Sind. Der llerrscher von Dollii. Sams-aldin (Altamiš) macht 624 der Herrschaft des Nisșir-aldin ein Ende. MB II 603. Vgl. Coins of the Mulaumadan States of ludia in the British Musemm. by S. Lane-Pooue i 885 S. 63.

\section{Zwei Dynastien von Kašmîr. \\ Erste Dynastie.}

A. H. $654-8$ I 4 .

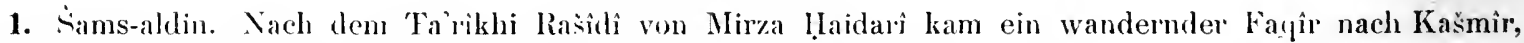
heiratete eine dort herrselende Fran und bemächtigte sich des Landes.

2. Sein Soln Alá-aldin. 3. Sein Soln Qutb-aldin. 4. Sein Sohn Iskender. Tat viel für die Aushreitung des Islans. 5. Zain-aleibidin. Regierte 52 Jahre. Die Dynastie erlischt.

$$
\text { 90. Zweite Dyuastic. Die Kašmirǚàhs. }
$$

1. Muhammed Sih. Zu seiner Zeit 939 kam von seiten des Sultans Abu Salid der Verfasscr der Chronik, Mirza I!aidar mit lleeresmacht nach Kašmir, fülırte Krieg mit ilım, schloß dann Frieden und heiratete seine Schwester. Der licr genannte $\Lambda$ bu Sa id ist der driste Schaibanide 937-940 (s. LP' 27I).

2. Sein Sohn Ismäil Șih. Seine Schwester war mit dem Afghanen S̈̈rkhìn verheiratet. 
3. 'Tirak Sàh. Streit unter den limiren des Landes zur Zeit von Sirlhàn (946-952) num Hlimijum (\%wischen 937 und 963).

4. Mirza Haidar. War urspringlich in Dienst von Kimrin, Jen Solne Babars, in lallope. Regierte Io Jihre. Ermordet von Rebellen.

5. Jisuféek Khàn. Das Land wird 993 ron Kaiser Akbar annektiert.

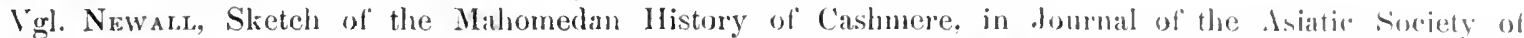
Bengal $1854, \mathrm{Nr}_{1}$. S S. 409-460; Catalogue of the Coins in the Indian Muscum Calcutta vol. Il, Oxford igno

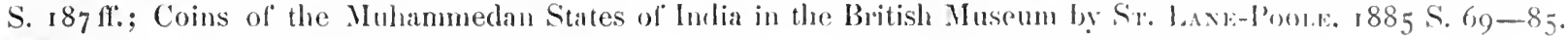
IIB III 143; LI' 304 .

91. Nachkommen Bahars in Ghazna, Kâlul und Kandahar.

A. II. :- :

1. Nirza Kimrân b. Babar. War von seinem Vater mit Kibul belehnt, besaff Kandahar und hesetzo

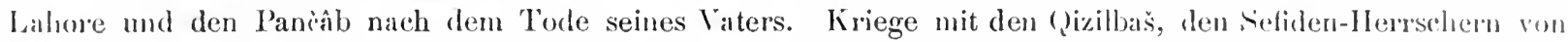
Persien. Exst friedliche, dann feindliche Beziehungen zu seinem Bruder Humijin. In let»teren geht el zugrunde, wird geblendet und stirbt in Mekka 964.

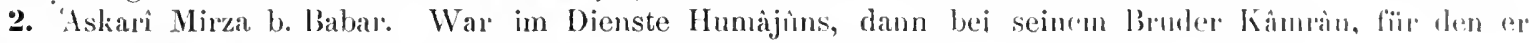
Kalunl und Kandahar verwaltete, sehliehlich im Streit mit Humijin. Stanly ebentalls in Meklia.

3. Hinlâl Mirza b. Babar. Fiel im Lrieg gegen Humajun $95^{8}$.

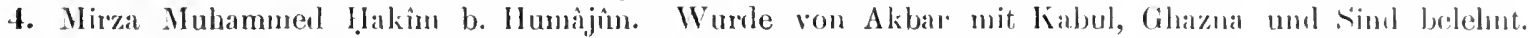
Sein Atabeg war zuerst Munim Khàn, dann dessen Sohn Ghani Khan. Eine Zeitlang regierte seine Mutter

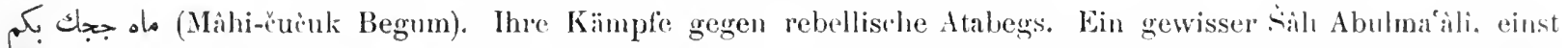
Freund von Humâjun, wird von Akbar verbannt. llieht 971 mach Kaluul und wird dort fienndlich aulfgenommen.

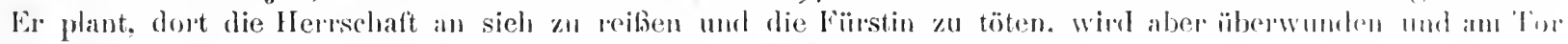
von Kabul grekreurigt. Weiteres ist nicht bekannt. MIB III $117 \quad 120$.

\section{Afghanen-Dynastien in Indien.}

I.

92. Die Naukhâui.j.je.

A. $11.925-97^{6}$.

1. Darjai Khin Nankhainî, urspriingliclı im Ilienst von Iskender Lodi, machte er sich unalhängign in Bilıâr: †े 930.

2. Sein Sohn Behàdur Khân. Zu seiner Zeit erscheint Babar in Indien, lionnte aber diesen Behidur Khan nicht besiegen. Er pflegte ein gutes Einvernehmen mit Humajìn. † 945 .

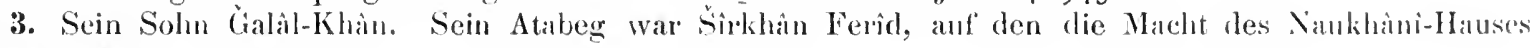
iblerging. MB III 13 I.

\section{II.}

\section{Die Sîri.j.je.}

1. 11. $9.77-97 \%$

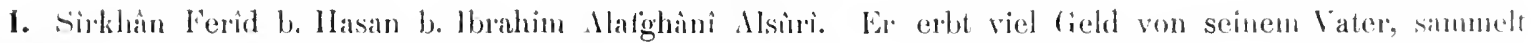
damit Mannschat, wird Räuber und set/t sich fest in Bengalen. Kämple mit llumijun. 5 Jalun lang, 947 bis $95^{2}$, Herrscher Indiens vom sind bis Bengalen.

2. Sein Sohn Selìn Kúhân. Verlegte seine Resislenz von Agra nach Gwalior. Regierte von 952-1,60.

3. Sein Sohn Fairìz Khàn, ein Kind. Verdrängt und getötet von

4. Mubâriz Khân, einem Vetter. Fiel 963 im Kanpf mit Hị! Khan, dem Padišilı von Bengalen. Yun $960-9^{6} 3$.

5. Sein Sohn Șirkhin. Ilerrschte in einigen Gegenden.

6. Sultan Iskender, Vetter von 5. Zuer'st Stathalter von Pançab, marhte er sich unablängin und schluy den in Delhi regierenden Ibrahim Khân. Yon IIumâjinn wurde ihm seine ganze Herrschatt abgenommen.

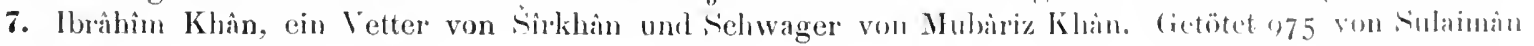
Khìn Karıinî.

8. Lir Mubammed Khan, Vetter von Sirkhàn. War von letzterem zam Statthalter von fiengalen bestellt, wo er sich unablängig macht. Krieg mit Mubàriz Khan, in dem er fiel.

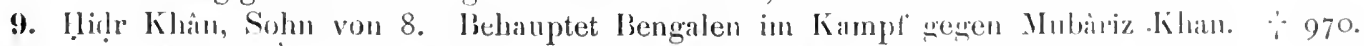

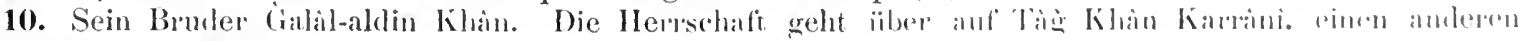
Afghanen.Stanm. NIB 111 124-130. 
III.

Die Kararânijje.

A. H. $960-980$.

S. LP 308 und Catalogue of Indian Coins in the British Museum by Sr. Lane-Poole. The Mnhammedan states. London 885 S. 59 . MIB III i 3 r.

94. Die Herrscher der Ghakkar, eines Volksstammes in Sind.

A. II. :-?

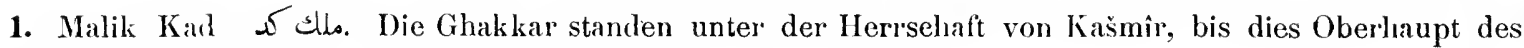
Stammes sie davon befreite. Lir war einer der limire von Ghazna.

2. Sein Sohn Malik Kalin

3. Sein Sohn Malik Tatâr. Kämpfte in den Kriegen Babars $(-937)$ auf dessen Seite. Fiel im Kriege.

4. Sein Sohn Sìz Beg. Getötet vom Afghanen sirkhìn.

5. Sein Bruder Sultan Adam. Half dem Humàjün in Kampf gegen seinen Bruder Kâmrân. Regierte lange.

6. Kemâlkhân b. Tatîr, Bruderssohn von 5. Eine Zeitlang in der Gelingenschaft von š̀̀rkhân. Stand in Beziehung zu Akbar, mit dessen Ililfe er 975 das Reich seines Vaters aus den Händen eines Onkels Kemailkhân befreite. MB III 142 . 143 .

Die Ghakkar sind ein Volksstumm im Nordwesten Indiens im Gebiet von Rawalpindi, ilr Hauptort Guğrat. Sie dienten dem (ieschlechte Babars, waren später den Sikh untertan, und sind seit 1849 englische Intertanen. Die Geschichte weiß von ihnen zu berichten. daß sie A. H. $602=1206$ den Beherrscher Indiens, Muhammed Ghori, zwischen Lahore und Ghami ermordet haben.

\section{Verzeichnis geographischer Namen'.}

\begin{tabular}{|c|c|c|c|}
\hline Ablastinn 28 & Buchara 14 & lliṣn-Kef 38 & Das Kristall-Land 76 \\
\hline Adana 29 & Bûšang̀ 70 & Ịliṣn Manșîr 28 & Kuicin ro \\
\hline Arlherbaiğ:in I8. 20.22.23. & ('aldiuân 79 & Ininwàn 34 & Kựùd 8. 9. 10 \\
\hline $\begin{array}{l}27 \cdot 74 \\
\text { Adrianopel } 28\end{array}$ & Chorasan 15. 26. 39. 69. & Hurmuz 48. 53 & Kins $7^{6}$ \\
\hline Ägypten 28. 29.35.38.43 & Cilicien 29 & Jamanal 40 & Lahırî 86 \\
\hline Afghanistan $8 \mathrm{I}$ & Daghestan 20 & Janbur 42 & Lakhnawti 87 \\
\hline Ahwìz 31 & Dailem 6 & Jarkand 76 & Lankìr 8 \\
\hline Aintaib 28 & Dellhi 87.88 & Jazda.jird 34 & Làr $5^{2}$ \\
\hline Alâijje 30 & Dinawar 34 & Jemen $43 \cdot 46-51$ & Lùristân 72.79 \\
\hline Alamint 4. 26 & Erzerûm 24 & Jezd 66 & Mài 76 \\
\hline Albațìil! 32. 33 & Erzingain 25 & Indien 78.87 & Malatia 27.28 \\
\hline Albistan 27.28 & 6.7 & Lavie $3 r$ & Mar'aš 28 \\
\hline Aleppo 29. 35 & a) 32 & Ispahan 66.68.79 & Marokk10 62 \\
\hline Amol 5. I 2 & Ginink 30 & Käbul 78.81 .88 & Mazara 64 \\
\hline àn 79 & un 53 & Kamakh 25 & Mâzenderần 6. 8. 75 . \\
\hline Antiochien 35 & Garba & Kandahar 78.79 .82 & Medina 40.4 I. 44 \\
\hline 76 & & har 76 & Mekka 40. 4 I. 42.43 .4 \\
\hline Araxes 22 & Georgien 27 & Kašmir 76. 89. 90 & Membiğ 35 \\
\hline Armenien 6. 18.22. 28 & Germsir 80.82 & Kith 17 & Mesopotamien 18 \\
\hline in 18.22 & $\tan 2$ & Kaukan 59 & Mongolei 76 \\
\hline Asadaibàd 34 & a 78.8 I. 88 & Kerak 37 & Mosul 71 \\
\hline Astribâd 12. $75 \cdot 79$ & Gidıla 40. 48 & Kermin 14. 71.88 & Multân 84.87 .88 \\
\hline Baalbek 36 & Gîlàn 7. 8. 10 & Khatra is 8 & Muqrầ $4^{8}$ \\
\hline $\begin{array}{l}\text { Bäb-alabwàb I8. } 20 \\
\text { Badakhšìn } 76.83\end{array}$ & $\begin{array}{l}\text { Girdkiih } 5 \\
\text { Gư̌rerait } 48\end{array}$ & $\begin{array}{l}\text { Kharput } 28 \\
\text { Khoten } 76\end{array}$ & $\begin{array}{l}\text { Nitil } 8 \\
\text { Neocaesareia } 27\end{array}$ \\
\hline Bagdad 39 & Gurgàn 3.4 .7 .8 .11 .13 & Khurramâbâd 72 & Nihâwand $34 \cdot 79$ \\
\hline lkh 78.79 & Gurganijie I $z$ & Khuttalan 80 & Nisabur 69 \\
\hline Bânijàs 26 & Ginzağın $\mathrm{I}$ & Khuzistân $67 \cdot 72$ & Nìr 8. 9 \\
\hline Basra 3I & Hağar 31 & Khwàrizm I4. I7 & Oman 54 \\
\hline galen 87 & Hamadan 68. & Kleinasien $22.49 \cdot 74.78$ & Oudh 87 \\
\hline Biskra 6I & Herat 39.70 . & Krim 20 & Persis $3 \mathrm{I} \cdot 65 \cdot 7 \mathrm{I} \cdot 79$ \\
\hline
\end{tabular}

1 Die neben den Namen stehonden Ziflem bezeichnen den Abschnitt, nicht die Seite. 
(Qairawin 63

()ais $5^{2 .} 53$

()armisin 34

Qazwin 26

()ihistàn I 5

Qiumis 4

() umimn $7^{8}$

Rai I 1 . 70

Riwalpindi 94

Rûdbà 6.8

Rìjiin 6. 8

Rustamaibud 6

Rustamdì. 5. 6
Sia da 45

Silins 8

Samsin 30

Sañà $45 \cdot 47 \cdot 48$

Sipirir 34

Sillija 12

Schiraz 65. 66. 73. 79

Segestiul 14. I5. 16

Sicilien 63. 64

Siǧilunasa 56

Sind 84. 88. 94

Sinope 30

- Siluif 52

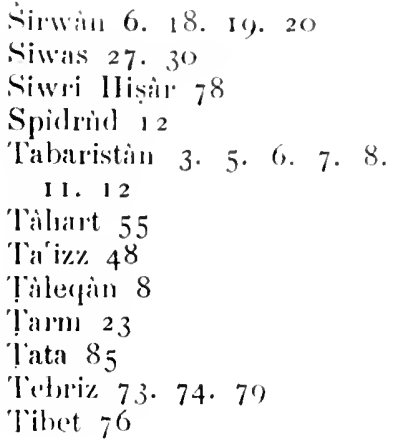

Titlis 18

Tlemsen 57

Joksil 27

Tuansoxamien 77. 78

Tripolis in Afrika 6

Tripolis in Syrien 28

limkestan 79

Tiis 13

IVisit 31

Kawidat 59

Yebid 48.49

\section{Verzeichnis der Dynasten".}

Abluas b. Aldadl (Sicilien) 63, 5

Abdallah b. Ahbas (Sicilien) 63.6
b. Dindau 8,6
b. Qarghan 77, 2
" (Sicilien) 64,6

Abdalmalik (Bab-alabwab) $2 \mathrm{I}, 4$
"
b. Laškari 2 I, 12

b. Manșแ1 2 I, IO

Abd-Alwatid $60,6.7$

- (Tlemsen) 57,8.10

Abderraluman b. Mutahhar 50, 3

Abis:? (Persis) 7 r, 2 (Tlemsen) 57.4

Abu Abdallah Alhusam $3 \mathbf{r}, \mathbf{I}$

" Mulı. (Mekkil) 40, 2

" M Mul. (Mekka) 40, 6

"Ahued Uhaidallah, Tiluiride $39 \cdot 5 \cdot 5 \cdot 5$

"Ali Muls. b. Alumed I 2. 3

" " b. Iljas 14,1

" " Imad-alıl. I 5, 4

" Azi\% ()atada 43, I

"Bekr Mirza (Kašglaur) 76.8

" (I'ersis) 7 7,2

$"$ "(Tripolis) 60. 4

Falita 44, I

Alfanas (Tlemsen) 57, 15

Cialfar Ahmed 40, 5

" IHasall 12,4

"Mul. (Mekkal) 41, 7

" Hammu Musa 57, 3.6

"Hasanun (Marokko) 62,4.7

"Hasim Mulh. 42, I

" Muh. (Mekka) 41,6

"Jalija Zakarij.ja 58, I

Abulabbas Abdallah (Sicilien) 63.16

(Biskra) 6r, 5)

Ma'mun 17,3

Abulfa!l Muls. b. Salurjar 8, r 2
Abulfalag h. Imran 32, 3

"Nuh. (Albala il!) 32, 4

Abulfatl! Jusuf (Sicilien) 64, 7

" I. Muh. $34, \mathrm{I}$

" Musa 22, 5

Abulfutul, Husain $4 \mathrm{r}, 10$

Abulghaith (Mekka) 43, I I, I 2

Abul!arith Muh. b. Ali 17,4

"Muh. b. Fereghun ।, I

Abulhasan Ali $3 \mathbf{I}, 2$

"Ali b. Nialmum 17.2

"Husain 1.. 'Imran 32, 2

" laškari 22, 2

Abulmaisicl Muhalhil 34, 2

" Muh. b. Ibralıim I 5, 3

Abulqaisinn Abdallah 3 1, 3

" Ali (Sicilien) 64.3

Abul'uswar Sadir 22,8

Abu Mulı, Abdallah (Albata'ilı) 33, 3

" Gafar (Mekkia) 4r, 8

" IIasall 47, 3

"Manșìr Ali i 8, 14

" b. Surkhitb 34,8

" "Zijalat-Allah (Sicilieu)

$6,3,17$

" Niș̣r Alımad b. Abuharith 1,2

" b. Lulu 35. 2

Abunneğm Bedr (Dinawar) 34, 2

Abuššauk Faris 34,3 .

Abu Tahir lexid is, 8

"Zakariji.ja Jalıja 62. 1

"Zijan Mulı. 57.7

Adud-ald. ( )ubad 8, 33

Afrasial) Cialawi 6,1

Aglulamg: (Gebel) 68.4

A islin (Medina) 44, 1

(Medinil) $44,13.15$

Almed b. Abdalnalik 2i, 5 Alital (Sicilien) 64.9
Alumed Beg Nialinula 49,9

" Beg b. Ramal!an 29. I

- (Biskrai) 61.3

b b. Ilasan (Sieilien) 64. 2

" b. Jalija (Garlsa) 58, 3

" b. Ilic qub (sicilien) 63,

" (Jemen) 47, 2

" (Marokko) 62,5

"b. Muh (in Sirwiall) 8.10

"Alnașir 45, 3

" b. Omar (Sicilien) 64, I 5

" Qadi Oglilu 59, I

" (in Segestan) 16.1

"Tlemsen) 57, I 2

" b. 'Uṭı̆ i 2,2

" (Vawada) 59, 4

Litay (Cliorasan) 70, 3

ditegin (Ilerat) 70,2

Aituglunus (Ciebel) 68,2

Ala'-ald. (Albistan) 28,9

" Ali 4.4

"Ali 5, 3

" IIasam 4. 6

" (Srllimiz) 60, 8

Ala -ahdin (kimingan) 25.2.4

(Kisšnir) 89, 2

IIuh. 87,5

.1li'-ilnurlk Kankin 52.7

$$
\text { " (Lar) 52.7.1 }
$$

Ali Beg (Albistan) 28.10

(Biskia) 6r. 4

"H. Ilaitham 18.7

"b. Murani (Risk1a) 61.

"(Tripolis) 60. 5

Mmunijial (c Inorasan) 69.1

Imjan (?) 44, 16. 00

Anur b. II:sim 2 I, 2

Irdassio b. Alat-alcl. t, 7

Ar:s:an Beg b. Silaiman 28.6

I Dis erste Ziller bezeichnet den Abschnitt, die zwoite don Unterahsohnitt. - Abhürmuren: Muh. = Muhanmed. ald. = aldaula, $\mathrm{h} .=$ Sohn. 
Asad b. Furat (Sicilien) 63, I

Askari Mirza 9 I, 2

Atijja b. Mansur 44. 5

Badi-alzaman 79, 12

Baduspan 8, I

b. Fredun 8, 8

b. Khumzad 8,3

Baha'aldin (Persis) 65, ro

Balıman b. Bisutun 9.6 b. Cielıangir $9 \cdot 4$

Bawand b. Śapur 3, 1

Bedr b. Thahir (Dinawar) 34,

Behadur Khan 92, 2

Behram Beg (Sirwan) 20. 4

$$
\text { " (.lemen) } 5 \mathrm{I}, \mathrm{I}
$$

" Pascha $5 \mathrm{r}, 14$

Biri (Chorasan) 70, 3

Bisutun b. Ciehanger 9. 5 b. 'Lerrinkemer 8, 22

Bughrategin (Chorasan) 70, 3

Bukhtanassar Ali I 8 , i 6

Bulaği (Kašghaı) 76, 2

Buraq (Kerman) 7 1,3

Burhan-aldin (Qadi (Siwas) 3o, IV

Burhan Ali (Sirwan) 20. 10

Dabuje $7 \cdot 1$

I)aigham (Medina) 44, 2 I

Danismend 27 , I

Darja Khan Naukhani 92, I

Darmila' $7 \cdot 3$

Daud Beg b. Ramadian 29, 4

" b. Isa b. Falita 42.7

" b. Musa (Mekka) 4 I. I

I)aulat Khatun (Klein Lmr) 72, I3

Derwis Beg b. Piri 29.8

Dhur-alnuu b. Hasan 84 . (Siwas) 27,7

Dindar Ummid 8, 5

Doghan Sall (Schiiaz) 66.7

Flisac b. Muh. I 4.2

Fadl (Arran) 22,4

" b. Šavil 22.9

Fadluje b. Hasanuje 65.1

Faditin b. Fadll 22, 10

Faipuz Khan 93, 3

Fairuzšah (Hurnuz) 53, 9

Fakilu-ald. Hasan 5, 7

Namwer 8, i 6

Namwer 8.23

Fakhr-aldin (Evzingan) 25.3

Falila b. Mulı. 42, 2

Farhad Pasclia 5I, 4

Farkhan Kebir 7, 2

Feramum 19,4

Feribury b. Salar 18.18

Feridun b. Feribur\% 18, 19

Ferruklijasar 20,3

Ferruklı Sals (Huımuz) 53, 17

Ferruklizad 19.2. 5

Fredun h. ()arin 8, 7

(iabir (Sicilien) 64:4

Giaftar b. Abulfatl (Sicilien) 64.8

b. Muh. (Sicilien) 63,10

Alrašid $45 \cdot 7$ (iafur b. Rustanı 3, 7

(Sicilien) 64, 5

b. 'Utu'us 12,2

Gajomarth b. Bahman 9, 7 b. Gehangir 9,3

Cialal-ald. Iskender 8, 3 I

Galal-aldin Fairuz 87.4

- Khan 93, 10

" (Persis) 65, 9

Cialal-Khan 92,3

Gamal-aldin Hadıa (Klein Lur) 72, 9 (Medina) 44,9

Ciammaz (Medina) 44, 3

Ciehangir (Klein Lur) 72, 2 I b. Malik Kaus 9, 2

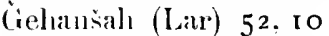

Gersasp (Klein L,u) 72, 4

Ghari Bry (Nirwan) 20, 5

Gijath-aldin (Persis) 65, 11

Gögce (i iebel) 68, I

Giimïstegin 27.2

Gunaid Beg (Cianik) 30, Il 3

Giintıgdı (Khuzistan) 67, I

Guštasp 19,3

Haitham b. Khalid 18,4

b. Muh. 18,6

IJamia Beg (Adana) 29, 3

Harun (Lar) 52. 12

Ilasan b. Alabbas (Sicilien) 63.11

b. Ali Uṭuš I 2, I

" (Biskı"a) 6r, 2

"Kaja 6.5

" (Klein Lur) 72,8

" (Medina) 44, 14

" (Meklia) 4o, 4

l'ascha $5 \mathrm{I}, 1 \mathrm{I}$

Pasclia 5I, I 3

b. Qatarla 43.2

Sabbal! 26 , 1

(Sicilien) 64.10

" (in Tabaristan) 13.4

Ilasanuje (Dinawar) 34. I

$$
\text { b. Hezarasp } 65.4
$$

Hasan h. Zaid I I. I

" b. Kaid (Sicilien) 64, I

b. Zului (Medina) 44, 25

Hašim b. Falita 42, 3

b. Sirraqa 21, I

Hezarasp (Persis) 65, 3

Hezarsendan b. Bundar 8, so

Hibat. Allah (Medina) $44 \cdot 7$

llich Khan 93, 9

Ililal b. Abunneğm (Dinawar) 34,3

Hindal Mirza 91,3

llošang (Ňirwan) 19,8

Husain b. Abmed (Sicilien) 63, 13

" Almuntakbab 45,4

" Beg 49, 3

" Beg (Gianik) 3o, 114

" b. Bekr Alšarabi 33, 4

$n$ (Jenten) 47,5

" (Klein Lur) 72, 8

" Kurdi 48, I
Husain b. Muh. (Meklka) 4I, 3

b. Mub. (Mekka) 4I, 5 ,

(Transoxanien) 77,3

Iusamı-ald. Ardašir 5, I Ardašir 8, I 5

" Ardašir 8, 24

Husam-illin 'Iwad! 87, 3

" $\quad$ Khalil(Klein Lur) 72, 5

Jaghy Arslan 27, 4

Jagmorasan b. Abd-Alwadd 57, r

Jalija Albali (San a) 45, I

" (Jemen) 5o, 4

" b. Muh. $47 \cdot 4$

" ('lipolis) 6o, 6.7

" b. Kakariıja $5^{\text {\%. }} 2$

Jamin-ald. Sahıanšah 16,7

. Tezid b. Mazjad ı 8, I

" (in Sirwan) I 8, 12

Jusuficek Khan (Kašnir) 90, 5

.Jusuf Sah (Schira\%) 66, 9

" (Tlemsen) 57,5

Ibrahiu b. Alimed 47,6

" Beg b. Alumed 29, 2

" Beg b. Piri 29, 9

- Khan 93, 7

"Khan (Lar) 52, 15

b. Malzuban 23,6

" b. Śimğur I 5, 2

(Niwas) 27,5

Imran b. Sahin 32, I

Inaneig (Rai) 70, I

'Isa b. Ga far' 4I, 9

"Tarklıan (Tata) 85, I

Isfandijar Fakhr-ald. 8, 26

" Kaikaus 8. I9

"Sahrakam 8, 25

Islanq b. Ibrahim, Tabiride 39, 1

Isliender Alšaililı 6, 4

" Beg 49, 2

"Beg 49.8

"b. Gajomarth Io, I

(Kasinir) 89, 4

(Zeb d) 48,3

Ismail b. llorahim 27.6

" Saffick Aluḷaidir 40, I

" Sah (Kašmir) 9o, 2

" (in Tabaristan) I 2, 5

"b. Wehsudan 23,5

Ispalibad Dàrà 3, 12

IIusam-ald. 4, I

$"$ " Terrinkemer 8. 13

Khuršid 7, 5

Rustan 3, 14

Sahrjar 3, I I

Sahrjar 3, I 3

Sarwin 3,5

Izz.-ald. Ilezarasp 8, 17

'Tzz-aldin Husain (Klein Lui') 72, 16 (Klein Lur) 72, r4

Muh. 46,2

Muh. (Klein Isur) 72, I 2

(Sehiraz) 66, 2 
Kaja Buzurg Unmid 26, 2

" Fakhr-aldin Gialawi 6, 2

- Guštasp 6,3

- Muh. 26, 3

Kaiqobad (Širwan) 19,6

Kalinğar (Lar) 52, 2. 5

Kiaus (Śirwan) 19,7

Kemal Beg (Jemen) 49, I

Kemalkhan b. Tatar (Ghakkar) 94, 6

Khafağa (Sicilien) 63,7

Khair-aldin Beg 49, 5

Khalaf b. Alined 16,2

Khalid b. Jezid I 8,2

Khalil Beg b. Daud 29: 5

" Beg b. Zain-aldin 28, 2

Khan Mirza 83, 2

Khudadad (Kašghar) 76, 3

Khurzad 8, 2

Khwand 'Ala'-aldin 26, 7

$$
\text { " Galal-aldin 26,6 }
$$

"IIasan 26, 4

"Muh. 26.5

nukı-ald. 26,8

Kubad (in Sัìwâun) 18, r 5

Kurdanšah (Hurmuz) 53, 5

Laila b. Nu man I 3, I

Laškari 2 I, 8

Ali b. Musa 22, 6

Latif Beg (Ala'ijje) 30, IV

Lulu 35, I

Mahdi Hasan b. Zaid I I, 3

Mahumud Beg b. Daud 29,6

b. Ghazi Beg 20, 6

b. Gïniiltaš (Lahıri) 86, 1

" Pascha 5 r, 8

"Sah (Schiraz) 66, 5

Mainun b. Ahned 21, 6

b. Mansur 2 I, I 3

Makan b. Kali I 3, 3

Malik 'Âdil 37

Fakhr-aldin 38, 5

"Khalaf 38,9

" Muğir-aldin 38, 2

" Sihab-aldin 38,3

Ala'-aldin 24, 3

Amğad 36, 4

Ardašiı (Persis) 65, 12

Ašinf ro, 3

As̀raf 74,3

As̀uaf Ahmèl 38,6

Gajomarth io, 5

Gehangir 10, 6

Kad (uhaklsar) 94, 1

Kajomarth 8, 35

Kai Khusıau 8, 27

Kalan (Ghakkar) 94. 2

Kanil Abu Bkr 38, I

Ahmed 38, 8

" Khalil 38, 7

Kaus 10, 4

Kaus b. Gajomarth 9 , I

Manșuu' 'Izz-aldin 36, 3

Mu ażaun Isa 37

Mu'ażam 'Tulanšah 36, 2
Malik Muọahid Islıal 7 I. I

" Mughith Fatli-aldin 37

" b. Mulalluil 34. 5

- Muh. b. Gehangir 10. 7

" Muh. Sahrjar 8.28

" Muh. b. Salig 24,2

"Muraffar Ali 71, 1

" Nasir Iaud 37

" Sialili Aln Bekr 38, 4

" Salil. (Batalbek) 36, 5

"Taý-ali. 10, 2

"Tatar (Ghakkar) 94. 3

Ma'mun b. Muh. 17, 1

Mangali (Gebel) 68, 3

Mangučak 25, r

Mani $^{c} 4,17$

Manșur Abdallah 46,1

Abdallali 47, 1

"Ablalmalik 21, 11

" (Bab-al'abwab 21,9

- (Medina) 44,4

Mar\%ubau (Arran) 22, 3

- b. Ismail 23.7

Mastud (Klein L.ur) 72, 6

" (Schiraz) 73, 2

Mihmerdan b. Surkhab 3. 3

Minurehı b. Jezid 18, I3

(Sirwan) 19.1

Mirza Abd-Alrazzak 81, 2

Ahu Bekr 8o, 2

Abu liekr $8_{3}$, I

Abu Bekr 2O, I I

Almed Mirek 79.5

Baiqara 79.6

Gani (Fata) 85,4

Gelıangir 78. I

Inaidar (Kašmıiı) 90. 4

ialija 78.6

Iskender 79.4

Kamran 91, I

Khalil 82.2

Khalil Sultan 78 . Io

Man:"1r 79. 10

Mul. Gelaangir 78.4

Mul. Ilakim 91. 4

Muh. Huma,jun 8,3, 3

Muh. Sultan 78.2

Mul. Sultan 78,9

Murad 82. 1

Mùaffa 79,9

Omar Srhaich 79. I

()mar Schaich 79.7

Pir Muh. 78.3

Pi. Ilıh. 79, 2

Qairlu 78, 7

(2)asim 80. 3

Rustam 79. 3

Sa'd Wayqus 78.5

Sanüar 78, 8

Sangar 79. 8

Sultan Ilusain 79, 11

I'lugh Beg 81. I

Walad 82.2

Mubariz-ablin Muh. 52,8
Mulsariz Khan 9.3. +

Muhaddib-alı. Abulhasan $\mathrm{Ali} 33,2$

Muhaddib-aldiu Mašud 30. 13

Mul. b. Abdallah (Sirilien) 63,4

b. Abdallah b. 'T'ahir 39.3

b. Abi-Al!uwwalal (Sirilien) 6,3,2

b. Abu 'Tahis' 18, 9

b. Almed (Bab-alabwab) 21,7

1. Almed (in Firwan) 18.11

b. Almed (\%awada) 59.5

ค. Amr (Bab-alabwab) 2 I. 3

b. Baklitijaur 87 . 1

bati ('lata) 85.2

lBeg b. Ibrahim 29. 10

begr (I I ill 52.13

1. Berekat +3.27

1. Alfurlli (Sicilien) 6.3.12

b. Gmmuštenin 27.3

Alhadi 45.6

llaidar (Kašghas) 76, 7

b. Haitham 18.5

b. Isluay. 'Tahiovide 39:2

b. Khafaga (Sicilien) 63.8

b. Khalid I 8.3

(Marokk(i) $62,3.6$

(Medina) 44,8

(Mekkal) 40, 3

(Mekka) 40,7

(Mekka) 43, 11

b. Musa (Mekka) 41.2

b. Mntahluar 47,8

Pajende (Tata) 85.3

(Persis). bis. 7 I. 2

( )alhati (Hlulmuz) 53, 1

b. Siaddad 22, 1

Sah (Hurmuz) 53.8

Sah (Hurnurz) 53,16

Sah (Kašghıı) 76. 4

sah (Kašmin) 90, I

Alsarayusi (Sicilien) 63. Is

1. Sihab-aldin 43 , 19

b. Sirau 87,2

b. Taluir 39.4

b. 'Tahir, 'Tahiovide 39.7

Tha'ir (Mekka) $4 \mathrm{I}+4$

(Temsen) $57,9.11$

(Tlemsen) 57,13

(Tripolis) 60. 2

Kaman 79, I3

(\%awadil) 59.2

Muluammadi Beg (Kloin l, m. 72.23

Mului-aldin (S.linar) 66.3 h. Mưin-aldin 30.1. 2

Mu'in-aldin lanwate 30. 1. 1

Mukthir (Melika) 42.5

$$
\text { b. Mukthir (Mekkil) } 42.6
$$

Murad l'aschia 51.10

Murtarla Mul. 45. 2

Musa (Kaukau) 59,3

Mlustata Bong 5o, 2

Pascelia 51.0

Mutahhar l. dal!jia 47.3

l.l(ment 50. 2 
Mutawakkil-alallah 50. I

Muraffar b. Ali 33. I

Muraffir'aldin 25,5

(Kerman) 7 г, 3

(Persis) 65.5

Nașir-ald. Sahrjar 5, 5 Salrijar 8. 29

Nasîl-aldiı Bahramšı ı 6.8 Muh Beg 28, 4

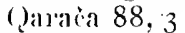

Neüm-ald. ()arin 4. 2

Neğm-aldin Ajjub b. Fadi 3.6, 1 (.Jemen) 46, 4. 6

Nizam-aldin Malımud 65.2 (Persis) 65,7 . I I

Nighair (Medina) 44,6

Nuširwan (Lar) 52, 14 b. Làškari 22.7

Nuspat (llurmuz) 53.2

Nușiat-aldin (Persis) 65,8

()gluz Khan (Klein L,ur) 72. 20

()thman b. Jagmolasan 57.2 Pascha 5 I, I 2

Padisal Khatun (Kerınan) † I, 3

l'iri Beg (Adana) 29.7

l'ir Muh. Khan 93.8

Purspai (Jemen) 48.2

()aim-billagq Mul. I I. z

(Qau Muṣtafa Pascha 5 I,7

()arghan, Emir 77, 1

Tarin h. Rustam 3,8

()asim b. Has̀im 42. 4

Mukhtal 45, 5

(Gobad Oghlu (Ganik) 30, II. I

() Imajjisa 43, Io

(2usaițil (Medina) 44. 22

()uth-aldin Abulfatl. (Kelman) 71.3

b. Kalingar 52, 3

(Kašmilu) 89:3

(Kerman) 71:3

Mirza Muh. Ginki 8o. 1

Mu'ajiad 52, I. 9

Mubarak 87,7

Muh. (Kerman) 7 7,3

(1'er'sis) 65.6

(S.liir:iz) 66, 4

'Tehemten (Hurmuz) 53.0

()utlugh Tarkin (Kerman) 7 I, 3

Rağih h. Jlasan 43.3.6

Ridlwan Pascha 5r, 9

Rukn-ald. Kaiklumsian 5,6

Rukn-aldin (Humuz) 53,3

Mubirak (Kerman) 71.3

Rimmaitha 43 , 10

Rumlı Mustata Beg 49, 4. 6

Rustanı (Klein L,ur) 72, 2

b. Nesim-ald. 4, 3

b. b. Qarin 3,

Sah Ghazi 4. 5

b. Siluwin 3,6

Said-ald. Tìs 8, 34

Sa'di b. Muhallit 34,6

Salı Baddag 28.8

" Ghari Fakhrald. 8, 32
Sah Hasan Beg (Sind) 84, 3

" IIusain (Klein Lur) 72. 18

- Rustam (Kleiu L,ur) 72, I9

" Rustam (Klein Lur) 72, 22

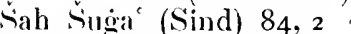

Sahrjar b. Baduspan 8.4

b. Baduspan 8,9

b. Samšid 8, 1 I

Şahrnuš b. 'Izz-ald. 8, is

Sahrukh (Tirwan) 20, 9

Sahsuwal Beg 28, 7

Sah Werdi (Klein Lur) 72.24

Sajjid Ali Beg 49, 7

Ali (Kašnhar) 75,5

Sajjidi Almed (Klein 1,m) 72, 17

Said b. Jalija (Gialıa) $5^{8.3}$

" (l'ersis) 7 I, 2

b. Zengi (Persis) 7 r. 2

Saif-ald. b. b. Ilusam-atd. 8.14

Sail-aldin Aideniz 88, 2

$$
\begin{array}{ll} 
& \text { (Lummuz) } 53,10 \\
& \text { (Lar) } 52.6
\end{array}
$$

Salall-aldin (Chorasan) 70, 3

Salar b. Jezid I8. 17

Salghal Sah (Hurmu\%) 53, 13

$$
\text { (Schiraz) 66, } 6
$$

Salil! b. Jalıja (Garba) 58.3

Salim h. Abu Falita 44. 2

Saliq (Erzerum) 24. I

Sallar Gustan 23,3

" Marzuban 23. 2

"Muh. b. Musafir 2.3, I

Welisudan 2.3, 4

Sinnla (Khuristan) 67.3

sams-aldin Abulfat! Almed I6.5

$$
\begin{array}{ll}
" & \text { (.lemen) } 46.3 \\
& \text { (Kašmir) } 89, \text { I }
\end{array}
$$

Sams-almuluk Mul. 5, 2

$$
\text { " liustam 4,8 }
$$

Şamṣam Malımud (Klein Lar) 72. I

Sam b. IVardan 66, I

Sangaršah (Chorasan) 69,3

Sansiz Mirza (Kašghar) 76,6

Sàr Abu Nasje Muh. 2, I

Sirraf-aldin Abu-Bekr. (Klein L،(u) 72. 3

Sah Malmmud 73. 1

Sarlian Bihsudan I 3,2

Sarim-aldin (Jemen) 46, 5

Siar Šalı Muh. 2, 2

Sarnje 7,4

Salvin b. Rustan 3, 10

Sawada b. Muh. (Sicilien) 63, I 4

Sa\% Beg (Glakkka 94. 4

Cichaikh Alı Isluag (Sehiraz) 73, 3

Hasan Saghir 74, 2

lbrahin (Sirwan) 20, 1. 7

Seldiukšah (Persis) 7 I, 2

Sicrit Abdallah 43,40

Abulhasan 43,34

Abulqasim 43, 25

Abu Numajji 43. 9

Abu Numai Muh. 43: 33
Serif Abu Sa id 43,4

" Abu 'Talib 43, 35

" Iğlan 43, I 5. I 7

" Ahmed 43, 38

" Ahmed 43, 47

, Ali 4.3. 2 I

" Ali 43, 24

"Bedr-aldin 43, 22

" Berekat 43, 26. 28

" Berekat 43,45

- Gamma\% 43, 5

" Ghanim 43, 7

" Hâzân 43, 30

- Lazzá 43, 29

"Idris 43,8

"Mris 43, 36

"Inan 43, 20

"Khamiṣa 43, 13

" Khamisa 43, 3 I

" Masiud 43, 39

"Muh. b. Abdallalı 43, 4 I

" Muhșin 43, 37

- Nami 43, 42

" ( )aitbai 43, 32

"Sa'd 43, 44

"Said 43.46

"Utaifia 43, I 2.14

Selim Khan (Indien) 93, 2

Sibab-aldin (Hurmuz) 53, I 2

" (Humuz) 53, I 5

" ljaz (Hurmuz) 53, 4

" Malımud 87,6

(Melkka) 43. 18

Simgrir I 5,1

Sind (Mekka) 43, 16

Sirklıan Ferid 93, I

b. Mubariz 93,5

Suga-aldin Khuršid 72, I

$$
\text { n Malımud (Klein Lur) }
$$

72,15

Sulaiman b. Abdallah, Tahiride 39,6

Beg (Albistan) 28.5

(Medina) 44, 19

b. Muh. I 4,3

Suli Ber b. Zain-aldin 28, 3

Sultan Adam, Gbakkas 94, 5

- Cialal-aldin (Kerman) 7 I, 3

" Ha⿳̆冖̆gağ (Kelman) 7 I, 3

" Iskender 93, 6

" Khalil 20, 2.8

Sunqur (Persis) 7 I. 2

Surkliab b. Abultatlı 34,4

"b. Bawand 3, 2

b. Bedr 34, 7

" b. Mihrmerdan 3, 4

" (Khuzistan) 67, 2

Tà̀-ald. Jazdağird 5,4 Zijad 8, 30

Ta⿳亠丷⿵冂Jyldyz 88, I Sah (Klein Lur) 72, 7 (in Segestan) I6, 6

Tağ-almáali Sukı 4 I, I I

'Tahir b. Hilal (Dinavar) 34, 4 
'Tahir (Segestan) 16,3

Takla (Persis) 71, 2

Tarak sah (Kašmir) 90. 3

Tašin ()ghlu $30, \mathrm{Il} .2$

Thabit b. Ammar 6o, I

" (Medina) 44, 10

" ('Tripolis) 6o, 3

Timurtaš b. Cupaı 74, 1

Tughanšah (Chorasin) 69, 2

Toghrul (Persis) $7 \mathrm{I}, 2$

Tuluk (Kas̀ghar) 76, I
Tiun Silh 53.14

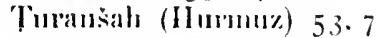

(IIIrmuz) 53.11

Uwais (in Nirr) 9.8

Uwais l'ascha 51,3

'Ozair (Medina) 44. I 2

Uzdenir l'ascha 5i, 5

Wathiaban (Medina) 44. 18

Vathiybillah. (Tlemsen) 57, 14

Zaid 43,43

'Zilin-al'abidin (Kašmio') 89. 5 \%inin-aldin +3.23

$$
\text { " (Yalatial } 28.1
$$

Zalkarijj: (Marokling) 6.2.2

Zamgi (Persis) 71. 2

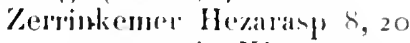

b. Khantan x. 21

Zuhair b. Aun (Sicilien) 6.3. 3

Zuhair (Medima) 44, 20

\%uhri (Mediua) $4+24$

Nachschrift. Den hier aufgefïhrten Dynastien können noch die Sìgiden angereiht werden. s. DFrai mary. Mimoire sur la famille des Sadjides im Jomrnal Asiatigue. sir. 4. 9. 409 ff. to. 39641. r847. 


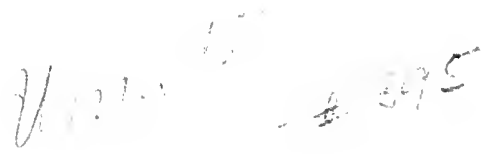






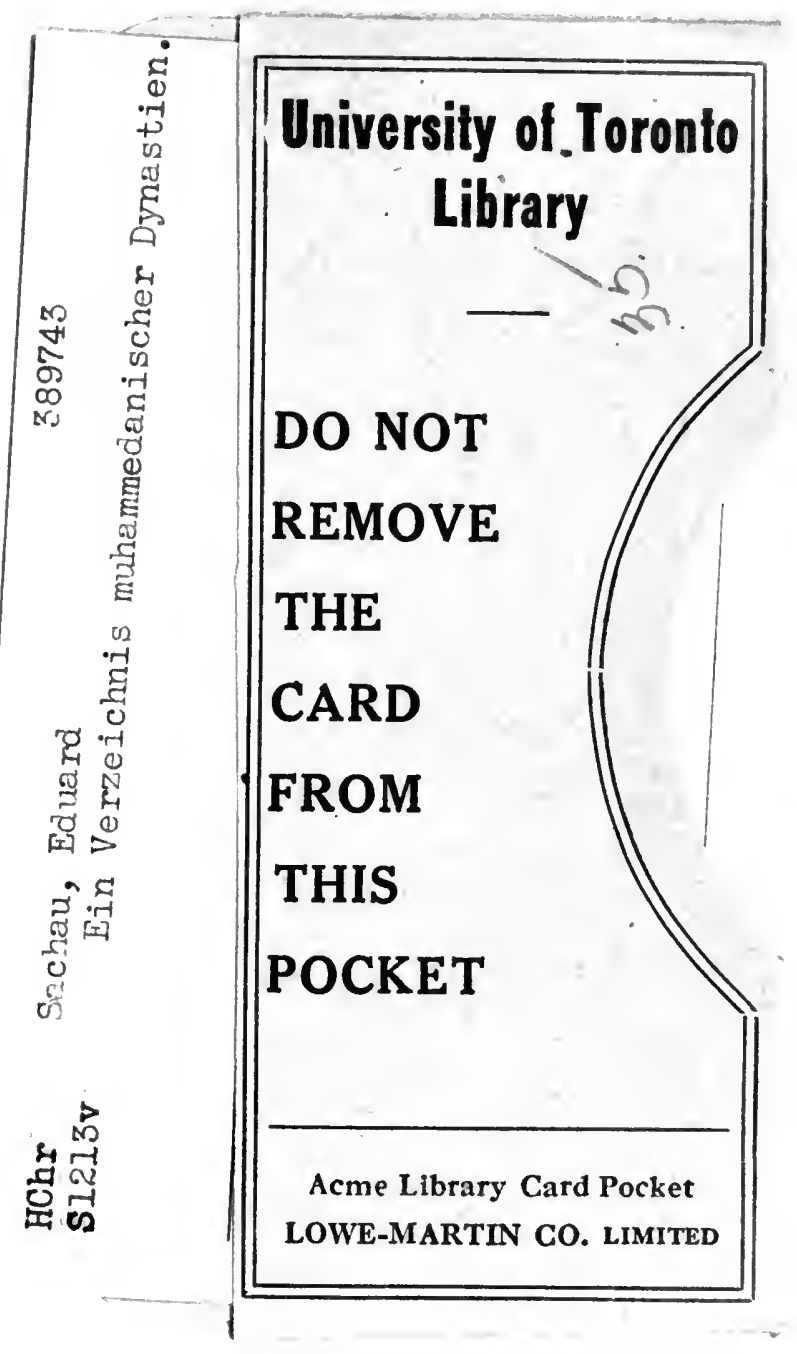




\section{Sonderabdrucke aus den Abhandlungen der Akademie von den Jahren 1918-1922.}

\section{Philosophisch-historische Klasse.}

Schuchindt: Die sogenannten Trajanswälie in der Dobrudscha. 1918

S. Singer: Arabische und europäische Poesie in Mittelalter. 1918 . 4. Chr. Jensen: Neoptolemos und Horaz. 1918 1.50

ERMAN: Reden, Rufe und Lieder auf Gräberbildern des alten Reiches. 1918 Diers und E. Schrams: Philons Belopoiika (Viertes Buch der Mechanik). 1918 G. Plaumann: Der Idioslogos, Untersuchung zur Finanzverwaltung Agyptens in hellenistischer und römischer Zeit. 1918

R. PELIssier: Mischär-Tatarische Sprachproben gesarnmelt im Nordosten des Bezirks Tjemnikov des Gouvernements Tambov im Herbst 1912. 1918 Sachat: Zur Ausbreitung des Christentums in Asien. 1919

TANGL: Bonifatiusfragen. 1919

A. von Le Coq: Türkische Manichaica aus Chotscho. II. 1919

Strupf: Spinozastudien. 1919

BANG: Vom Köktürkischen zum Osmanischen. 2. und 3. Mitteilung. 1919

Bresstau: Aus der ersten Zeit des großen abendländischen Schismas. 1919 K. Meyer: Bruchstücke der älteren Lyrik Irlands. Erster Teil. 1919

Erdmann: Berkeleys Philosophie in Lichte seines wissenschaftlichen Tagebuchs. $1919^{\circ}$

E. Meyer: Die Gemeinde des neuen Bundes im Lande Damaskus. Eine jüdische Schrift aus der Selenkidenzeit. 1919

- 2.50

- 3.50

- 5. -

- 4.

- 3.25

- 4.25

, 2.-

- 3.-

- 2.50

- 4.25

- 2.50

- 3.75

6.25

- 3.50

- 2.50

DE Groot: Der Thūpa, das heiliâste Heiligtum des Buddhismus in China. Ein Beitrag zur Kenntuis der esı,terischen Lehre des Mahāyāna. 1919 . .

Difls und E. Schram: Exzerpte ans Philons Mlechanik B. VII und VIII (vulgo Fünftes Buch). 191!).

Kenr: Das Erzbistum Magdeburg und die erste Organisat'on der christlichen Kirche in Polen. $19 \% 0$

F.W.K. MüıL:R: Uiguries III. Uigurisch Avadāna-Bruchstücke(I-VIII). 1920

Erdmannt: Die philosophischen Grundlagen von Helmholtz' Wahrnehmungstheorie. 1921

BAnG: Vom Köktürkischen zum Osmanischen. 4. Mitteilung. 1921.

Seufrert: Prolegomena zn einer Wieland-Ausgabe. VII. Nachträge und Untersuchungen. 1921

M. Welcmann: Die Georgika des Demokritos. 1921 . . . . . . . . . 2.50

Schuchardt: Zur Kenntnis d's Baskischen von Sara (Labourd). 1922. . . „ 2.50

A. von LE Coq: Türkische Manichaica aus (hotscho. III. Nebst einem christlichen Bruchstiuck aus Bulayïr. 19:2

K. Mührer: Beitrïge zur Geschichte der Verfassung der alten Kirche. 1922 Hour: Augustins innere Entwicklung. 1922 .

M. Hizznimer: Die Tierknochen aus deu Gruben des Lossower Ringwalls bei Frankturt a. O. 1922

Auf alle Preise wird cin Teuernngszuschlag naeh der jeweiligen Schliusselzahl erhoben. Auf die Grundpreise der A bhandlungen bis einschließlich Jahrgang 1922 wird für das Inland ein Preisnachlaß von 20 Prozent gewährt. 